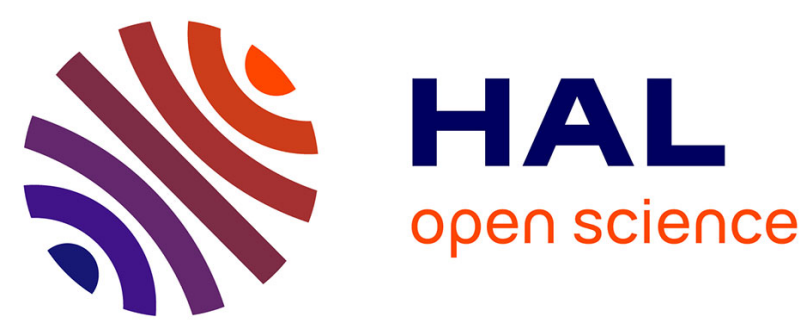

\title{
The Marsquake catalogue from InSight, sols 0-478
}

John Clinton, Savas Ceylan, Martin van Driel, Domenico Giardini, Simon C Stähler, Maren Böse, Constantinos Charalambous, Nikolaj L Dahmen, Anna Horleston, Taichi Kawamura, et al.

\section{- To cite this version:}

John Clinton, Savas Ceylan, Martin van Driel, Domenico Giardini, Simon C Stähler, et al.. The Marsquake catalogue from InSight, sols 0-478. Physics of the Earth and Planetary Interiors, 2021, 310, pp.106595. 10.1016/j.pepi.2020.106595 . hal-03163521

\section{HAL Id: hal-03163521 \\ https://hal.sorbonne-universite.fr/hal-03163521}

Submitted on 9 Mar 2021

HAL is a multi-disciplinary open access archive for the deposit and dissemination of scientific research documents, whether they are published or not. The documents may come from teaching and research institutions in France or abroad, or from public or private research centers.
L'archive ouverte pluridisciplinaire HAL, est destinée au dépôt et à la diffusion de documents scientifiques de niveau recherche, publiés ou non, émanant des établissements d'enseignement et de recherche français ou étrangers, des laboratoires publics ou privés. 


\section{The Marsquake catalogue from InSight, sols 0-478}

John F. Clinton ${ }^{\mathrm{a},{ }^{*},}$, Savas Ceylan ${ }^{\mathrm{b}}$, Martin van Driel ${ }^{\mathrm{b}}$, Domenico Giardini ${ }^{\mathrm{b}}$, Simon C. Stähler ${ }^{\mathrm{b}}$, Maren Böse ${ }^{\mathrm{a}, \mathrm{b}}$, Constantinos Charalambous ${ }^{\mathrm{c}}$, Nikolaj L. Dahmen ${ }^{\mathrm{b}}$, Anna Horleston ${ }^{\mathrm{d}}$, Taichi Kawamura ${ }^{\mathrm{e}}$, Amir Khan ${ }^{\mathrm{b}, \mathrm{n}}$, Guenolé Orhand-Mainsant ${ }^{\mathrm{f}}$, John-Robert Scholz ${ }^{\mathrm{g}}$, Fabian Euchner ${ }^{\mathrm{b}}$, William B. Banerdt ${ }^{\mathrm{h}}$, Philippe Lognonné ${ }^{\mathrm{e}, 1}$, Don Banfield ${ }^{\mathrm{i}}$, Eric Beucler ${ }^{\mathrm{j}}$, Raphaël F. Garcia ${ }^{f}$, Sharon Kedar ${ }^{\mathrm{h}}$, Mark P. Panning ${ }^{\mathrm{h}}$, Clement Perrin ${ }^{\mathrm{e}}$, William T. Pike ${ }^{\mathrm{c}}$, Suzanne E. Smrekar ${ }^{\mathrm{h}}$, Aymeric Spiga ${ }^{\mathrm{k}, 1}$, Alexander E. Stott ${ }^{\mathrm{c}}$

${ }^{\text {a }}$ Swiss Seismological Service, ETH Zurich, Zurich, Switzerland

${ }^{\mathrm{b}}$ Institute of Geophysics, ETH Zurich, Zurich, Switzerland

${ }^{\mathrm{c}}$ Department of Electrical and Electronic Engineering, Imperial College London, London, UK

${ }^{\mathrm{d}}$ School of Earth Sciences, University of Bristol, Bristol, UK

${ }^{\mathrm{e}}$ Institut de Physique du Globe de Paris, Université de Paris, CNRS, Paris, France

${ }^{\mathrm{f}}$ Institut Supérieur de l'Aéronautique et de l'Espace SUPAERO, Toulouse, France

${ }^{g}$ Max Planck Institute for Solar System Research, Göttingen, Germany

h Jet Propulsion Laboratory, California Institute of Technology, Pasadena, CA, USA

${ }^{\mathrm{i}}$ Cornell Center for Astrophysics and Planetary Science, Cornell University, Ithaca, NY, USA

${ }^{\mathrm{j}}$ Laboratoire de Planétologie et Géodynamique, Univ. Nantes, Univ. Angers, CNRS, Nantes, France

${ }^{\mathrm{k}}$ Laboratoire de Météorologie Dynamiquee, Sorbonne University, Paris, France

${ }^{1}$ Institut Universitaire de France, 1 rue Descartes, Paris, France

${ }^{\mathrm{n}}$ Institute of Theoretical Physics, University of Zurich, Zurich, Switzerland

\section{A R T I C L E I N F O}

\section{Keywords:}

Marsquakes

Mars seismicity catalogue

InSight mission

\begin{abstract}
A B S T R A C T
The InSight (Interior Exploration using Seismic Investigations, Geodesy and Heat Transport) mission began collecting high quality seismic data on Mars in February 2019. This manuscript documents the seismicity observed by SEIS, InSight's seismometer, from this time until the end of March 2020. Within the InSight project, the Marsquake Service (MQS) is responsible for prompt review of all seismic data collected by InSight, detection of events that are likely to be of seismic origin, and curation and release of seismic catalogues. In the first year of data collection, MQS have identified 465 seismic events that we interpret to be from regional and teleseismic marsquakes. Seismic events are grouped into 2 different event families: the low frequency family is dominated by energy at long period below $1 \mathrm{~s}$, and the high frequency family primarily include energy at and above $2.4 \mathrm{~Hz}$. Event magnitudes, from Mars-specific scales, range from 1.3 to 3.7. A third class of events with very short duration but high frequency bursts have been observed 712 times. These are likely associated with a local source driven by thermal stresses. This paper describes the data collected so far in the mission and the procedures under which MQS operates; summarises the content of the current MQS seismic catalogue; and presents the key features of the events we have observed so far, using the largest events as examples.
\end{abstract}

\section{Introduction}

The InSight mission to Mars expects to use seismology to elucidate the structure and formation of the red planet (Banerdt et al., 2020). In order to achieve this, InSight is equipped with the SEIS package (Lognonné et al., 2019) that includes 2 co-located 3-axis seismometers, a very broadband sensor (VBB) and a short period seismometer (SP), both acquired on a 24-bit digitiser (EBOX). InSight landed on Mars on $26 \mathrm{Nov}$ 2018, Sol (Martian Day) 0 for the mission. SEIS was placed on the ground on Sol 25, and full protection was achieved on Sol 70 after the Wind and Thermal Shield (WTS) was placed over it. In addition to other instrumentation, InSight includes a full weather station (Banfield et al.,

\footnotetext{
* Corresponding author.

E-mail address: jclinton@sed.ethz.ch (J.F. Clinton).
} 
2019). InSight has a nominal mission duration of 1 Martian year (about 2 Earth years) and is designed to be capable of operating well beyond this. Currently, SEIS operates as expected, achieving and exceeding its target noise levels (Lognonné et al., 2020).

A key component of the InSight ground services is the Marsquake Service (MQS), which is tasked with producing a catalogue documenting the seismicity InSight records on Mars (Clinton et al., 2018). In order to fulfill this goal, MQS is responsible for 1 . prompt routine data monitoring in order to detect and discriminate seismic signals - where possible providing locations for these marsquakes; and 2. curating the seismicity catalogue, updating as our understanding of Martian seismicity evolves. The MQS team is led by ETH Zurich and includes members from across the entire SEIS science team. A frontline team of 10 members share duty to check all incoming data within hours of reception on Earth, screen for seismicity, and catalogue all events. SEIS waveform data (InSight Mars SEIS Data Service, 2019) are produced by SISMOC (SeIS on Mars Operation Center) at CNES (Centre National D'Etudes Spatiales) and curated by the Mars SEIS data service, while the Mars interior models expected at the end of nominal mission will be integrated and curated by the Mars Structure Service (Panning et al., 2017).

Once a marsquake is identified, MQS utilizes single-station approaches to determine a distance and back-azimuth (Khan et al., 2016; Böse et al., 2017) from a set of a priori reference models (Smrekar et al., 2019), and magnitudes when it is possible to obtain a distance (Böse et al., 2018). All the methods currently employed by MQS in operations have been vigorously tested prior to landing using synthetic waveforms and event catalogues (Clinton et al., 2017; van Driel et al., 2019). Nevertheless, the actual data we observe is quite different to what was expected, and the pre-mission approaches have been adapted in order to glean as much information as possible regarding each event. The L1 Mission target for locating marsquakes is to determine the distance and back azimuth to within $25 \%$ and $20^{\circ}$ respectively (Lognonné et al., 2019).

The MQS catalogue is immediately available to the InSight science team members, and with a short delay, is also made available to the wider scientific community, alongside the raw seismic data, via the IPGP data center and IRIS. Currently, the raw waveform data and the associated seismicity catalogue are released every 3 months, with a delay of 3 months.

A first release of the MQS marsquake catalogue was made on 2 January 2020, including all events up to 31 September 2019, or InSight Sol 299 (InSight Marsquake Service, 2020a). A subsequent release was made on 1 April 2020, comprising seismicity recorded until 31 December 2019, or InSight Sol 389 (InSight Marsquake Service, 2020b). This paper documents the seismicity included in the third catalogue release, including all events up to 31 March 2020, or InSight Sol 478. In this period, 465 events that we classify as marsquakes have been detected. Additionally, 712 events we interpret as near-lander seismic signals have been identified. The paper also describes the evolution of SEIS data collected on InSight so far, and the methodologies, tools and services that allow us to provide the catalogue. Key seismic events are described in detail. The catalogue described in this paper can be found as InSight Marsquake Service (2020c), indicated hereafter as V3. This is a companion paper to Ceylan et al. (2020), also in this issue, that provides an overview of the non-seismic features of the InSight dataset.

The MQS categorises the marsquake events observed so far into 2 broad families. The primary distinction between these families is the frequency content (Giardini et al., 2020). In the V3 catalogue, 41 events are predominantly longer period, with energy mainly between 1 and 10 $\mathrm{s}$, which have occurred at a relatively constant pace since the WTS was placed over SEIS. A first interpretation is that these events range from $25^{\circ}-100^{\circ}$ epicentral distance, and originate below the crust. The majority of marsquake events, 424, contain energy mostly at higher frequencies, always including energy at $2.4 \mathrm{~Hz}$ and often rising up to and beyond $10 \mathrm{~Hz}$. These events were rare until June 2019, whereupon there was a sudden increase in the rate, that was sustained until December, since then there has been a further drop in activity - though estimating rate changes is hampered by strong diurnal and seasonal fluctuations in the background seismic noise. A key feature of these events is the excitation of energy at $2.4 \mathrm{~Hz}$. Events from both families have a long duration, ranging from a few minutes to over $30 \mathrm{~min}$. Only the largest events have energy that can be seen in unfiltered broadband timeseries, and only 3 have clear arrivals with polarised energy and can be located. For longer period events, arrivals are interpreted as $\mathrm{P}$ and $\mathrm{S}$ waves. No high frequency events have azimuthally polarised arrivals, but there are often 2 clear energy packages interpreted as Pg and Sg (van Driel et al., 2020).

Another class of seismic signals have been observed that are of much shorter duration and restricted to frequencies above $5 \mathrm{~Hz}$. Over 700 of these have occurred since Sol 182, when continuous data began to be collected at higher sampling rates. These events cluster over weeks with events occurring at similar times of day, typically in the evening period (Dahmen et al., 2020).

Data from the seismometers on SEIS are produced on the EBOX generally at 100 sps for the SP and 20 sps for the VBB after digital filtering and are stored on-board InSight. Data can be decimated to lower sampling rates and continuous chunks are transferred to Earth, typically between 1 to 3 times per Sol. When requested by scientists and engineers, higher sampling rate data available at up to $100 \mathrm{sps}$ can also be retrieved for short time intervals. The maximum available sample rate is systematically requested around identified marsquake signals. The sampling rate for continuous data, and the duration of higher sample rate data requests, are dependent on available Martian satellite bandwidth. The acquisition and download configuration has changed during the course of the mission - in the early period, shortly after VBB began to operate round-the-clock, only 2 sps VBB 3-component data was available, with a single 10 sps vertical VBB combination channel (58. BZC) also acquired. In steps, this was extended, as InSight took advantage of unexpectedly large bandwidth allocations, and since 1 June 2019 / Sol 182, 20 sps data from both SP and VBB has been continuously transmitted, with few exceptions. The raw components from the VBB and SP channel have non-standard and different orientations, and are labelled as $\mathrm{U}, \mathrm{V}$ and $\mathrm{W}$. All data is collected and made available using the SEED standard and metadata is in datalessSEED (Ahern and Dost, 2012). Lognonné et al. (2019) and Ceylan et al. (2020) provide a thorough description of SEIS instrument, data acquisition and data management, including naming conventions.

Seismic data has been previously collected on Mars, from the Viking 2 seismometer in 1976-77 (Anderson et al., 1977). The seismometer was located on the lander, so much higher noise levels were observed. Only a single potential marsquake was identified - on Sol 80 of this mission. The short $70 \mathrm{~s}$ duration event is estimated to be at $110 \mathrm{~km}$ distance with an equivalent Richter Magnitude M2.8. Noise evaluation suggests that no event less than magnitude 5 could be seen at distances of $20^{\circ}$, and at 6.5 globally. Recent evaluation by Lorenz et al. (2017) indicates it is unlikely the Sol 80 event is produced by a wind gust.

Nevertheless, as will be illustrated in this manuscript, the InSight marsquake catalogue recorded so far includes only small amplitude seismicity. Given the high noise observed on the Viking seismometer, that mission would not have been able to detect a single one of the marsquakes seen by InSight, assuming similar epicentral distance. Also, with a duration of less than $60 \mathrm{~s}$ (Lorenz et al., 2017), the potential event on Sol 80 differs significantly from all marsquakes and therefore seems unlikely to be a seismic signal of the kind recorded by InSight and described in this manuscript.

\section{MQS methods, tools and testing - before landing}

The core of the Marsquake Service was built in the 5 years prior to InSight landing. Various methods were developed to locate and characterize marsquakes and a software framework was developed to 


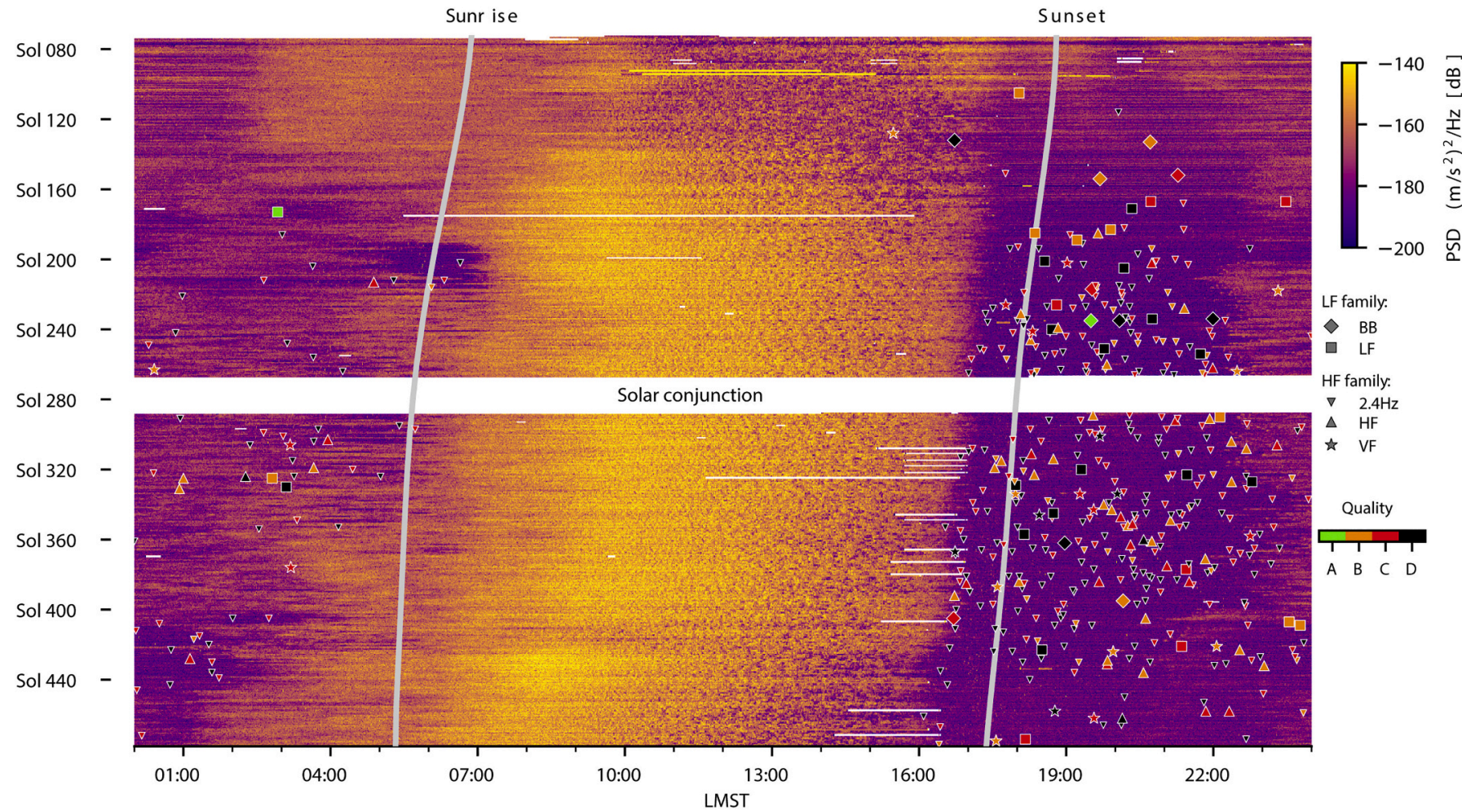

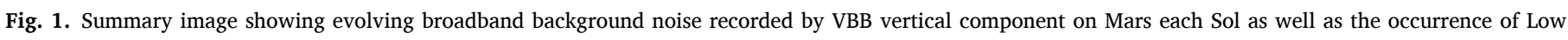

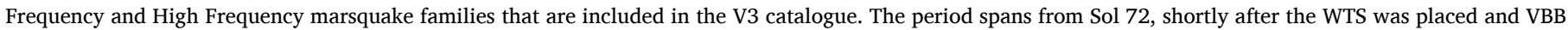

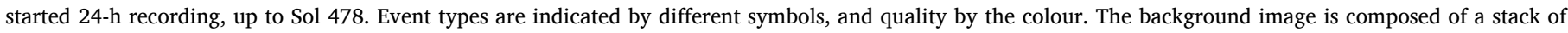

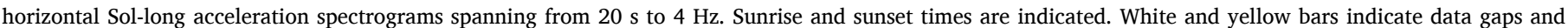

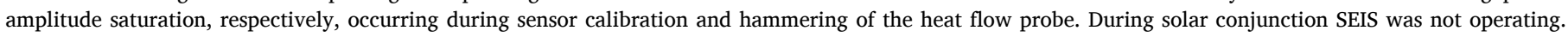

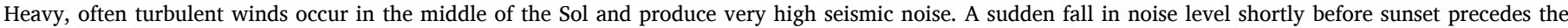

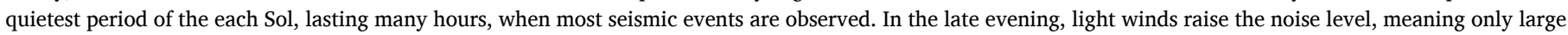

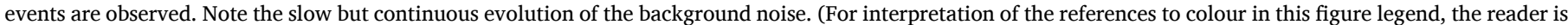
referred to the web version of this article.)

manage the arriving InSight datasets, screen waveforms for marsquakes, locate events, and manage the catalogue.

Since InSight is the only seismic station on Mars, and the mission aims to generate a planetary-wide seismicity catalogue, MQS needs to operate using single-station location tools that must span all ranges of distance and magnitudes that can be observed. Due to the ubiquity of seismic sensors on Earth - in particular at the global scale, there is limited literature on single-station earthquake location to build on. Single station approaches require an independent estimation of the hypocentral distance and the back azimuth, that can be combined to provide a location. Pre-landing, it was expected that the largest events InSight would observe would be teleseisms, and surface waves would be a primary feature of the marsquake timeseries. Hence first efforts focused on using multi-orbit surface waves to estimate distance, and first-orbit Rayleigh polarisation for back azimuth (Panning et al., 2015, 2017; Khan et al., 2016). A comprehensive approach providing a probabilistic framework that combines multiple different approaches for each of distance and back-azimuth was presented in Böse et al. (2017). A standard back azimuth using body wave polarisation was adopted. This paper also introduced a more traditional travel-time approach using identified first arriving picks for body phases and group velocity for band-passed surface waves. Travel times are generated from candidate plausible velocity models. A key feature of this framework was the ability to combine location information from any or all of the different approaches.

Pre-landing magnitude scales were built following magnitude scales standard in Earth seismology (Böse et al., 2018), comprising surface wave magnitude, $\mathrm{P}$ and S-wave body magnitudes, local magnitude and
Moment magnitudes based on spectral fitting. The magnitudes were derived using synthetics using a set of plausible velocity models (Ceylan et al., 2017). At the time, the expected continuous data rate for 3-component VBB data was 2 sps, with a combined vertical component at $10 \mathrm{sps}$ created by on-board combining of the raw VBB and SP components (higher sampling rates up to $100 \mathrm{~Hz}$ were available only for short event requests), hence the body wave and local magnitude scales were derived at longer periods than used on Earth.

In order to manage the data and facilitate event locations and catalogue management, a software framework was built by ETH and gempa GmBH (Clinton et al., 2018). This is based on the SeisComP software package, an open-source complete seismic network management solution currently ubiquitous in regional seismic networks (Hanka et al., 2010). The methodologies developed in Böse et al. (2017) are all supported. It includes an interactive GUI (graphical user interface) to review data, explore and create events, and manage the event catalogue.

The entire MQS framework was road-tested in the MQS Blind test (Clinton et al., 2017; van Driel et al., 2019), where expected Martian rates of seismicity, generated using an unknown 1-D velocity model, was hidden in a year of data derived from a pre-launch weather and thermal seismic noise model (Mimoun et al., 2017; Murdoch et al., 2017). The test was also an open community invitation to contribute best estimates of the catalogue. MQS had a magnitude of completeness of $M_{w}=3.5$ for the planet, which dropped to $M_{w}=2.5$ within $30^{\circ}$ distance from InSight. MQS provided a quality value that provided an indication of their confidence in their analysis. For the vast majority of high confidence solutions, including all events with $M_{w}>4.0$, MQS could produce locations with distance and back-azimuth errors within the L1 mission targets of 
$20 \%$ and $25^{\circ}$ respectively.

\section{Data from Mars}

In practice, once we landed, the Martian dataset provided many surprises. Most importantly, once the deployment and commissioning phases were concluded, the VBB and SP seismometers were observed to be capable of operating at or exceeding their target noise levels (Lognonné et al., 2019, 2020). During quiet periods, the observed noise on all 3 components is well below that seen on Earth, orders of magnitude below the Earth Low Noise Model (Peterson 1993) at frequencies affected by the Earth microseism. There were very significant reductions in noise observed during the deployment phase. This period spans data collected first from the SP sensor, when it was initially turned on days after landing while SEIS was still placed on the deck (Panning et al., 2020), to that observed by the VBB following the deployment on the Martian surface about $1 \mathrm{~m}$ away from the lander, through the completion of various efforts to reduce stresses induced from the tether that connects SEIS to the lander, and finally placement of the WTS over SEIS (Ceylan et al., 2020). Unfortunately, despite these efforts to isolate the signal from lander noise and local weather perturbations, SEIS is still highly sensitive to local weather, generally recording very large diurnal variations in noise. For the majority of the period described in this paper, the Martian noise is consistently low for a brief period of time in the early evening (Giardini et al., 2020), with however coherency between VBB axis suggesting non-random noise (Lognonné et al., 2020). Fig. 1 presents the evolution of broadband VBB vertical noise for each Sol, starting from Sol 72 when VBB data began to be continuously collected in the days after the WTS was placed over SEIS, until Sol 478, the end of the period described in this paper. The 465 marsquakes are also indicated. It is notable that at the start of the project, noise was persistently high across the day, and marsquakes have not been identified in this period. In addition to the long duration signals from winds (Lognonné et al., 2020; Charalambous et al., 2020) and from pressure drops (Banerdt et al., 2020; Lognonné et al., 2020; Kenda et al., 2020), there are a number of other persistent signals in the data that make data analysis challenging. Large number of glitches, often with high amplitudes, appear in the data as one-sided pulses representing each component's response to an impulse of energy. Glitches have a short duration, about $25 \mathrm{~s}$, but through their ubiquity and broadband nature, they have a very disruptive effect on the signal. They are observed on both the VBB and SP sensors throughout many periods of the Sol (Lognonné et al., 2020; Scholz et al., 2020). At higher frequencies, impulsive energy termed 'donks' also abound throughout the Sol, though these are only chiefly visible on the 100 sps data (Ceylan et al., 2020) and so distort the event signal for rare events with energy above $10 \mathrm{~Hz}$. The highly varying nature of the SEIS data makes automated detection of seismic signals challenging, and, coupled with the weak SNR of most marsquakes, are the key reason MQS operators rely primarily on manual review of all data.

Natural frequencies from spacecraft lander elements, including resonances of the solar panels, the tether and associated service loop are seen in the daily spectrogram. The amplitude and frequencies of these narrow-banded resonances wander across the day, affected by temperature and wind changes. A treatment of these modes is given in Ceylan et al. (2020).

The resonance at $2.4 \mathrm{~Hz}$ is different from other modes. It is characterised by having a broader frequency range of amplification alongside only a slow variation of excitation from the background noise over each Sol. The amplification is strongest on the vertical component. Unlike other resonances, the $2.4 \mathrm{~Hz}$ mode amplitude and frequency is not strongly influenced by daily weather variation, or seasonal changes. It is most likely produced by a local subsurface feature, though the mechanism of the resonance, its stability as observed during low noise periods and its excitation by ambient noise and events remains unclear. However, as this mode amplifies marsquake signals and is not affected by
Table 1

List and descriptions of Event Types included in the V3 catalogue.

Low frequency family: event energy generally at long period

$\begin{array}{ll}\text { Low frequency (LF) } & \text { Energy in } 3 \text { components all below } 2.4 \mathrm{~Hz} \\ \text { Broadband (BB) } & \begin{array}{l}\text { Energy in } 3 \text { components predominantly below } 2.4 \mathrm{~Hz} \text { though } \\ \text { also includes excitement at and possibly above } 2.4 \mathrm{~Hz} .\end{array}\end{array}$

High frequency family: event energy generally at high frequency

High frequency (HF) Energy in 3 components predominantly at $2.4 \mathrm{~Hz}$ and above. 'Predominantly' indicates some energy below $2.4 \mathrm{~Hz}$ is possible.

$2.4 \mathrm{~Hz} \quad$ Energy in 3 components centered around $2.4 \mathrm{~Hz}$ resonance, with very limited excitation above or below. (It is likely these are small amplitude HF events.)

Very high frequency Special case of high frequency events that show clear (VF) differences in energy between vertical and horizontal components. Horizontal energy is significantly larger than vertical energy at higher frequencies.

Other signals
Super high
$\quad$ frequency (SF)

Very short duration high frequency events that do not include energy at $2.4 \mathrm{~Hz}$ or below. Typically between 5 and $10 \mathrm{~Hz}$, and horizontal energy is significantly larger than vertical energy.

local noise perturbations, it is a key discriminator for marsquakes detection. The majority of events in the MQS catalogue include an enhanced excitation of this resonance while having no effect on the other modes that are attributed to the spacecraft or tether.

The data from the APSS (Auxiliary Payload Sensor Suite; Banfield et al. (2019)) is also a key tool for identification of Martian seismicity. APSS is an additional InSight science package located on the lander that includes a pressure sensor, two booms for measuring wind direction and speed, and a magnetometer (InSight FluxGate magnetometer, IFG). This data is important for discrimination of seismic events from any suspicious signals observed in the data (Charalambous et al., 2020). Though not used in MQS procedures beyond for visual inspection at the moment, APSS data could also be used to remove pressure-derived fluctuations in the seismic data (Murdoch et al., 2017; Garcia et al., 2020). Additionally, lander activity logs that include information such as lander wakeups, communications passes, arm motion and basic quality control and functional activity are also available that allow us to confirm that signals we observe are not locally produced.

\section{MQS catalogue overview}

As we have gained familiarity with seismic signals over the duration of the mission so far, the MQS team has learned to group similar events by their frequency content. The majority of events excite the $2.4 \mathrm{~Hz}$ mode (often exclusively), and may include energy either above or below this resonance. This resonance serves as a natural divide between the various event types and allows us to group events into two clear families: a low frequency family and a high frequency family. The MQS convention is to assign marsquake event types according to the frequency content rather than describing the source in order not to prejudice any interpretation. The two families include event types that are summarised in Table 1. Examples of all types are provided in the following sections.

The low frequency family comprises 2 event types that have energy between 1 and $5 \mathrm{~s}$, and can include energy down to 10s. Events assigned as low frequency (LF) do not excite the $2.4 \mathrm{~Hz}$ mode. In contrast, a broadband (BB) event does include some clear excitation of this resonance mode at some point during the longer period excitation. BB events do not generally exhibit clear relationships between the $2.4 \mathrm{~Hz}$ excitation and the longer period signal - the onset time of energy at $2.4 \mathrm{~Hz}$ can be earlier, co-incident or later than the long period onset, and the 
Table 2

List and descriptions of Event Qualities included in the V3 catalogue.

\begin{tabular}{|c|c|c|}
\hline Label & $\begin{array}{l}\text { Quality } \\
\text { summary }\end{array}$ & Key features \\
\hline A & High & $\begin{array}{l}\text { Multiple clear and identifiable phases/clear polarisation } \\
\text { (implies possibility both distance and back azimuth are } \\
\text { determined, and hence location) }\end{array}$ \\
\hline B & Medium & $\begin{array}{l}\text { Multiple clear and identifiable phases but no polarisation } \\
\text { (implies possibility of distance but no location) OR } \\
\text { polarisation, but not enough clear phase picks for a } \\
\text { distance estimate }\end{array}$ \\
\hline \multirow[t]{4}{*}{$\mathrm{C}$} & \multirow[t]{4}{*}{ Low } & $\begin{array}{l}\text { Signal is clearly observed but phase picking is } \\
\text { challenging: }\end{array}$ \\
\hline & & $\begin{array}{l}\mathrm{HF} / 2.4 \mathrm{~Hz} / \mathrm{VF}: \mathrm{Pg} \text { and Sg pickable, but speculative OR } \\
\text { large uncertainty OR low SNR }\end{array}$ \\
\hline & & $\begin{array}{l}\text { LF/BB: no clear phases can be identified OR only a single } \\
\text { phase is clearly identifiable OR multiple phases are } \\
\text { identifiable, but no clear picks can be attributed to P and S } \\
\text { phases }\end{array}$ \\
\hline & & $\begin{array}{l}\text { SF: peak signal amplitude of data with } 7-9 \mathrm{~Hz} \text { filter is } \\
\text { above } 2 \times 10^{-9} \mathrm{~m} / \mathrm{s}\end{array}$ \\
\hline \multirow[t]{3}{*}{$\mathrm{D}$} & \multirow[t]{3}{*}{ Suspicious } & $\begin{array}{l}\text { Signal only weakly observed OR Signal may not be } \\
\text { attributable to a seismic event }\end{array}$ \\
\hline & & HF/2.4/VF: impossible to pick both Pg and Sg \\
\hline & & $\begin{array}{l}\text { SF: peak signal amplitude of data with } 7-9 \mathrm{~Hz} \text { filter is } \\
\text { below } 2 \times 10^{-9} \mathrm{~m} / \mathrm{s}\end{array}$ \\
\hline
\end{tabular}

duration and intensity of this $2.4 \mathrm{~Hz}$ energy can vary.

The high frequency family consists of 3 event types. High frequency (HF) events excite the $2.4 \mathrm{~Hz}$ mode and higher frequencies, up to $10 \mathrm{~Hz}$. $2.4 \mathrm{~Hz}$ events only excite the $2.4 \mathrm{~Hz}$ mode, and are considered to be small amplitude versions of HF events. By convention, a $2.4 \mathrm{~Hz}$ event does not include energy above $4 \mathrm{~Hz}$, selected as this is a wind-excited lander mode that is easily distinguished in the data. As weaker events that only excite the $2.4 \mathrm{~Hz}$ mode, these events often are only visible in the vertical component. HF events though typically have similar amplitudes on vertical and horizontal components outside the $2.4 \mathrm{~Hz}$ mode. Very high frequency (VF) events are differentiated by the presence of a strong excitation of horizontal components at frequencies above $5 \mathrm{~Hz}$, rising to $10 \mathrm{~Hz}$ and sometimes reaching up to $35 \mathrm{~Hz}$. For VF events, energy from the event is often not visible at all on the vertical component at higher frequencies. The high frequency family are presented in detail in van Driel et al. (2020).

Events from the low and high frequency families have generally similar duration, on the order of minutes to tens of minutes. Another signal type with a much shorter duration are also being observed and catalogued by MQS. These are the super high frequency (SF) events, lasting only about $20 \mathrm{~s}$ and exciting energy above $5 \mathrm{~Hz}$. They have a similar energy distribution across components as the VF, with stronger signals on the horizontals, and normally rise up to $10 \mathrm{~Hz}$ but can exhibit energy up to $35 \mathrm{~Hz}$. These likely have a very different and local source, so we separate these signals in our catalogue. The events are described in detail in Dahmen et al. (2020).

As we would expect on Earth, there are also large variations in the fidelity of the seismic event signal observed on our seismometers on Mars. The majority of events we observe have small amplitudes and are difficult to resolve above the background ambient noise. Like on Earth, there are fewer large events than small events, and events closer to the lander have higher amplitude than those farther away. But crucially, another critical factor in signal quality is the background noise, which has a very wide range on the InSight seismometers. For large periods each Sol - the duration is varying over the seasons - weather contamination raises the broadband background noise very significantly. Further, there are periods of the Sol, especially around dusk when temperatures are dropping rapidly, when the SEIS signal is generally quiet as winds are low, but the data is corrupted by broadband glitches and high frequency donks. In general, as is documented in further chapters, the amplitudes of marsquakes are weak, so the quality of event recordings, and indeed the ability to detect events, are very susceptible
Table 3

Breakdown of the V3 catalogue in terms of event types and qualities.

\begin{tabular}{llllll}
\hline Event type & Total number & Quality A & Quality B & Quality C & Quality D \\
\hline \multicolumn{2}{l}{ Low frequency family } & & & & \\
LF & 28 & 1 (S0173a) & 6 & 11 & 10 \\
BB & 13 & 1 (S0235b) & 1 & 9 & 2 \\
\multicolumn{2}{l}{ High frequency family } & & & & \\
VF & 23 & 0 & 9 & 8 & 6 \\
HF & 52 & 0 & 31 & 18 & 3 \\
$2.4 \mathrm{~Hz}$ & 349 & 0 & 38 & 137 & 174 \\
Other event types & & & & \\
SF & 712 & 0 & 0 & 128 & 584 \\
\hline
\end{tabular}

to these large changes in background noise. In order to indicate differences between the signal quality for different events and aid consistent interpretation, MQS has assigned an event quality to each event. Table 2 summarises the four qualities that can be assigned to each event. The event quality indicates how well an event can be characterised - focus is on the ability to identify and interpret phases. Quality A events are those where multiple phases are observed and identified and polarisation can be determined, leading to a location. Quality B is assigned to events with clear phases without polarisation, so only a reliable distance can be determined. There is a single additional event assigned Quality B, where polarisation is present for the single clearly identifiable phase. Here the direction can be estimated, but not a reliable distance. Quality C are events that have good signal to noise, but where phase identification is challenging. Quality D events are only weakly observed, or are strongly contaminated by noise. MQS has defined detailed rules and conventions for pick detection and phase assignment that are described in subsequent sections.

The MQS team makes every effort to identify all possible events within the data and provide the most complete catalogue possible for all event types. On 31 March 2020, the MQS catalogue included 465 events that are interpreted to be distant marsquakes. Only 41 marsquakes are in the low frequency family, although these include the only 2 Quality A events in the catalogue so far, as well as an additional 11 Quality B events. The remaining 424 marsquakes are from the HF family, although the majority are weak $2.4 \mathrm{~Hz}$ events. $23 \mathrm{VF}$ events and $52 \mathrm{HF}$ events have been observed. 712 additional events are labelled as SF events and interpreted as associated with local thermal cracking. The number corresponding to each event types and qualities are shown in Table 3. As would be expected with any Earth seismicity catalogue, there are fewer high quality events than low quality events.

Fig. 1 displays the temporal distribution of all event types in the MQS catalogue, overlain on the background VBB vertical broadband noise. LF and $\mathrm{HF}$ events were not observed until the low noise evening period began to appear. Fig. 2 shows the distribution of the SF events overlain on background VBB east noise with a narrow 7-9 Hz high frequency band, representative of the energy at which SF events are detected. In general, the high frequency horizontal noise matches that of the broadband vertical signals. Note that SF events have only been systematically detected since Sol 198, when 20 sps VBB data began to be continuously transmitted.

Table 4 provides the general characteristics for each LF and HF family event type in the V3 catalogue. Supplementary Table 1 details the individual characteristics of each of the 41 LF family events, and Supplementary Table 2 details those from the $424 \mathrm{HF}$ family events. The following sections documents how these characteristics are identified and determined.

\section{Building the MQS catalogue - methods, procedures and operation}

The Mars dataset recorded by SEIS is very rich and varied in terms of noise signals. The companion paper Ceylan et al. (2020) summarises the 


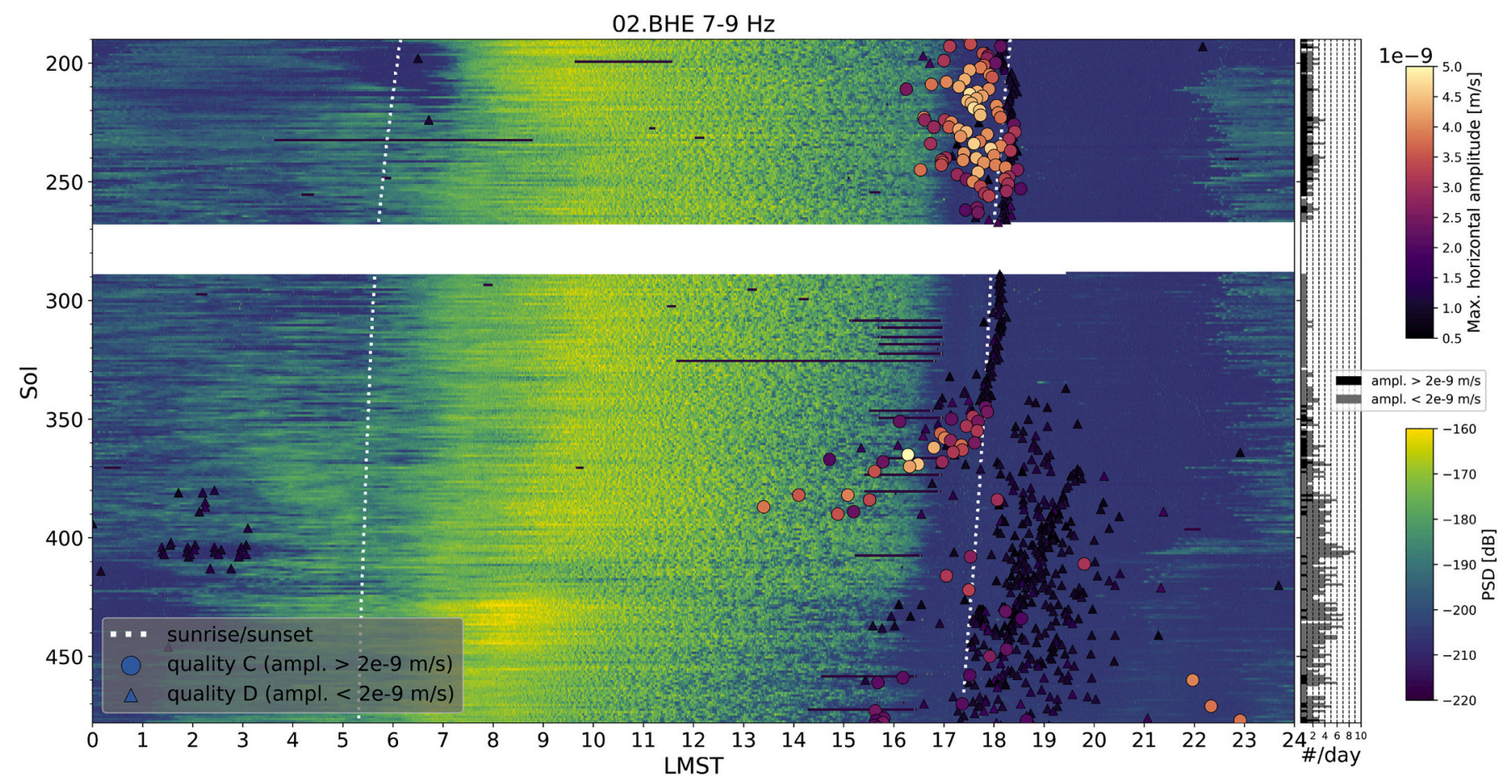

Fig. 2. Summary image showing evolving high frequency background noise recorded by VBB east component on Mars each Sol as well as the occurrence of SF events in the V3 catalogue. The period spans from Sol 190, when 20 sps data began to be continuously collected, enabling routine detection of SF events, up to Sol 478. SF event quality is indicated by shape. The background image is composed of a stack of horizontal Sol-long velocity spectrograms spanning 7 to $9 \mathrm{~Hz}$. Black bars indicate short data gaps. The long gap around Sol 280 is the conjunction period when SEIS was not operating. Even though the noise represents a very different frequency band on a different component to Fig. 1, the general patterns are the same. SF events predominately occur during the quieter periods, though cluster near sunset.

Table 4

Key characteristics of each event type in the V3 catalogue.

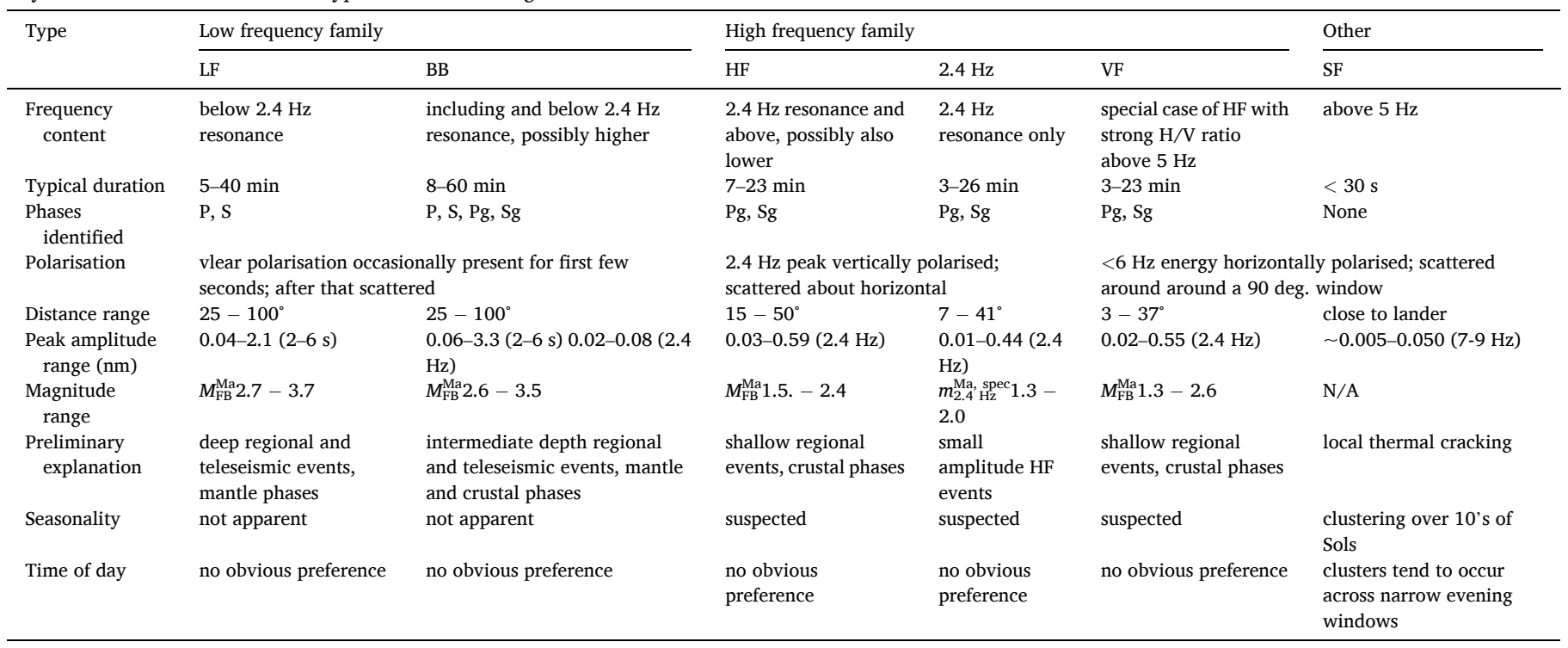

general features of the seismic data. For the majority of the Sols described in this paper, the large variation in noise between day and night is the first order feature, driven by local turbulent, rapidly-varying winds (Fig. 1). The winds are steady in the early morning. There is a transition to higher turbulent winds, including transient gusts in the mid-day period, when pressure drops, often greater than $1 \mathrm{~Pa}$ and up to $10 \mathrm{~Pa}$, are routinely observed, leading to elevated seismic signal contamination with very variable amplitude and duration. Suddenly, about an hour before sunset, the ambient turbulent wind and consequently the seismic noise drop significantly to the lowest level of the Sol, this extremely quiet period is often observed for between 6 and $8 \mathrm{~h}$. Other noise sources include InSight lander operations as well as impulses of energy likely associated with thermal expansion and contraction affecting the lander, tether and SEIS. These sources excite discrete structural resonances, and for transient events, also include more broadband energy, glitches and high frequency donks.

The marsquakes identified so far are generally very small in amplitude, and, with few exceptions, are only observed during particularly 


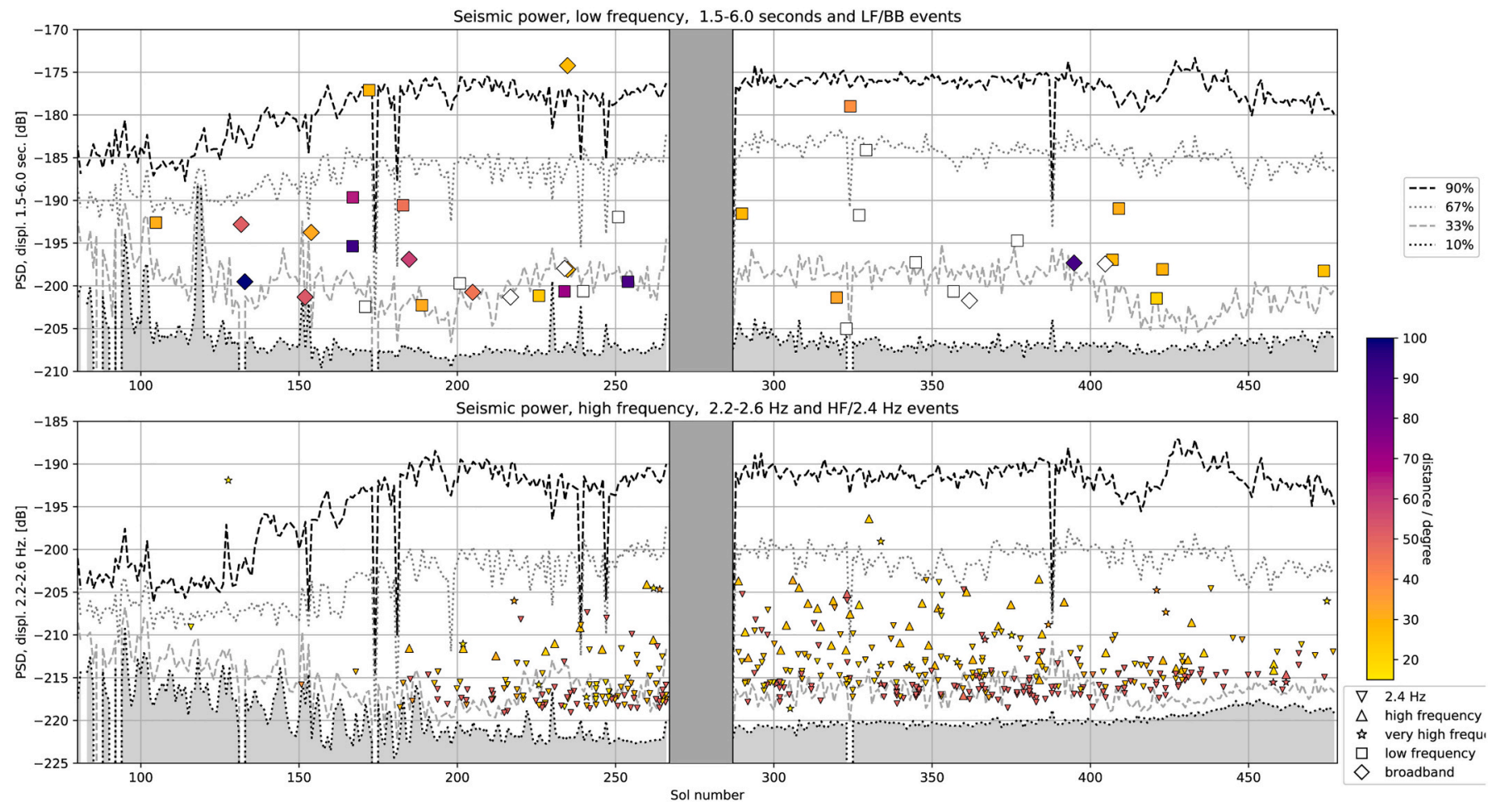

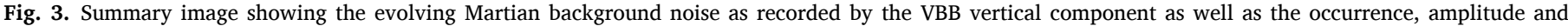

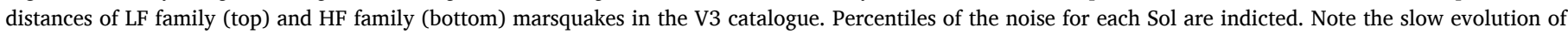

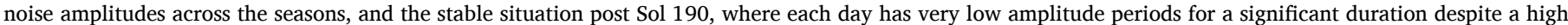

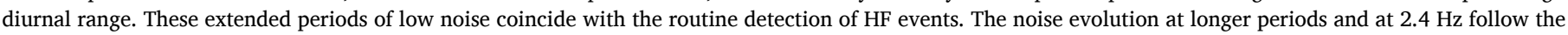
same trends.

quiet periods of each Sol (Fig. 1). Fig. 3 shows the daily evolution in the noise, tracking the 10th, 33th, 67th and 90th PSD percentiles of noise for each Sol. The upper panel shows the noise within a 1.5 - $6 \mathrm{~s}$ period bandwidth, covering typical energy from LF family events. The lower panel focuses on the $2.4 \mathrm{~Hz}$ resonance mode for the HF family events. Since about Sol 190, the daily noise variation has been stable, with a 30 $\mathrm{dB}$ difference between the 10th and 90th percentiles. Before this time, there was a much smaller variation and the 10th percentile low noise was systematically higher, especially at $2.4 \mathrm{~Hz}$. The PSD amplitude of each individual marsquake is also shown. Very few events exceed or even approach the 90th percentile for noise - and only these events would have a high likelihood to be identified on all days at any time during the dataset. The majority of events are within $6 \mathrm{~dB}$ of the 5 percentile noise of the given Sol, tracking the 30th percentile. This indicates they are only marginally above the lowest noise seen during each Sol, and well below the noise seen during the majority of the Sol. Considering the noise and size of observed marsquakes, it is not surprising that so few events were detected early on in the project - this is particularly true for the HF events that are reliant on observing excess energy at $2.4 \mathrm{~Hz}$ for detection. The ability to detect events is strongly modulated by the lowest noise observed each Sol. The stable conditions with a low minimum noise that are favourable to event detection conditions began around Sol 190. This is due to the global seasonal weather pattern and had been predicted in atmospheric models before landing (Spiga et al., 2018). It is also predicted by these models that the conditions will worsen significantly once the dust storm season begins around Sol 500.

Considering the hugely variable strength of the noise signal, the low amplitude of marsquakes relative to the noise, and the variety of transient non-seismic signals, identifying marsquakes is not a trivial exercise. Building a consistent, high quality marsquake catalogue that is as complete as possible is a challenge, requiring a dedicated team that operates according to standard procedures. At this stage of the project, catalogue creation and curation also requires flexibility, with changing operations that reflect our improved understanding about the marsquake and noise signals we are monitoring.

The methods and procedures described in this section will be illustrated using the example of Sol 421, an exceptionally quiet day on Mars during which 4 marsquakes were identified: an LF Quality C, a VF Quality B, and two $2.4 \mathrm{~Hz}$ Quality D. Supplementary Tables 1 and 2 provide a full list of all the marsquake events in the V3 catalogue.

\subsection{Organisation}

The Marsquake Service operates a frontline team that is responsible for the prompt and thorough screening of all data that arrives from Mars. This international team currently consists of members from ETH Zurich, IPG Paris, ISAE Toulouse, Imperial College London, University of Bristol, JPL Pasadena and MPS Gottingen. In addition to taking individual turns to review all incoming data, the frontline team regularly convene to review recently identified events and ensure the catalogue is complete. As we are building a catalogue of new signals, and we continue to be in a phase where we are updating our identification and interpretation of events, we also periodically review procedures. All members of the InSight science team are invited to attend weekly meetings to review seismicity and generally discuss seismicity analysis and interpretation.

The MQS team use an interactive GUI to explore the InSight dataset, identify and characterise events, and manage the catalogue. MQS also provide a suite of tools, including daily spectrograms for all seismic streams in raw UVW and ZNE rotated components, as well as summaries of key features for all events. 


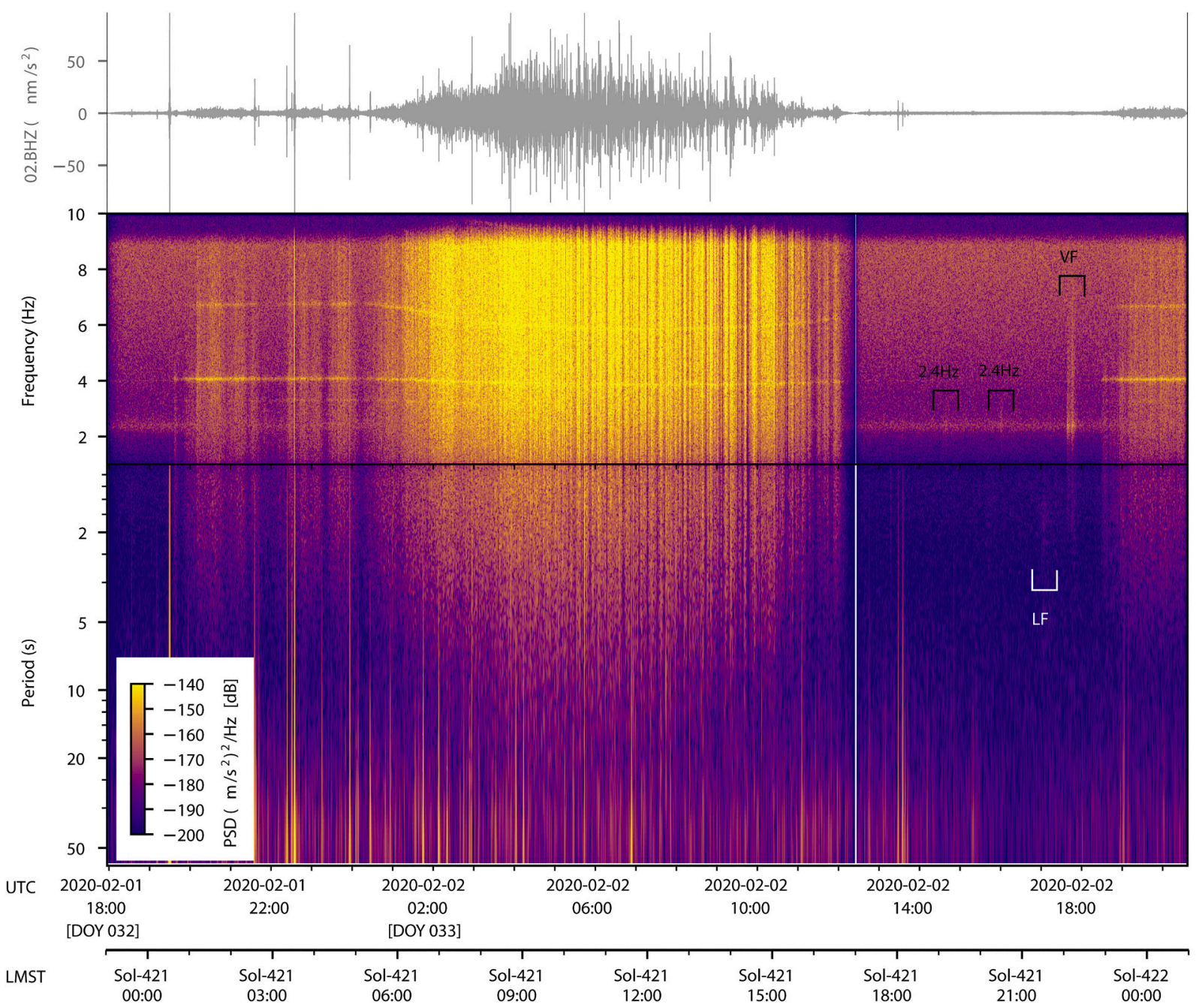

Fig. 4. Sol 421 - vertical component 20 sps timeseries and spectrogram. Marsquakes are indicated. The white space at 17:00LMST is a data gap.

\subsection{Event detection, preliminary discrimination, and naming}

Through experience, the MQS team have learnt that the majority of marsquakes can be identified by inspection of the 20 sps VBB vertical component spectrogram for each Sol - Fig. 4 shows this for Sol 421. The vertical component is the primary detection channel as it is the least affected by pressure-induced noise and glitches, during the quiet evening period when it is significantly lower in noise across the relevant frequency band. Further, the amplification of the $2.4 \mathrm{~Hz}$ mode is highest on the vertical. Note nevertheless that noise is generally lower on the horizontal components above $1 \mathrm{~Hz}$ during the daytime and late night periods (Supplementary Material SI1, Lognonné et al. (2020)). In order to aid screening procedures, spectrograms for both raw UVW orientations and ZNE rotated components are available to frontline members for both SP and VBB sensors.

Marsquakes may excite frequencies from $10 \mathrm{~s}$ to beyond $10 \mathrm{~Hz}-$ Nyquist on the continuous 20 sps data. No event has yet been observed that includes energy above $10 \mathrm{~s}$ period. Note although this does not exclude the presence of significant energy at these frequencies, since instrument noise is increasing with $f^{-3 / 2}$ in displacement amplitude, surpassing even the strongest event recorded so far at around $10 \mathrm{~s}$ period (Lognonné et al., 2020; Stutzmann et al., 2020). Since event amplitudes are supposed to have a flat displacement spectrum at longer periods, this prohibits any observation unless significantly larger marsquakes are observed. Marsquakes do not excite the lander modes visible near 3, 4 and 6-7 Hz. Since seismic events also have a typical duration of 10-30 min, during the stable periods when the background noise does not vary, they are often clearly visible on the daily spectrogram. In particular, if they include energy at the broad $2.4 \mathrm{~Hz}$ resonance, the change in amplitude of the mode is clearly observed. For marsquakes, energy is generally also present in all 3 components when rotated into vertical, north and east. In contrast, glitches, donks and other wind or lander noise signals excite a broader frequency range, typically also excite the lander modes, most obviously at $4 \mathrm{~Hz}$, and often excite only certain components. The $2.4 \mathrm{~Hz}$ resonance period is not significantly excited by any local weather, lander activity or sensor glitches. This is seen in Fig. 4 where even light winds strongly excite the $4 \mathrm{~Hz}$ mode on the vertical component, and large but transient spikes from glitches are seen at longer periods throughout the day.

The daily spectrograms are sufficient for preliminary detection of the majority of marsquakes and a first discrimination between marsquake and other noise sources, and between marsquake types. On the spectrogram for Sol 421, 4 events are visible during the quiet noise window in the early evening. The first two events show only weak excitation of the $2.4 \mathrm{~Hz}$. The third event is a long period excitation, and the last event, the strongest of the Sol, lights up a very broadband window from $2 \mathrm{~s}$ to the Nyquist at $10 \mathrm{~Hz}$.

The duty person also analyses the incoming data in more detail using the MQS GUI, to search for weaker energy signals that may be missed on the daily spectrogram, or buried between noise bursts. In particular, weak $2.4 \mathrm{~Hz}$ events are found in this manner. For barely perceptible events, we establish a minimum threshold for $2.4 \mathrm{~Hz}$ events, using a 

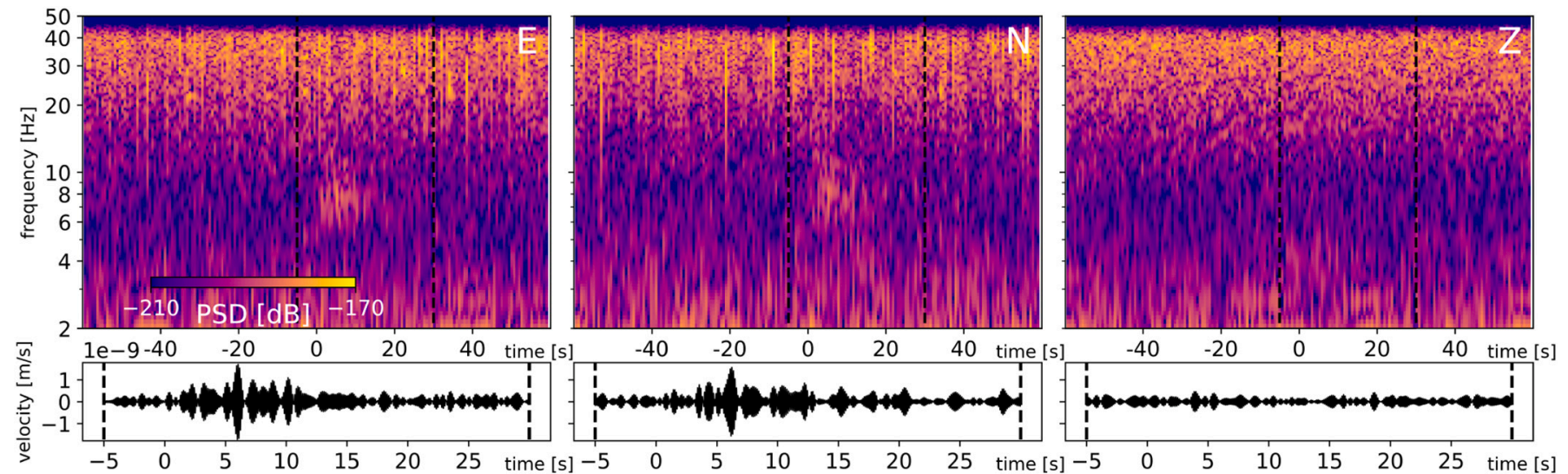

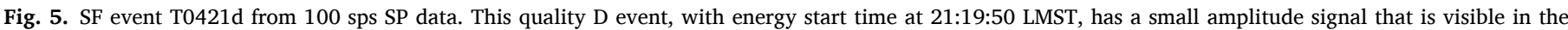

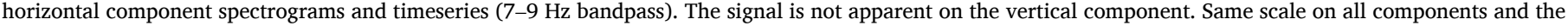
black-dotted line in spectrogram corresponds to the section shown in the timeseries.

short-term / long-term average (STA/LTA) detector, of 100 and $1000 \mathrm{~s}$ respectively, on a time series filtered in a $2.2-2.8 \mathrm{~Hz}$ narrow band 6 pole filter for the VBB vertical component. For ambiguous cases, an STA/LTA amplitude threshold of 1.3 is required in order to include an event in the catalogue. On Sol 421, the VF event has an STA/LTA amplitude of 3.5, whereas the first and second events have amplitudes 1.3 and 1.4 respectively.

Once detected, suspected seismic events are further investigated by review of other relevant data streams collected on InSight, including wind speed and direction, atmospheric pressure, reported lander activity, and magnetometer data. The majority of detected seismic events, including the four from Sol 421, occur during the most benign environmental conditions on Mars, with little or no indication of suspicious high or transient winds and pressure signals. Unfortunately, the wind sensors are not considered reliable for wind speeds below $1.8 \mathrm{~m} / \mathrm{s}$ and can be unreliable up to $2.8 \mathrm{~m} / \mathrm{s}$ (Banfield et al., 2020), often the case for the duration of most marsquakes we have detected.

During Sol 421, an error occurred on the APSS that resulted in pressure and wind data being lost between 19:22LMST and 02:43LMST on Sol 422. This relatively rare occurrence unfortunately means that only limited discrimination can be done for these events, but this is not considered significant as the event occurs during very stable conditions. Examples of how APSS, magnetometer and lander activity information are used to aid discrimination are given for other events in the next section describing individual marsquakes.

In Supplementary Material SI1, Giardini et al. (2020) document a number of different approaches to determine a quality factor, or estimate of signal-to-noise (SNR) for each marsquake. The simplest of these, $S N R_{S}$, compares the power spectral density (PSD) of the seismic signal to a nearby representative period of noise, within a narrow frequency band that depends on the type of event $(0.2-0.5 \mathrm{~Hz}$ for LF family events, 2.2 $-2.8 \mathrm{~Hz}$ for HF family events). The noise and signal windows are determined by the frontline team. More complex SNR methods compare seismic energy with pressure and wind, although these are not systematically applied to all events. Charalambous et al. (2020) have recently developed a comodulation technique that can match seismic amplitudes with the background pressure and wind signals. This approach identifies energy in the seismometer data that is in excess of background weather, and hence can be interpreted as being from a seismic source. The authors show that the seismic energy during marsquakes is in general found to depart from the energy level that can be explained by the changing atmospheric signals. This approach provides an independent set of SNR values from comodulation with each of pressure $\left(S N R_{P}\right)$ and wind $\left(S N R_{W}\right)$, and is particularly successful in terms of discriminating marsquakes during periods when wind gusts are occurring.

Events that appear to be clearly different from background noise,
Table 5

Summary of events on Sol 421. See text for definition of the $S N R_{S}$ metric, but note that amplitude SNRs are the square-root of those listed here. The high $S N R_{S}$ for T0421a and T0421c are an artifact of strong high frequency donk signals occurring during the events. The start time indicates the time of energy onset in the seismogram, in LMST.

\begin{tabular}{|c|c|c|c|c|}
\hline Name & Type & Quality & Start time & $S N R_{S}$ \\
\hline \multicolumn{5}{|c|}{ Low frequency family $\left(S N R_{S}\right.$ from 2 to $5 \mathrm{~s}$ ) } \\
\hline S0421b & $\mathrm{LF}$ & $\mathrm{C}$ & $21: 22$ & 2.3 \\
\hline \multicolumn{5}{|c|}{ High frequency family $\left(S N R_{S}\right.$ at $\left.2.4 \mathrm{~Hz}\right)$} \\
\hline S0421a & $\mathrm{VF}$ & B & 22:04 & 8.1 \\
\hline S0421c & $2.4 \mathrm{~Hz}$ & $\mathrm{D}$ & $19: 07$ & 2.2 \\
\hline S0421d & $2.4 \mathrm{~Hz}$ & $\mathrm{D}$ & $20: 25$ & 2.2 \\
\hline \multicolumn{5}{|c|}{ Other event types $\left(S N R_{S}\right.$ from 8 to $\left.12 \mathrm{~Hz}\right)$} \\
\hline T0421a & $\mathrm{SF}$ & $\mathrm{D}$ & $18: 38$ & 28.6 \\
\hline T0421b & SF & $\mathrm{D}$ & $18: 58$ & 2.3 \\
\hline T0421c & SF & $\mathrm{D}$ & $19: 42$ & 9.4 \\
\hline T0421d & SF & D & $21: 19$ & 2.8 \\
\hline
\end{tabular}

even if they occur during windy conditions, are added to the catalogue and then characterised and categorised. Periodically, all events are reviewed to ensure the energy cannot be explained by local activity especially when new approaches are developed, such as the comodulation approach.

Once an event is added to the catalogue, it is assigned a name. MQS have assigned a convention that marsquakes are given a similar code, SYYYYX, where $Y Y Y Y$ indicates the Sol on which the event occurs, and $x$ is a unique letter assigned to each event, starting from $a$. Typically, the first event of the Sol is assigned to be $a$, but in the case of Sol 421, the VF and LF events are most obvious and were identified first, hence they are assigned S0421a and S0421b respectively. The 2 preceding $2.4 \mathrm{~Hz}$ events were only confirmed on careful review later, and hence are assigned S0421c and S0421d.

Due to their short duration and limited energy in the vertical component, SF events are not generally visible in the daily vertical component spectrograms. They are though one of the very few event sources that excite energy between 7 and $9 \mathrm{~Hz}$, and they do not excite lander modes. An automated procedure that is effective in detecting these events compares the energy ratio between the $7-9 \mathrm{~Hz}$ and the $4 \mathrm{~Hz}$ lander mode - when this ratio is high, its likely triggered by an SF event. Cross-correlation of typical SF event waveforms is used to complete the catalogue during periods when SF occur during windy condition. These methods are detailed in Dahmen et al. (2020). To distinguish between SF and the other marsquake event types, SF events names are prefaced with a $\mathrm{T}$ instead of an S. On Sol 412, four SF events were detected, labelled 


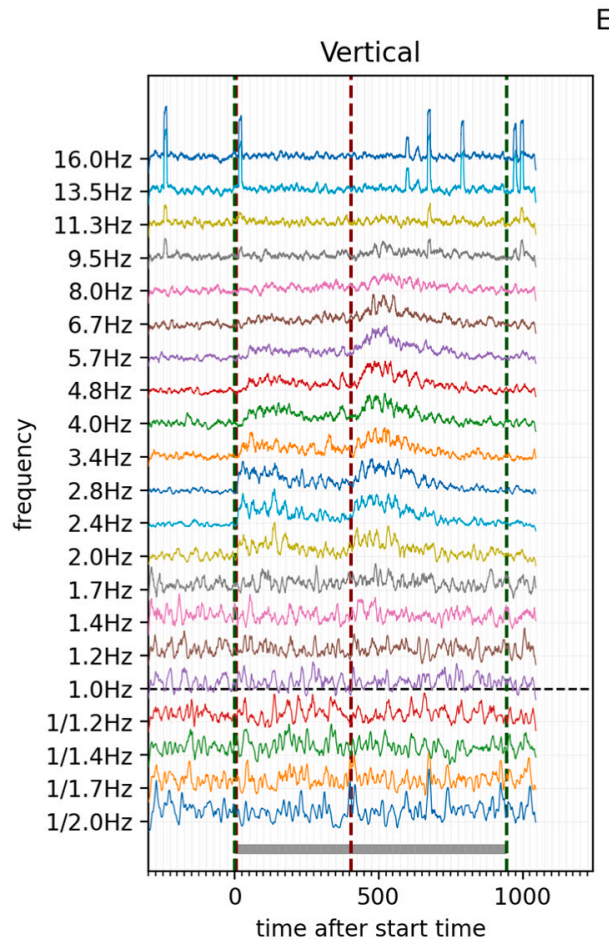

Event S0421a (0.500-16.000 Hz)

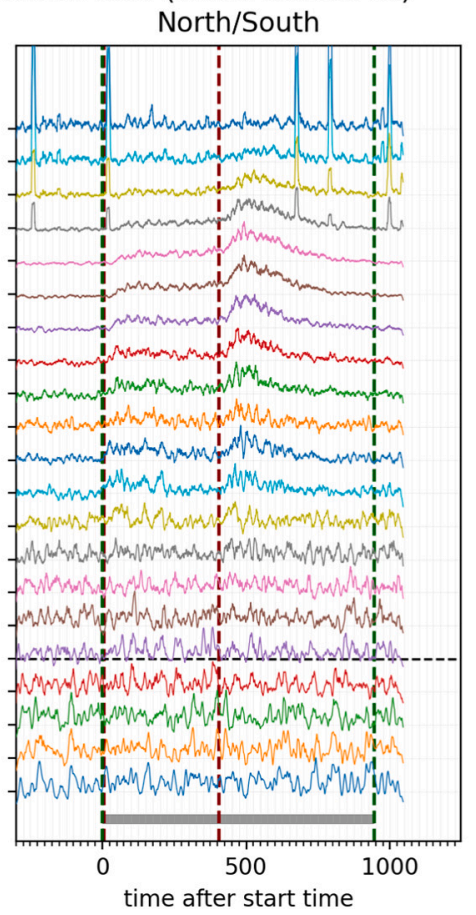

East/West

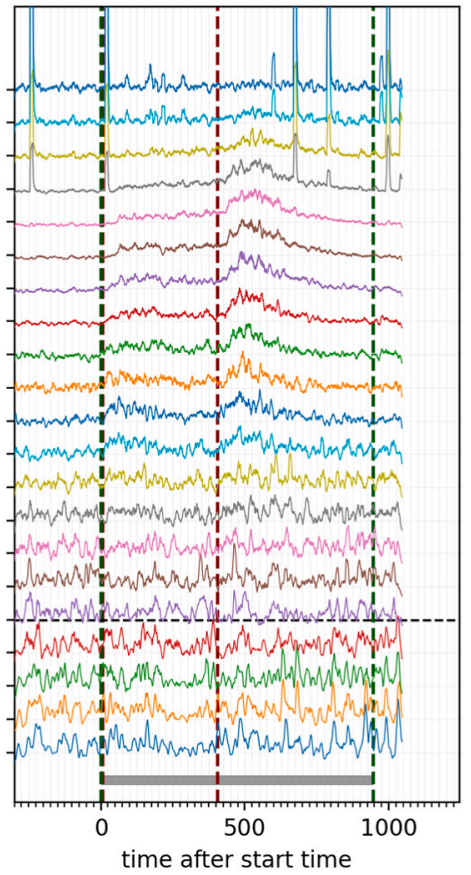

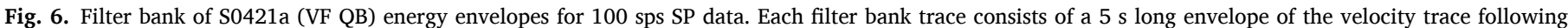

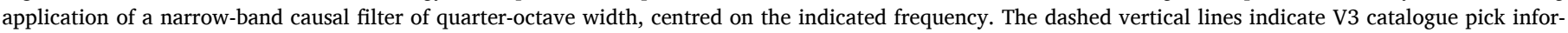

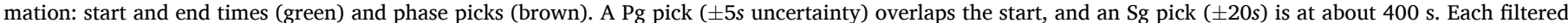

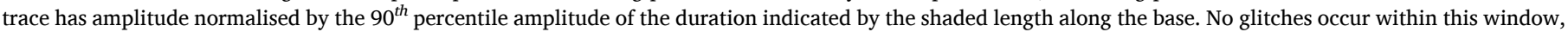

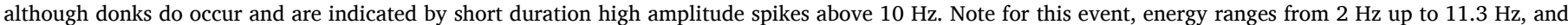

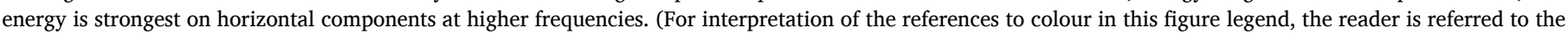
web version of this article.)

T0421a-d. Fig. 5 shows the waveforms and spectrograms for T0421d.

The summary of the 8 events detected on Sol 421, including their $S N R_{S}$ values, are shown in Table 5. No event on this day has an SNR from commudulation due to the short term loss of APSS data at the time each of these events occurred.

It is apparent in the filterbanks shown in this manuscript that glitches and donks are present in many events. In fact these artifacts are ubiquitous in the data, with repeating patterns each day. At quiet times of the day, both classes are observed to occur in clusters. Since marsquakes are also observed during this quiet times, it can be expected that on occasion there is significant contamination of the seismic event record, and unfortunately this includes overlapping glitches and donks on phase picks. MQS takes significant effort to avoid confusing phase arrivals and amplitudes with these well-known data artifacts. Each picked arrival is manually reviewed to make sure that it differs significantly from donks and glitches before and after.

\subsection{Event characterisation}

Once an event has been observed, the MQS team identifies its key features, provides a location estimate if possible, and classifies it. An MQS review first includes identification of the earliest and latest possible energy from the event, indicated as start and end times for the event. Further, an appropriate period of representative background noise near to the event, is indicated by noise start and noise end. All glitches that occur within and near the event start and end are marked.

\subsubsection{Phase detection}

Whenever possible, discrete energy onsets are identified as picks in the data. On Earth, event onsets are readily identified in the timeseries, with or without filtering. Marsquakes however have weak signals that are rarely sufficiently impulsive to be unambiguously identified in the time domain, and are often corrupted by glitches. Consequently, picks are often identified using spectrograms. A pick uncertainty is assigned guided by the method used to identify the pick. Phase picks are placed at the most likely onset start time, and an equal-sided uncertainty window is selected.

A key tool that allows MQS operators to identify pick arrivals, which can also crucially help distinguish between glitch signals and seismic arrivals, are filter banks. Here, filter banks are a set of narrow band envelope timeseries that effectively show energy partitioning across the duration of an event. Examples for S0421a and S0421b are shown in Figs. 6 and 7 - in the latter, an example of a strong glitch can be seen just before the start time. Note although the glitch has a strong distortion on the NS component up to $2 \mathrm{~s}$, there is no impact on the other 2 components.

In the case of the LF family, for a handful of high amplitude events, onsets may be identified in the time domain, where they are assigned uncertainty typically ranging from 1,2 or $5 \mathrm{~s}$. For weaker onsets, or those occurring during glitches, spectrogram-based picks are given 20 or 60 s uncertainty. Most typically, 2 separate, generally broadband, energy pulses are observed, which are assigned $x 1$ (for the earliest phase) and $x 2$ phase labels, indicating they are of unidentified phase type. Some events, in particular BB events, have an additional impulsive arrival within a narrow frequency, indicated by $x 3$. For a number of events, no clear phase arrival can be identified, rather energy is emergent, hence no pick is made. S0421b has 2 weak but broadband phases visible on a spectrogram that are assigned $x 1$ and $x 2$, with very wide uncertainty window of $\pm 60 \mathrm{~s}$. A third later but more impulsive phase, visible at longer periods but only in a narrow band, is assigned $x 3$ with uncertainty \pm 20 s.

For the HF family, for consistency, all phases are identified by slope 


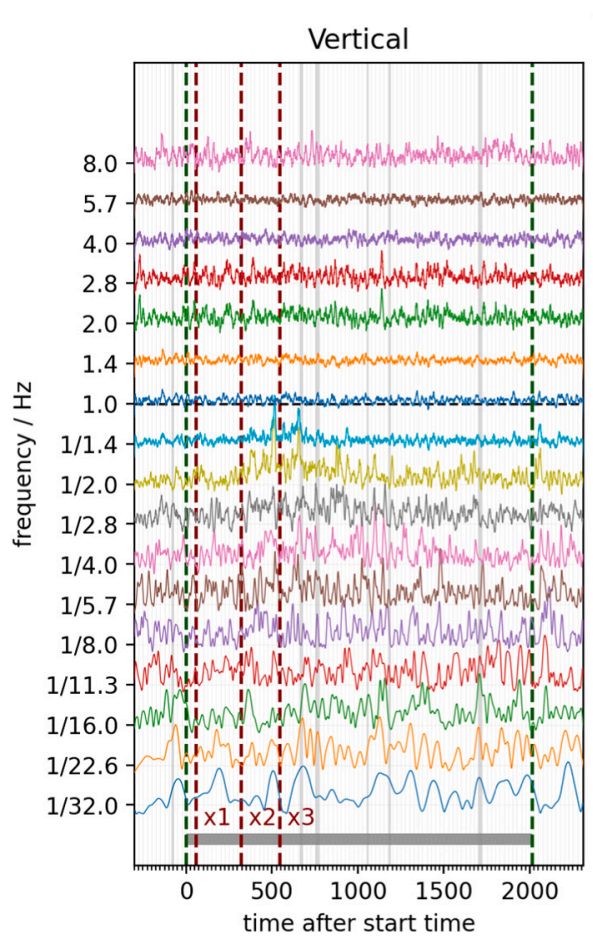

Event S0421b $(0.031-8.000 \mathrm{~Hz})$

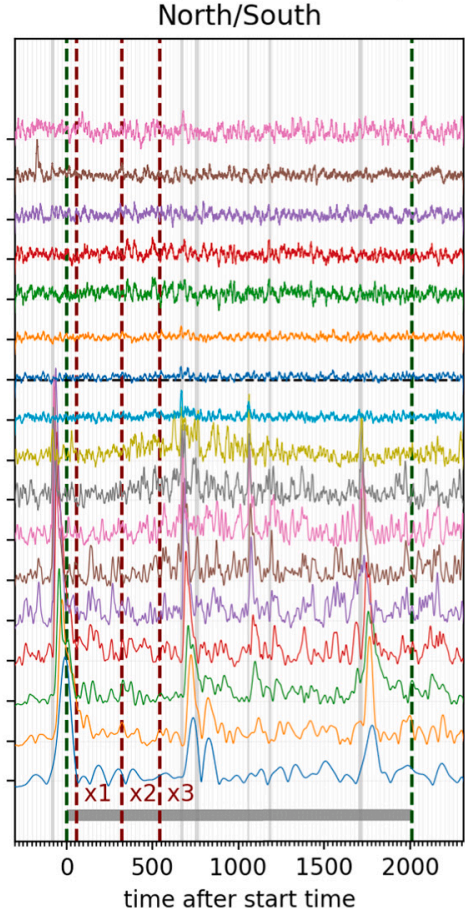

East/West

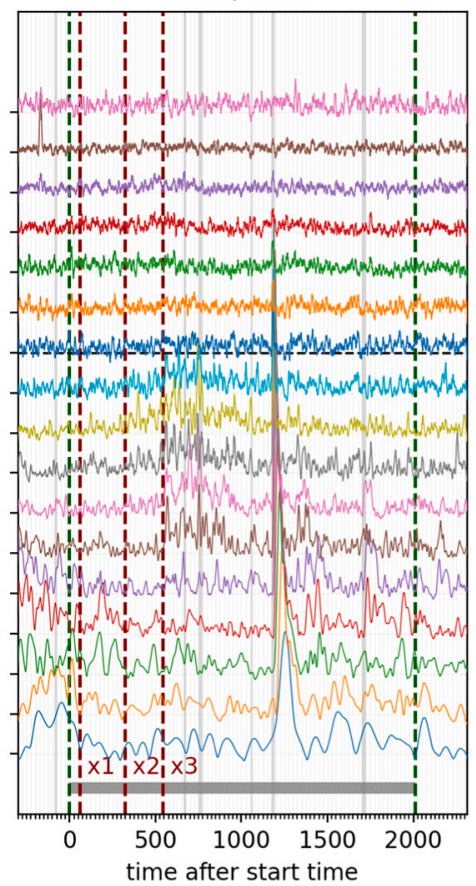

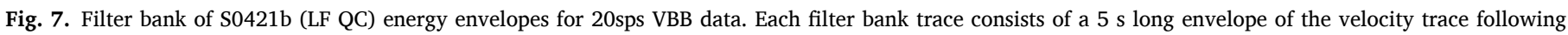

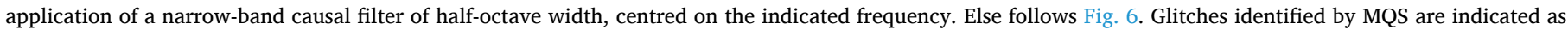

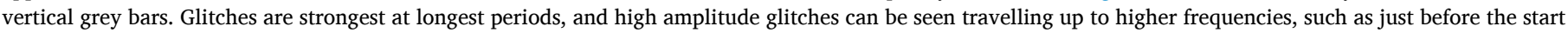

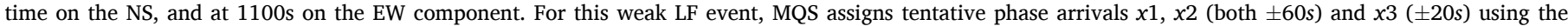
emergent energy from about $1.4 \mathrm{~s}-5.7 \mathrm{~s}$ with long duration.

breaks using a timeseries derived from an STA/LTA algorithm. For 2.4 $\mathrm{Hz}, \mathrm{HF}$ and VF events, the same event detection STA/LTA centered on $2.4 \mathrm{~Hz}$ is used, and 2 energy changes on the vertical component are typically identified, even for small amplitude events. For VF events, phase picks could also be identified on horizontal components of an STA/LTA filter tuned to 7.9-9 Hz. Phases are similarly assigned $x 1$ and $x 2$. Note it is not always immediately clear that an event is VF rather than HF, and for VF events, phase pick times and uncertainties would generally be very similar whether they are made using the 7.9-9 Hz or $2.4 \mathrm{~Hz}$ filter, although there are cases where there are small but systematic delays or advances in arrival times as frequency rises. Generally, for the HF family, uncertainty widths are assigned $\pm 10, \pm 20$ or \pm 60 s, though some events have a very sharp slope break and a more narrow uncertainty, up to $\pm 2 s$, can be assigned. For S0421a, Fig. 6 shows the second phase is slightly delayed at higher frequencies, and uncertainties of $\pm 5 s$ and $\pm 20 s$ are assigned to $x 1$ and $x 2$ respectively (see subsequent section for Pg and Sg phase assignment). The two $2.4 \mathrm{~Hz}$ event are too weak to identify impulsive phases.

SF events do not include impulsive arrivals, and no picks are made for these events.

\subsubsection{Phase polarisation}

Polarisation of ground motion can provide key evidence for identifying surface and body waves, assigning body phase types, and providing an estimate of the back azimuth of an event, a key step in single-station location.

Although MQS systematically analyses all events for hints of polarised motion, it is rare to see any. The vast majority of events are weak, and have low signal-to-noise and non-impulsive arrivals. Few events have strong impulsive signals that are significantly above the noise in all 3 components.

MQS produces images for each event showing the degree of ellipticity, the angle of inclination and the horizontal polarisation. The MQS
GUI also can determine polarisation using hodograms - targeting first motions from impulsive body phases (the $180^{\circ}$ degree ambiguity can be resolved by considering the vertical component polarity), and from Rayleigh waves, as described in Böse et al. (2017). None of the events on Sol 421 exhibit any polarisation.

So far, no event has strong suggestion of elliptical ground motion. The angle of inclination does vary strongly but systematically. The 2.4 $\mathrm{Hz}$ resonance is always vertically inclined, and for VF and SF events, energy above $5 \mathrm{~Hz}$ shows horizontal inclination. Longer period motions during LF and BB events do not show systematic trends in terms of inclination.

Horizontal polarisation is extremely rare. In the entire V3 catalogue, only 3 LF family events exhibit clear polarisation following impulsive arrivals. These are the two Quality A events, S0173a (91 ${ }^{\circ}$ ) and S0235b $\left(74^{\circ}\right)$, as well as a Quality B event S0183a $\left(73^{\circ}\right)$. All three events have strong and impulsive P-arrivals. Their horizontal polarisation is shown in Fig. 8, which shows the vertical VBB timeseries and horizontal particle motions for these three events. Figs. 13 and 16 show the ellipticity, inclination and polarisation across the event duration for S0173a and S0273b, the two largest events.

\subsubsection{Phase association}

In general, it is challenging to assign phase types to the detected phase, in the absence of clear polarisation.

For the LF family, only the two largest events (S0173a and S0235b) show horizontal planar polarisation of the first and second impulsive energy arrivals. There is clear change of polarisation between the impulsive arrivals, and the second arrival is strongest on the horizontal components. If the horizontal components are rotated into radial and transverse using the back azimuth determined from the first arrival, the secondary energy is dominant on the transverse. We conclude for these events, that we are observing a primary longitudinal phase followed by a secondary shear phase. Giardini et al. (2020) infer that in general these 

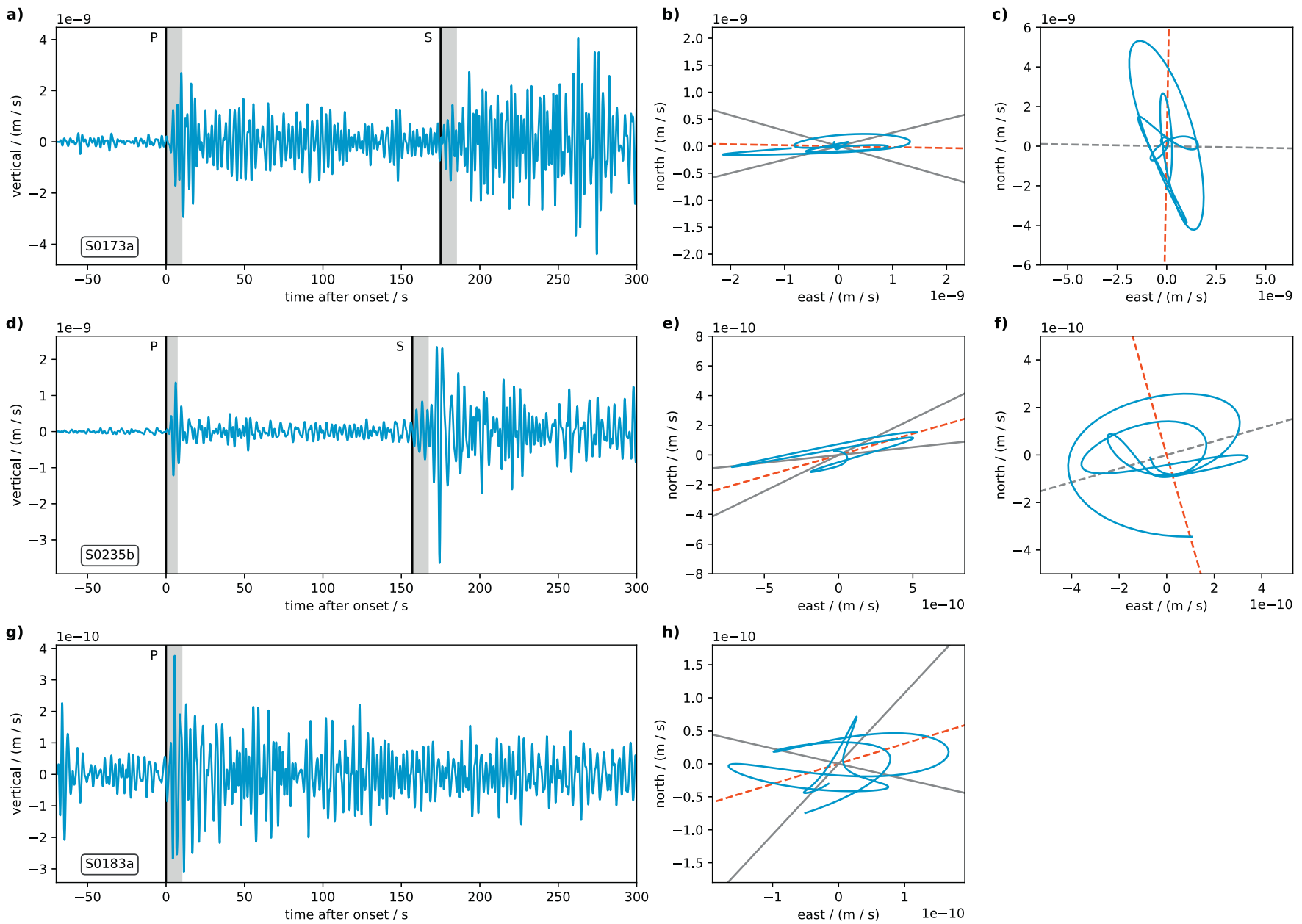

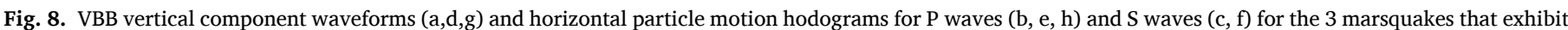

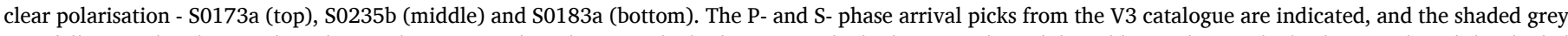

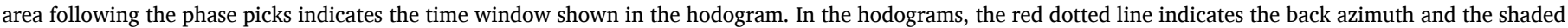

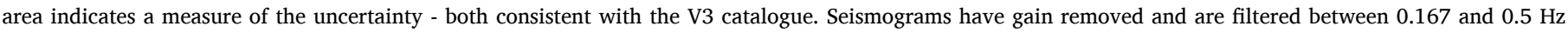

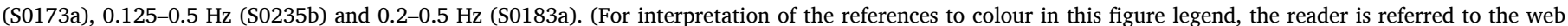
version of this article.)

LF family events are at a relatively deep source and at regional to teleseismic distances, and the body waves phases are travelling through the mantle. Hence, following the IASPEI naming convention (Storchak et al., 2011), we label them as P and S. Also, the first arrival of S0183a is assigned to be a $\mathrm{P}$ phase, although there is no strong $\mathrm{S}$ wave arrival observed for this event.

For other events in which polarisation is not clear, we consider the similarity of energy arrivals with these 3 events. A systematic effort has been made to align event waveform envelopes, following Giardini et al. (2020). Similar patterns of energy packets are systematically observed across many events, in particular for better recorded events without significant glitch or wind contamination. This allows us to associate $\mathrm{P}$ and $\mathrm{S}$ arrivals to many LF picks. When alignment does not support this interpretation, phases are left labelled as $x 1, x 2$ or $x 3$ as unknown arrivals.

Note however that for low SNR events, the first detected $\mathrm{S}$ waves could be SS phases with shallower incidence angle for events further than $40^{\circ}$, if the mantle attenuation of Mars is much larger than that of the lithosphere. (Lognonné et al., 2019).

For the majority of the stronger HF family of events, there are 2 clear, often impulsive phases identified. As described in van Driel et al. (2020), these events are interpreted to be occurring in the crust, and primarily produce trapped body phases. The MQS convention, following Storchak et al. (2011), is to label these as Pg and Sg.

In the V3 catalogue, only first arriving $\mathrm{P} / \mathrm{Pg}$ and $\mathrm{S} / \mathrm{Sg}$ phases have been assigned to events. An extended study is required to identify other phases in the dataset.

In the case of the Sol 421 events, for the VF S0421a, Pg and Sg are assigned to the $x 1$ and $x 2$ phases. For LF S0421b, phases are not clearly matching those from larger events, so they are left $x 1, x 2$ and $x 3$.

\subsubsection{Distance, origin time and location}

Böse et al. (2017) presented a probabilistic approach to locate marsquakes that combines solutions from 4 different methods - 2 measures for estimating epicentral distance and origin time, based on 1/ multiple orbit surface waves and 2 / body and surface wave arrival times phase picking; and 2 measures for estimated the back azimuth, based on analysis of 1 / Rayleigh waves and 2/ body waves. Since surface waves have yet to be identified in the InSight dataset, our application of this methodology has been restricted to distance and back azimuth estimates derived from observed body wave phase arrivals. The back azimuth estimation has been addressed above.

The phase-arrival method takes into account uncertainties associated with phase pick timing uncertainty (though assumes the phase identification is correct) as well as the uncertainty in the velocity model, which is represented by using a large set of velocity models that are 

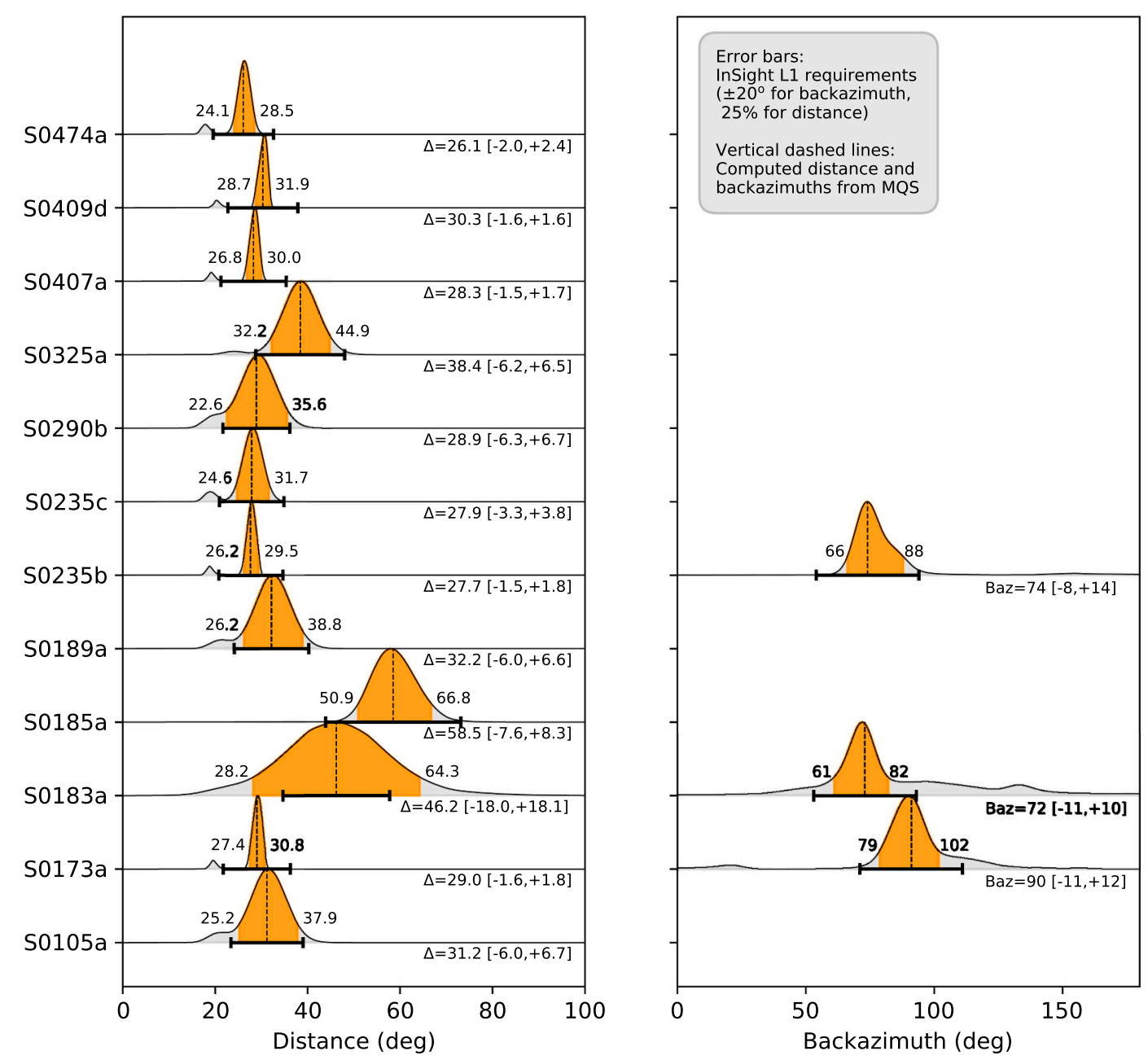

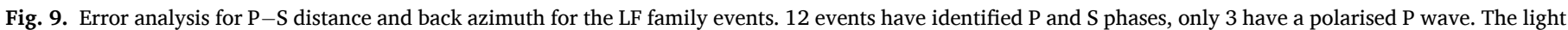

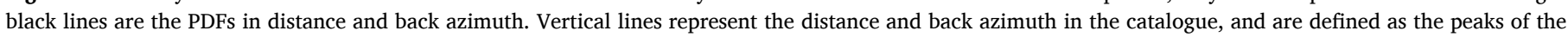

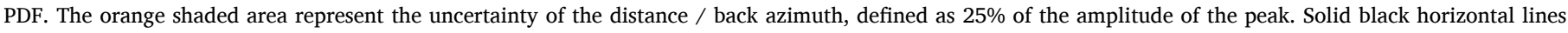
indicate the Mission L1 requirements for location errors.

expected to span the range of plausible Martian structure. Uncertainty is provided in terms of a probability density function (PDF).

In advance of the landing, a set of 2500 1D interior models were produced by 3 independent teams. These models are discussed in detail in Supplementary Material SI1 in (Giardini et al., 2020) and were based on Mars interior structure a priori (Smrekar et al., 2019). For operational considerations, the number of models was pruned down to a set of 250 . For this, travel times for $\mathrm{P}$ and $\mathrm{S}$ were calculated for a set of distances and a clustering algorithm was run to select 250 out of 2500 models that span a wide range of predictions.

Like the first two catalogue releases, V3 continues to use this a priori set of 250 models. It is expected that the model set may be revised when stronger constraints on the Martian interior are available, which would lead to a revision of these distances in future catalogue versions. This will most likely be possible following identification of additional phase arrivals for seismic events,

For events that have $\mathrm{P}$ and $\mathrm{S}$ mantle body phases assigned, a distance and origin time can be estimated using this method. Thus, such distance estimates are restricted to the LF family of events. In V3, there are $12 \mathrm{LF}$ family events with distances estimated in this way, ranging from $26 \pm 2^{\circ}$ (S0474a) to $58 \pm 8^{\circ}$ (S0185a). Fig. 9 shows the uncertainties derived from the PDFs (probability density function) for all 12 events. Although the shape of the PDF is not simple, we assign an uncertainty-width to each distance and back azimuth by selecting $25 \%$ of the peak, as indicated in orange, for each event. The figure also contains the L1 target requirements defined by the mission proposal for marsquake location (Lognonné et al., 2019) - 25\% for distance and $20^{\circ}$ for back azimuth. These results indicate that when events are large enough to identify phases, we are generally reaching and in many cases exceeding the target level of uncertainty - although of course without ground-truth events, this is not possible to independently verify. The uncertainty for the distance is primarily driven by the phase pick uncertainty, though the range of velocity models is also important, model outliers being responsible for the small amplitude peaks in the PDFs at closer distances.

An alternative method of determining the distance and also origin time is presented in Giardini et al. (2020), where energy envelopes from all LF family events are compared. Using sample single velocity models and anchored by known distances from the strongest events, weaker events may also be aligned by comparing waveform similarity, including onset times, but also considering the overall energy profiles. A total of 25 events can be included in an updated alignment study for the V3 catalogue, as seen in Fig. 10. 10 events have distance and origin time estimates from both the body phase and alignment approaches. Location uncertainties are not provided for aligned origins.

The envelopes shown in Fig. 10 are computed using instrument corrected waveforms in acceleration with a $30 \mathrm{~s}$ window length and an overlap of $50 \%$. The envelope amplitudes are normalized to be equal on the vertical component using the maxima per event, after masking-out 

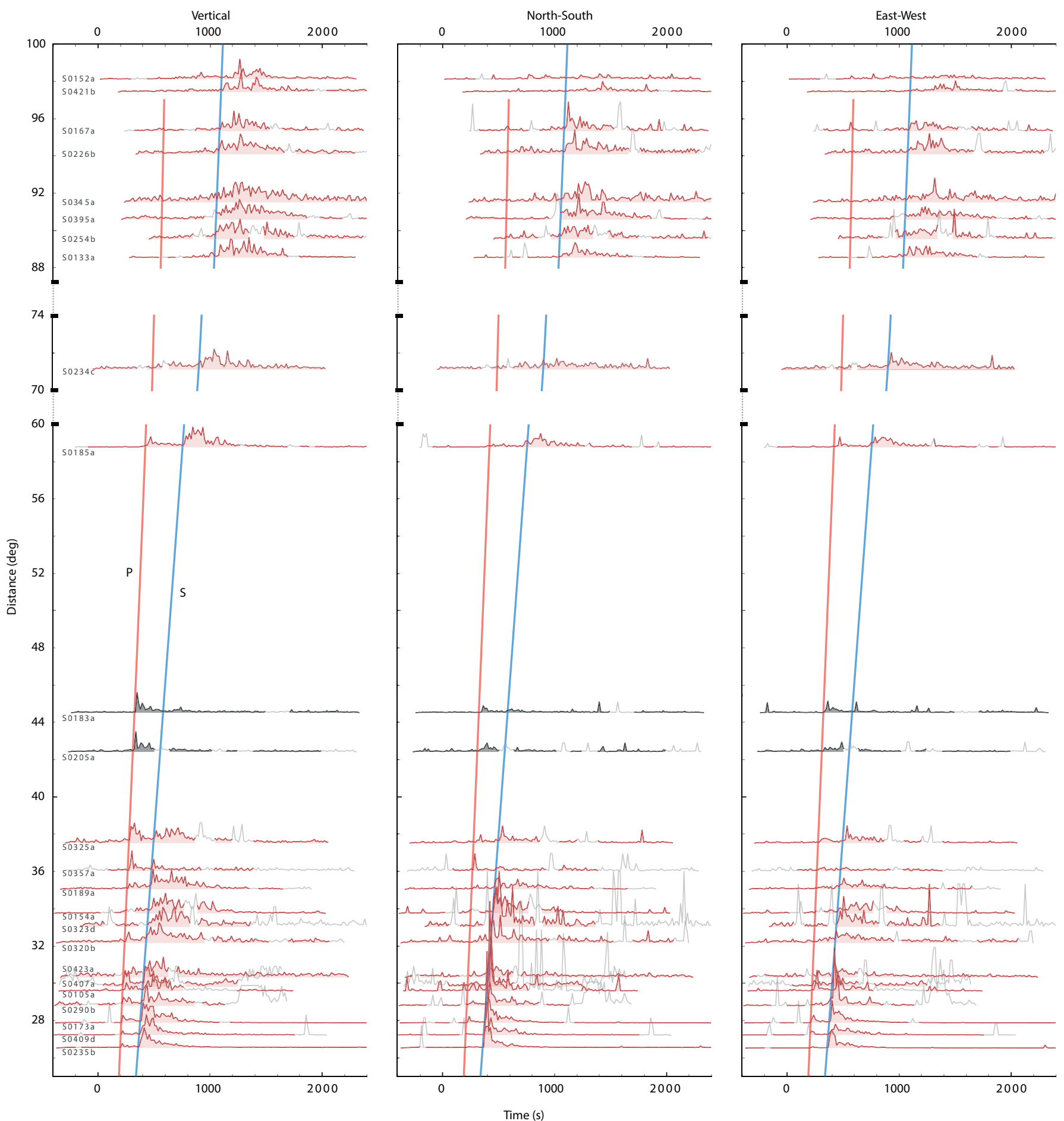

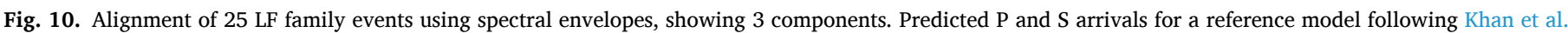

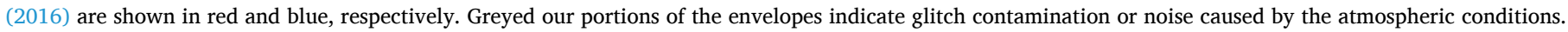

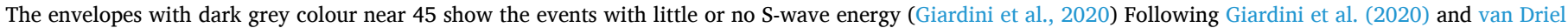

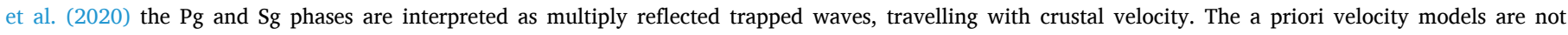

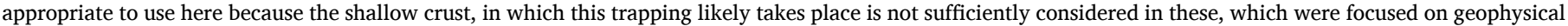

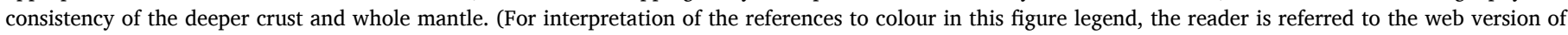
this article.)

the glitch-contaminated portions. Envelopes are bandpassed with individually assigned frequency limits that accentuate energy.

For the HF family of events, with identified Pg and Sg phases, and alternative approach is required. Sicne these event were not expected, there are no appropriate set of a priori models to use. For these events, an intermediate reference velocity has been adopted to provide a distance and origin time, using $v_{s}=2.3 \mathrm{~km} / \mathrm{s}$ and $v_{p}=1.73 v_{s}$. In this implementation, the phase pick uncertainty is not taken into account. Since the observed Sg-Pg time varies significantly, ranging from below $60 \mathrm{~s}$ to over $400 \mathrm{~s}$, distances estimated for the HF family range from 

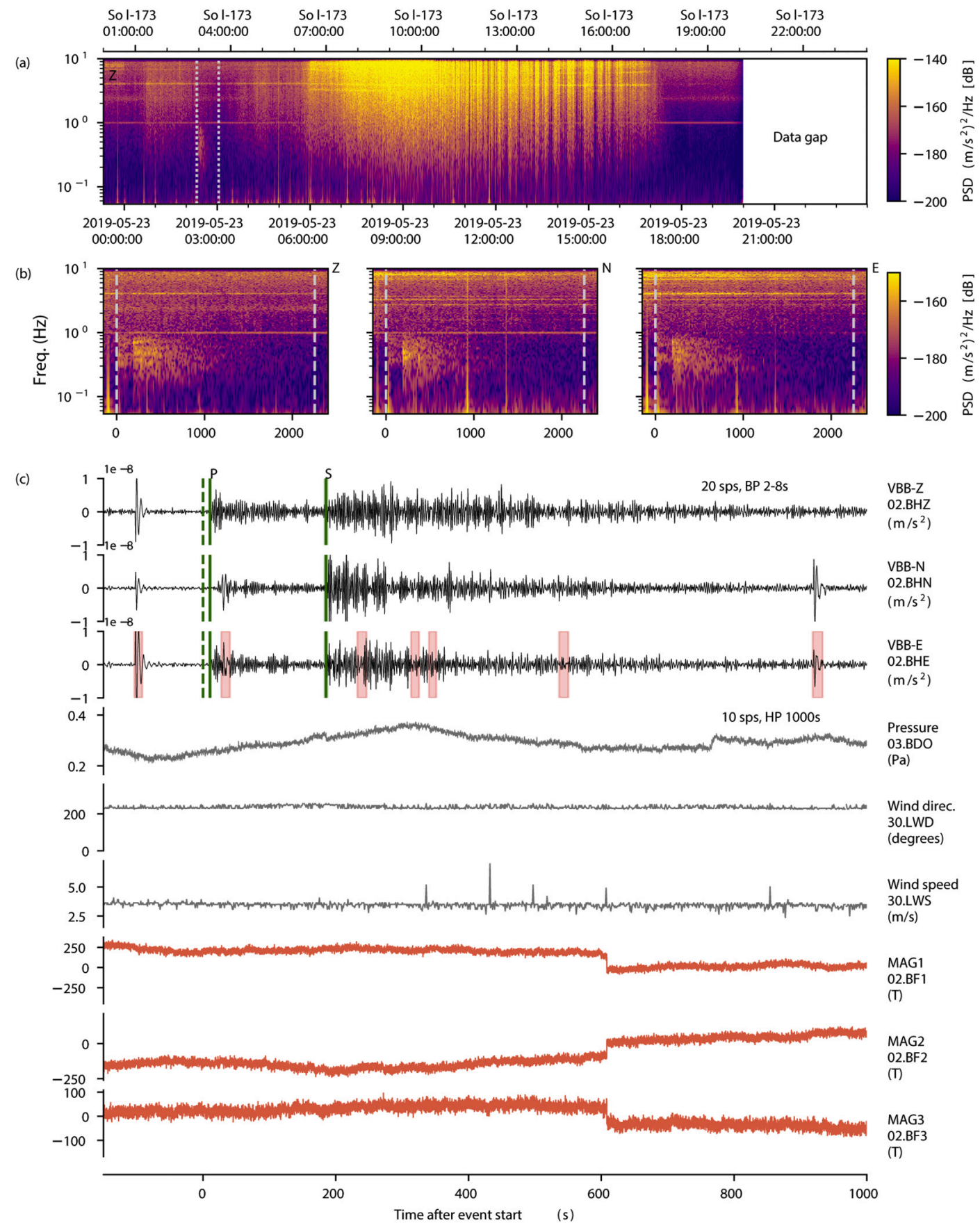

Fig. 11. Summary of seismic and non-seismic data for S0173a (LF QA). (a) provides the context of the event in the full Sol spectrogram on the VBB vertical (Z) component. (b) shows spectrograms for all 3 VBB components rotated into ZNE orientations, the event start and end time are indicted by the vertical dashed white lines in (a). (c) shows the timeseries from the VBB acceleration, pressure, wind speed, wind direction and magnetometer channels. The seismic and pressure timeseries are filtered as indicated to accentuate seismic and pressure signals. The vertical dotted lines in (b, white) and (c, green) indicate the event start and end times. Overlain on the seismic timeseries are the $\mathrm{P}$ and $\mathrm{S}$ phase picks in green and glitch windows in red; and on the magnetometer channels in grey are indications of any reported lander activity. During this event, there is no lander activity, there are multiple glitches, including one directly following the P-phase pick. The event occurs during a relatively quiet period in the morning, where winds are steady but light, and there is no transient pressure or magnetic signal. (For interpretation of the references to colour in this figure legend, the reader is referred to the web version of this article.)

under $5^{\circ}$ to over $40^{\circ}$. An uncertainty range of $\pm 75 \%$ is adopted for all these events, reflecting the large uncertainty in the reference crustal velocity.

A location can be estimated only for those events that include both distance and back azimuth. This is only possible for $3 \mathrm{LF}$ family events: S0173a, S0183a and S0235b. In our event catalogue, all events must have location coordinates assigned, so for the other events, including SF, the lander coordinates $(4.50 \mathrm{~N}, 135.62 \mathrm{E})$ are used as default.
With only direct first arriving $\mathrm{P} / \mathrm{Pg}$ and $\mathrm{S} / \mathrm{Sg}$ phases being identified, it is not possible to provide any information on depth. In fact depths are not populated for any event in the V3 catalogue.

On Sol 421, the VF S0421a has one of the largest Sg-Pg time differences in the catalogue, at almost $400 \mathrm{~s}$, and so is one of the most distant $\mathrm{HF}$ family events, estimated at $36.8^{\circ}$ from SEIS, and has an origin time almost 9 min before the Pg pick time. As S0421a only has $\mathrm{x} 1$, $\mathrm{x} 2$ and $\mathrm{x} 3$ phase picks, there is no body phase arrival distance, but this event is 


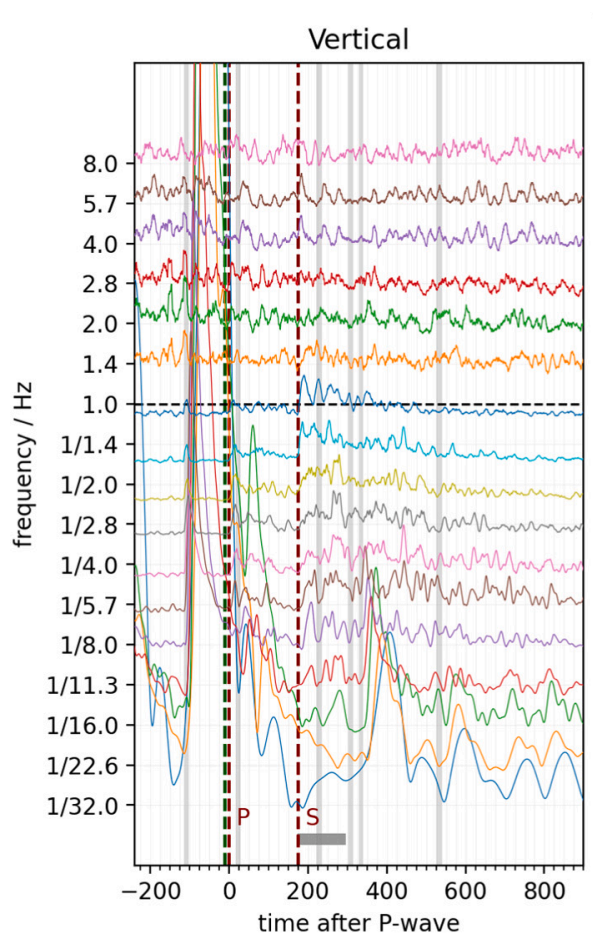

Event S0173a (0.031-8.000 Hz)

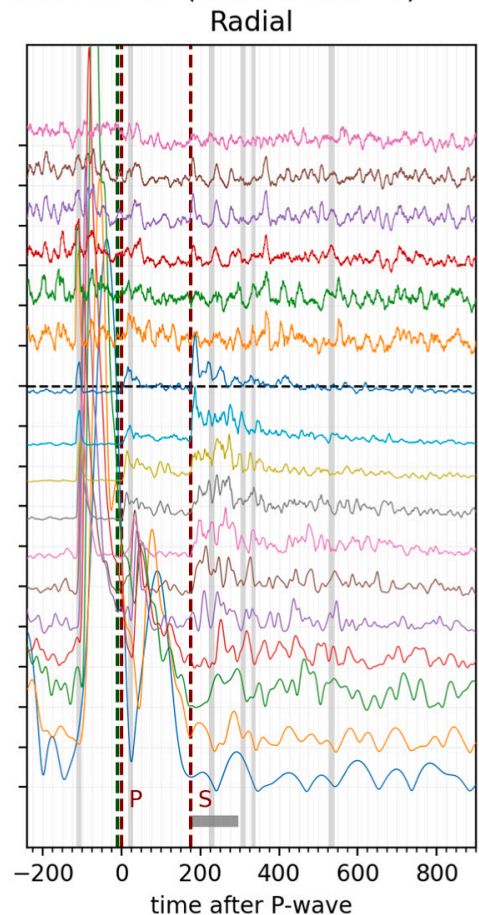

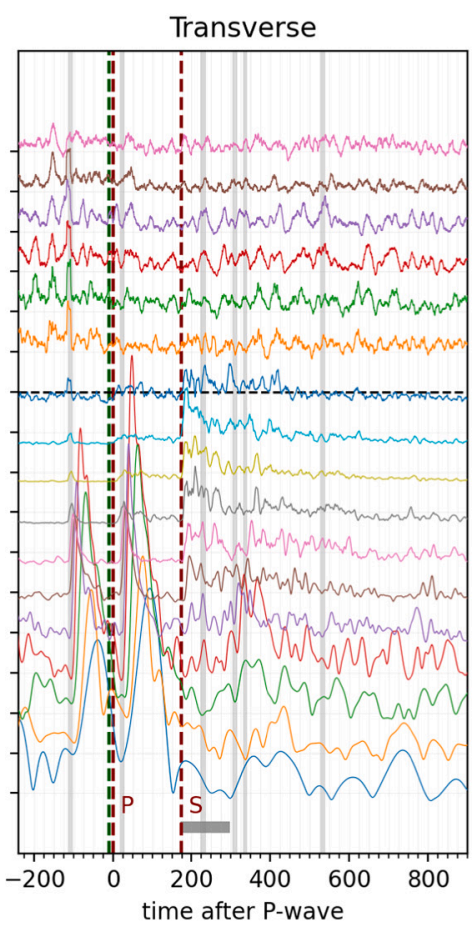

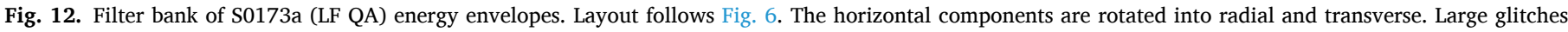

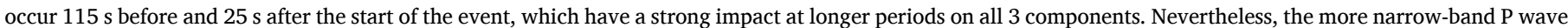
and in particular the broadband $S$ wave arrivals are visible.

assigned a distance via alignment (Fig. 10). S0421a is also one of the most distant LF family events, at $97^{\circ}$, with an origin time about $13 \mathrm{~min}$ before the start of the observed energy. None of the other Sol 421 events have distance estimates.

\subsubsection{Event classification}

At this stage, each event is saved to the MQS database and assigned an Event Type and Event Quality as described in Tables 1 and 2.

S0421a is a VF event as it has higher amplitude energy in the horizontal components at high frequencies, and with clear Pg and Sg phases, though without polarisation, it is Quality B (Fig. 6). S0421b is a LF event as there is no $2.4 \mathrm{~Hz}$ excitation, and is Quality $\mathrm{C}$ as the event is clearly observed, but clear phases cannot be identified (Fig. 7). S0421c and S0421d are weak events that faintly excite the $2.4 \mathrm{~Hz}$ resonance just at threshold level required to include in the catalogue. They do not have phase picks, and so are both $2.4 \mathrm{~Hz}$ Quality D events.

T0421a-d are 4 SF events with amplitudes that do not reach the required amplitude. They are all SF Quality D.

\subsubsection{Event magnitude}

Böse et al. (2018) derived a number of magnitude scales for marsquakes in advance of landing, and the Supplementary Material SI3 in Giardini et al. (2020) provides an update reflecting the actual marsquake energy content that we observe on Mars. Magnitudes are assigned to all events that have a distance estimation, $\Delta$ in ${ }^{\circ}$. Magnitude scales based on both $\mathrm{P}\left(m_{\mathrm{b}}^{\mathrm{Ma}}\right)$ and $\mathrm{S}\left(m_{\mathrm{bS}}^{\mathrm{Ma}}\right)$ body wave peak amplitudes are applied to LF family, and a pair of magnitudes based on the peak amplitude $\left(M_{2.4}^{\mathrm{Ma}, \mathrm{Hz}} \mathrm{Hz}\right)$ and spectral fit $\left(M_{2.4}^{\mathrm{Ma}} \mathrm{Hz}\right)$ of the $2.4 \mathrm{~Hz}$ resonance are used for the HF family. A magnitude scale $\left(M_{\mathrm{FB}}^{\mathrm{Ma}}\right)$ based on the longperiod plateau of the event displacement spectra, $A_{0}$, can be applied to all event types except $2.4 \mathrm{~Hz}$. In the V3 catalogue, these relationships have been re-calibrated to account for the near doubling of events, as described in Böse et al. (2020). The paper also includes magnitude uncertainties that take into account location uncertainty, as well as the uncertainty in estimating spectral fits - although these are not included in the V3 catalogue. Magnitude uncertainties range from 0.2 to 0.5 . Approximately 0.1 of this would be due to a distance uncertainty of $25 \%$

In V3, by convention the preferred magnitude is $M_{\mathrm{FB}}^{\mathrm{Ma}}$ when available, and for $2.4 \mathrm{~Hz}$ events $M_{2.4 \mathrm{~Hz}}^{\mathrm{Ma} \text { spec }}$ is preferred. The formulae used for these magnitudes in V3 are:

$M_{\mathrm{FB}}^{\mathrm{Ma}}=\frac{2}{3} \log _{10}\left(M_{0}\right)-9.1$

where $\log _{10}\left(M_{0}\right)=\log _{10}\left(A_{0}\right)+0.9 \log _{10}(\Delta)+21.475$ for the HF family and $\log _{10}\left(M_{0}\right)=\log _{10}\left(A_{0}\right)+1.1 \log _{10}(\Delta)+21.475$ for the LF family.

$M_{2.4 \mathrm{~Hz}}^{\mathrm{Ma}, \mathrm{spec}}=0.5120 \log _{10}\left(A_{2.4 \mathrm{~Hz}}^{\mathrm{spec}}\right)+0.6 \log _{10}(\Delta)+6.3648$

$A_{0}$ (for $M_{\mathrm{FB}}^{\mathrm{Ma}}$ ) is computed by fitting the slope of the displacement power spectrum between 0.1 and $1 \mathrm{~Hz}$ where it is at least $3 \mathrm{~dB}$ above the noise power spectrum to a function $A(f)$ assuming an attenuated flat source spectrum.

$A(f)=A_{0} \exp -\pi t^{*} f$

$A_{2.4 \mathrm{~Hz}}^{\mathrm{spec}}$ (for $M_{2.4 \mathrm{~Hz}}^{\mathrm{Ma} \text { spec }}$ )is computed by fitting the amplitude of the 2.4 $\mathrm{Hz}$ excitation between the event start and end.

The preferred magnitudes for all events are included in Supplementary Tables 1 and 2. Magnitudes of the LF family range from $M_{\mathrm{FB}}^{\mathrm{Ma}} 2.6$ - 3.7, and for the HF family from $M_{\mathrm{FB}}^{\mathrm{Ma}} 1.5-2.6$.

VF QB S0421a has magnitudes $M_{\mathrm{FB}}^{\mathrm{Ma}}=2.2$ and $M_{2.4 \mathrm{~Hz}}^{\mathrm{Ma}}$, spec $=2.1$. LF QC S0421b has $M_{\mathrm{FB}}^{\mathrm{Ma}}=3.2, m_{\mathrm{b}}^{\mathrm{Ma}}=3.2$ and $m_{\mathrm{bS}}^{\mathrm{Ma}}=3.1$.

For the other magnitudes, the MQS operator directly selects the amplitudes that are used. This is done by selecting peak VBB displacement amplitudes in sections of the event that are glitch-free and match:

$A_{2.4 \mathrm{~Hz}}^{\text {iick }}$ (for $M_{2.4 \mathrm{~Hz}}^{\mathrm{Ma} \text { pick }}$ ): vertical channel with 6 pole $2.2-2.8 \mathrm{~Hz}$ Butterworth filter.

$A_{\mathrm{P}}$ (for $m_{\mathrm{b}}^{\mathrm{Ma}}$ ): vertical channel within the $\mathrm{P}$ wave train, if visible, with 6 pole $2-6 \mathrm{~s}$ Butterworth filter.

$A_{\mathrm{S}}$ (for $m_{\mathrm{bS}}^{\mathrm{Ma}}$ ): the largest amplitude on either of the horizontal 

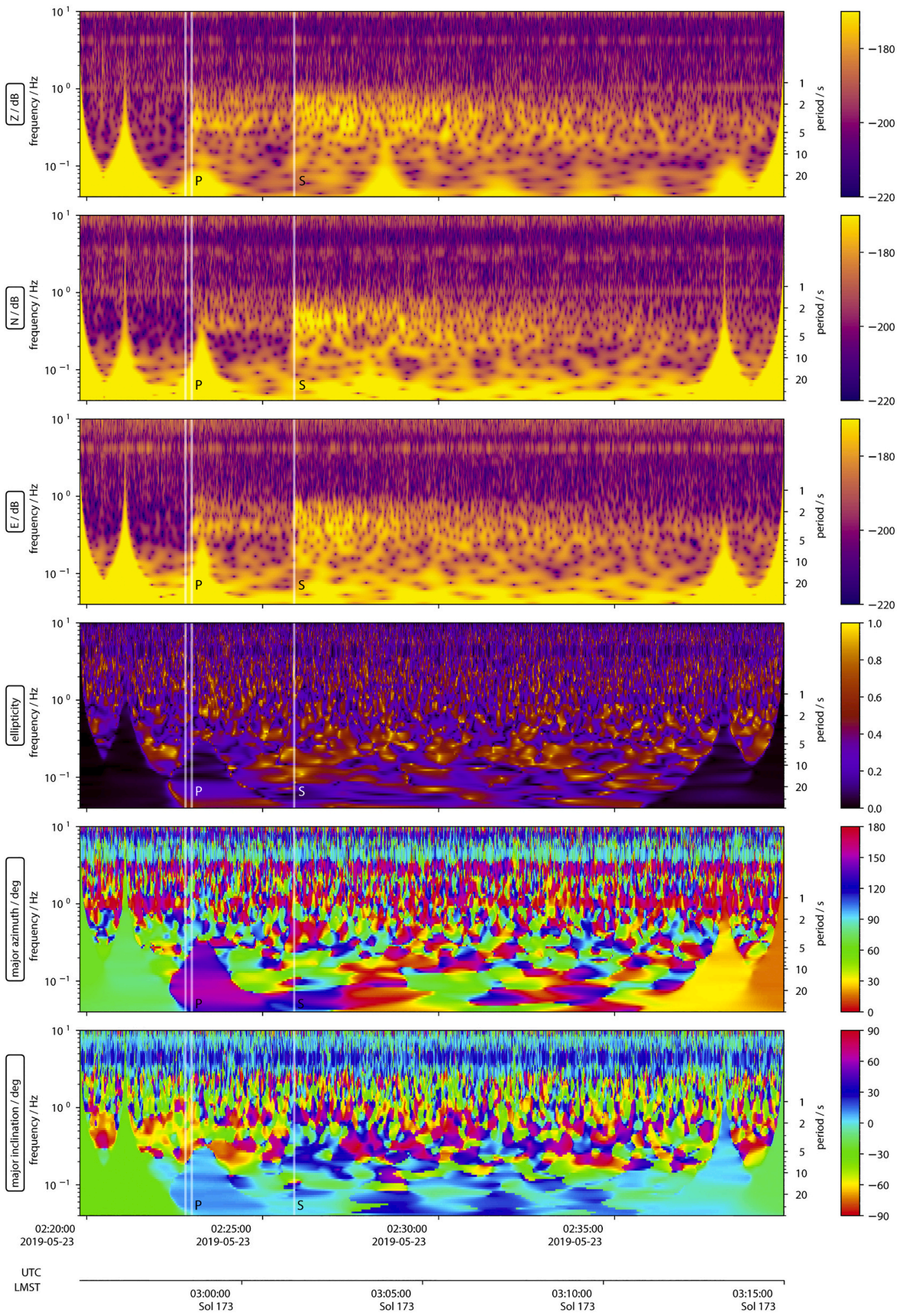

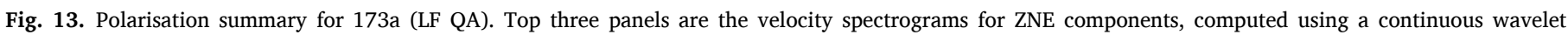

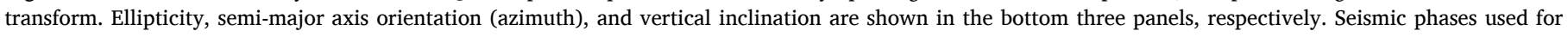
determining the event distance are labelled. The units displayed in the colour bar are indicated on the boxed text on left.

channels within the $S$ wave train, if visible, with 6 pole $2-6$ s Butterworth filter.

Böse et al. (2020) includes all magnitudes, their associated amplitudes, as well as $A_{0}$ and $t^{*}$ computed for each event.

\section{Characteristics of Marsquakes}

In this section, individual events from each event type are described. The most significant and best recorded events are presented in detail. We describe our observations including identified seismic phases, event 

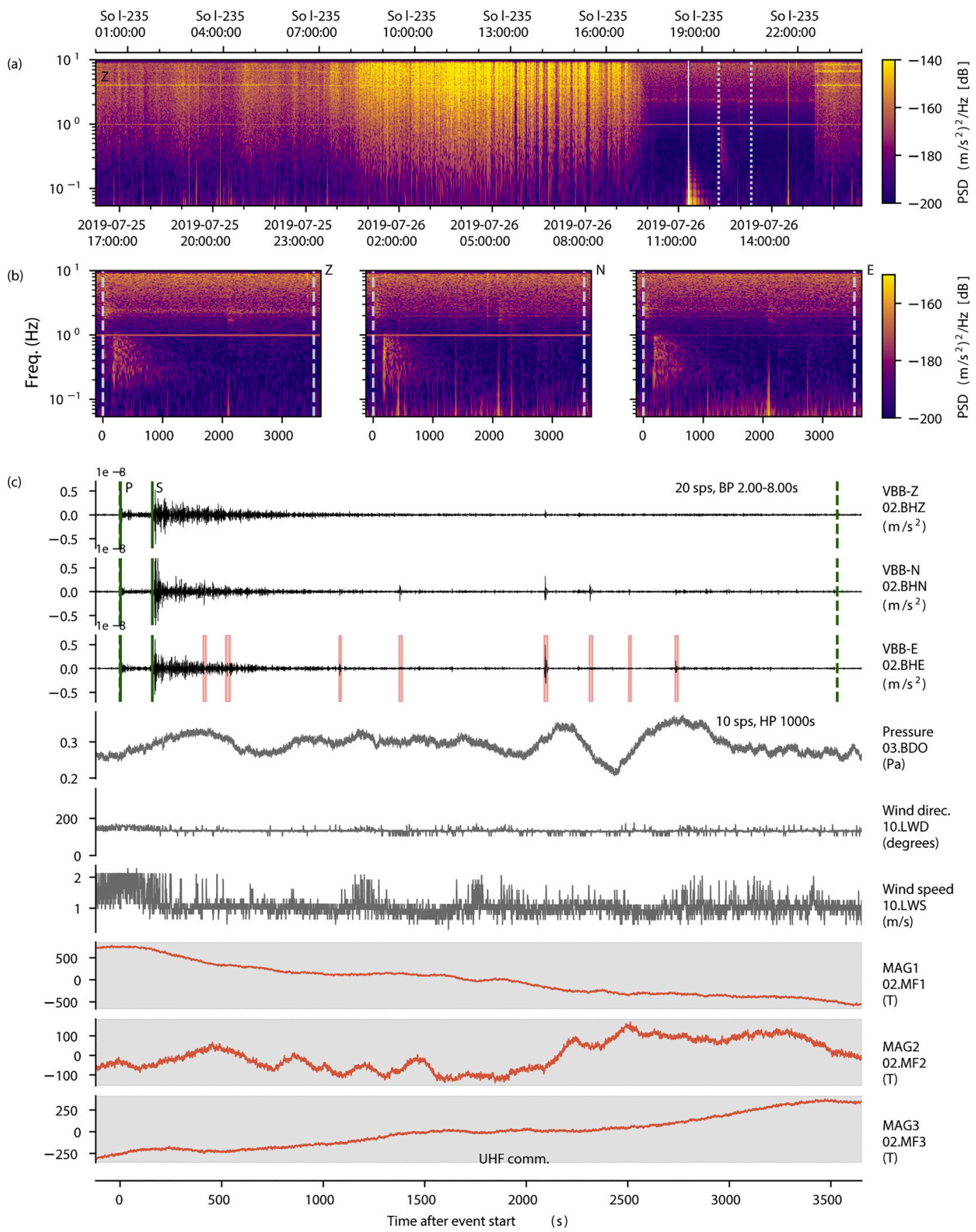

Fig. 14. Summary image for S0235b (BB QA). Layout follows Fig. 11. A small event we interpret as an aftershock, S0235c, occurs at 12:53UTC, 2100 s after the start time. The event is not contaminated by glitches except in the S-coda and during the middle of S0235c, and there are no pressure or magnetic perturbations. The event occurs during lander UHF communication. Wind speed is below the resolution of the wind sensor. The small gap and long period noise signal $1 \mathrm{~h} \mathrm{before} \mathrm{the} \mathrm{event}$ seen in (a) is a re-centering of a VBB component.

characterisation when possible, and artifacts on the waveforms that may arise from environmental or instrumental factors. Other events with notable features are described briefly. Note for all events, all distances, back azimuths, magnitudes, SNRs and phases, with relevant uncertainties, are documented in Supplementary Tables 1 and 2.

Note S0421 a HF QB and S0421b LF QC have been presented in detail the preceding section.

\subsection{LF family}

The 2 largest events are presented in detail. Key features of other notable events are then highlighted.

\subsubsection{S0173a - LF quality $A$}

The event on Sol 173, S0173a (origin time 2019-05-23 02:19:33 UTC, 02:55:17 LMST), was a milestone for InSight. This high amplitude event has clear and horizontally polarised phase arrivals, and it was the first event ever to be located on Mars. To date, it remains the second highest amplitude LF family event recorded. The S0173a seismogram includes strong energy in all three components at periods from 1 to $10 \mathrm{~s}$. Spectrograms and timeseries for the seismic data, and corresponding timeseries from associated sensors are shown in Fig. 11. The filterbank 


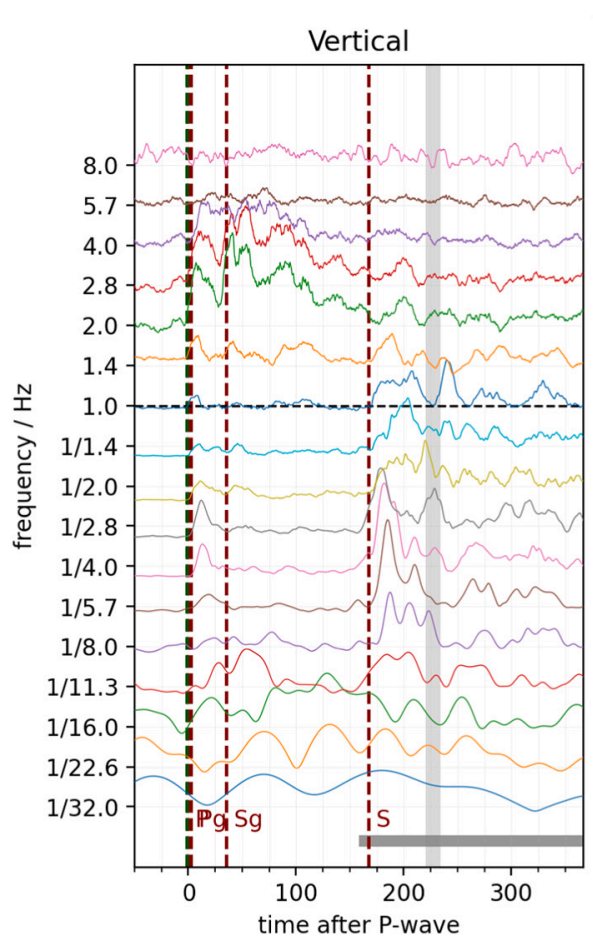

Event S0235b (0.031-8.000 Hz)

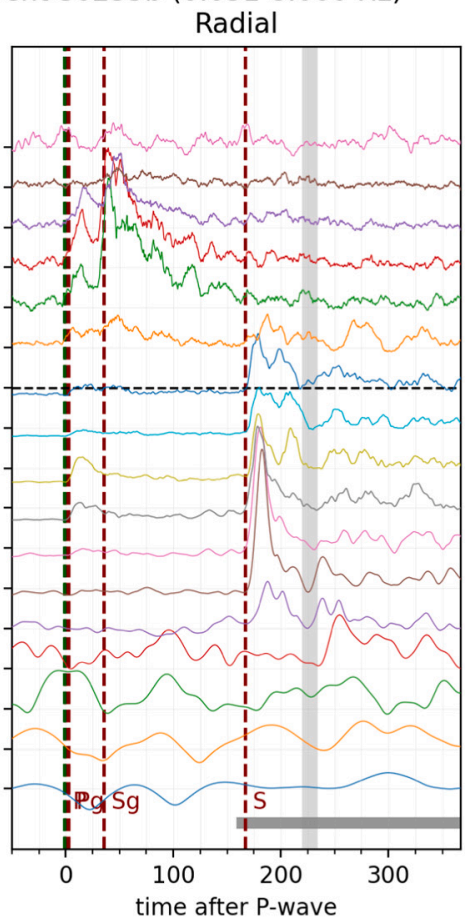

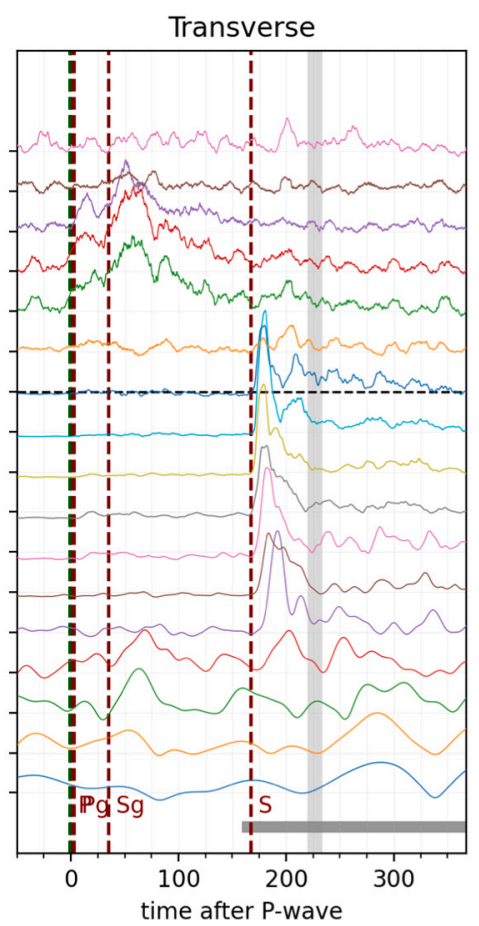

Fig. 15. Filter bank of S0235b (BB QA) energy envelopes. Layout follows Fig. 6. The horizontal components are rotated into radial and transverse. The P and Pg phases are basically overlapping. The Sg phase, picked on the $2.4 \mathrm{~Hz}$ energy, occurs significantly before the broadband $\mathrm{S}$ phase. In the time window shown that focuses on the observed phases, there are no significant glitches.

for the event is in Fig. 12. Two impulsive phase arrivals are clearly identifiable both in time and spectral domains (Fig. 11), that we identify as P- and S-phases, due to their polarisation in the horizontal plane (Fig. 8). Phase pick uncertainties are \pm 1 and $\pm 2 s$ respectively, and the $P$ wave has an upward first motion. The event duration is approximately $25 \mathrm{~min}$. The $\mathrm{P}$ arrival is smaller in amplitude and more narrow band than the $\mathrm{S}$ arrival.

Using the phase picks shown in Fig. 11, the computed distance for S0173a is $29.0^{\circ}$ (with uncertainty $-1.6^{\circ},+1.8^{\circ}$ ). The P-wave train is contaminated with a glitch approximately $25 \mathrm{~s}$ after the initial P-wave arrival. Recent work shows this and some other glitches can be removed efficiently (Scholz et al., 2020). The back-azimuth estimation (Figs. 8 and 13) using the P-wave energy before the glitch indicates a location towards East at $\sim 91^{\circ}$ (with uncertainty $-11^{\circ},+12^{\circ}$ ). Polarisation is no longer evident on the $\mathrm{P}$ wave following the glitch. The final location of this Quality A event points to Cerberus Fossae. The aligned distance is $27.9^{\circ}$. In the LF alignment, this event is the 3rd closest to the lander (Fig. 10). The event magnitude is estimated to be $M_{\mathrm{FB}}^{\mathrm{Ma}} 3.6$. The broadband peak signal amplitude is on the S-arrival on the transverse component at about $8 \mathrm{~nm} / \mathrm{s}$.

The event occurred around 3 am LMST, typically a part of day devoid of turbulence but when moderate, steady winds could be common. However, the conditions for S0173a are fortunately quiet, comparable to evening conditions at Mars. Both the wind speed of $\sim 3.4 \mathrm{~m} / \mathrm{s}$ and wind direction are very stable during the event. The pressure data exhibits only long period fluctuations normal at this time of Sol. These observations indicate that there is negligible contamination from atmospheric conditions. Furthermore, there are no lander related activities or anomalies on the magnetic channels around the event that could have caused artifacts on the seismic waveforms. SNR values for the event are $S N R_{S} 91.3 S N R_{W} 81.4$ and $S N R_{P} 54.5$.

Fig. 13 demonstrates the lack of general polarisation in both the noise and event signal. The steady wind excites the $4 \mathrm{~Hz}$ mode, which is strongest on the East and Vertical components. There is no strong evidence of elliptical signals in the noise or seismic signal. The short duration horizontally polarised signals following the $\mathrm{P}$ and $\mathrm{S}$ phase arrivals do not show up in this view.

\subsection{2. $S 0235 b-B B$ quality $A$}

The S0235b (origin time 2019-07-26 12:16:03 UTC, 19:30 LMST) broadband event has the largest LF amplitudes in the catalogue, the Swave measuring about $13 \mathrm{~nm} / \mathrm{s}$ on the broadband transverse component. Polarised P- and S-waves are clearly identified; hence, the event is locatable and is classified as Quality A. S0235b is unique in the MQS catalogue as another broadband event is visible in its coda, about 35 mins after the main event starts. This event is catalogued as S0235c and has a similar profile to the main energy package, and may be interpreted as an aftershock. The main event duration is approximately $1 \mathrm{~h}$.

Unlike S0173a, this event occurs during the quietest period of the Sol, at 19:30LMST (Fig. 14). The waveforms, especially around the seismic phase arrivals, are not contaminated with artifacts such as glitches. The pressure, wind direction and wind speed data show very stable atmospheric conditions throughout. Lander activity during the event is an UHF (Ultra high frequency) communication with the orbiters, a regularly occurring planned activity for data transmission and has no apparent effect on the waveforms.

Fig. 15 shows this event has strong excitation out to $8 \mathrm{~s}$ and up to 4 $\mathrm{Hz}$. The initial energy arrival has strong amplitudes on the vertical at long periods and at $2.4 \mathrm{~Hz}$ on all 3 components. The P pick, with first motion down, and uncertainty of $\pm 1 s$ precedes the Pg pick by $3 \mathrm{~s}( \pm 2 s)$. The Sg picks $( \pm 5 s)$ occurs about $33 \mathrm{~s}$ later. An extremely large broadband $\mathrm{S}$ occurs much later, $107 \mathrm{~s}$ after the $\mathrm{P}$, with peak amplitude on the radial component. It is rare that the $2.4 \mathrm{~Hz}$ part of a $\mathrm{BB}$ event displays such a widely different $\mathrm{Sg}-\mathrm{Pg}$ time to the $\mathrm{S}-\mathrm{P}$ time. This event has much faster decaying coda than S0173a, and indeed the majority of other LF family events (Fig. 10). SNR values for the event are $S N R_{S} 288.9$ and $S N R_{P} 112.5$. $S N R_{W}$ is not available due to gaps in the wind data.

Using the body-wave picks, the distance of this event is computed as $27.7^{\circ}\left(-1.5^{\circ},+1.8^{\circ}\right)$ with a back-azimuth of $74^{\circ}\left(-8^{\circ},+14^{\circ}\right)$ (Fig. 16). Similar to S0173a, this location also points to the source being near 

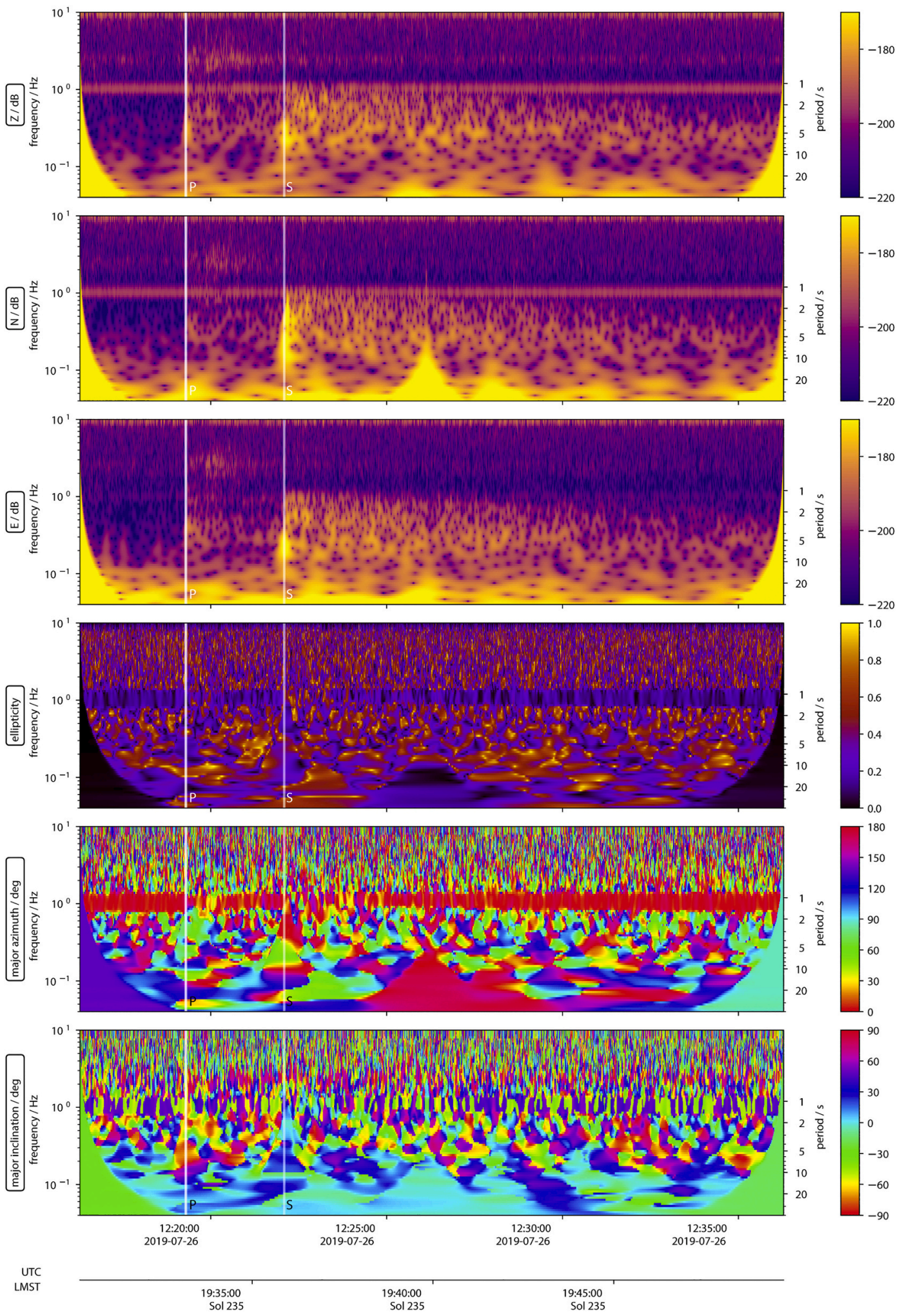

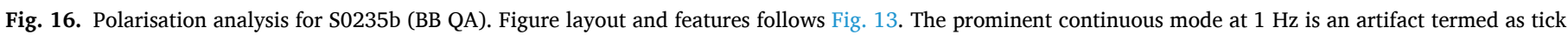

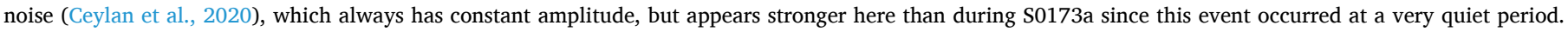

Cerberus Fossae. The aligned distance is $26.5^{\circ}$ - the event closest to the lander of all the aligned LF family. The event magnitude is estimated to be $M_{\mathrm{FB}}^{\mathrm{Ma}} 3.5$.

In comparison to S0235b, the aftershock S0235c has a distinctly larger ratio of $2.4 \mathrm{~Hz}$ to low frequency energy. This second event also has identifiable $\mathrm{P}$ and Pg energy (both \pm 20 ) arriving at similar times, although the arrival time of these phases is compromised by a donk that precedes a glitch. No Sg phase is identified, although there is a strong amplitude $S$ phase $( \pm 10 s)$. The $S-P$ time provides a very similar distance to $S 0235 \mathrm{~b}$, at $27.7^{\circ}\left(-3.3^{\circ},+3.8^{\circ}\right)$. The event magnitude is $M_{\mathrm{FB}}^{\mathrm{Ma}} 2.6$, and the $S N R$ values are $S N R_{S} 2.2, S N R_{W} 1.3$ and $S N R_{P} 1.0$ - the event is difficult to identify within the background noise and mainshock coda. 


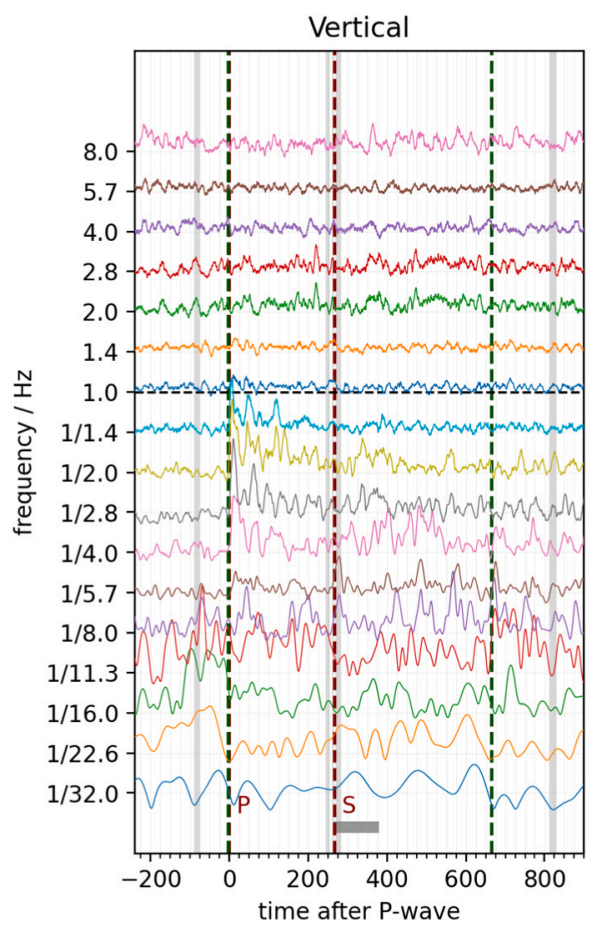

Event S0183a $(0.031-8.000 \mathrm{~Hz})$

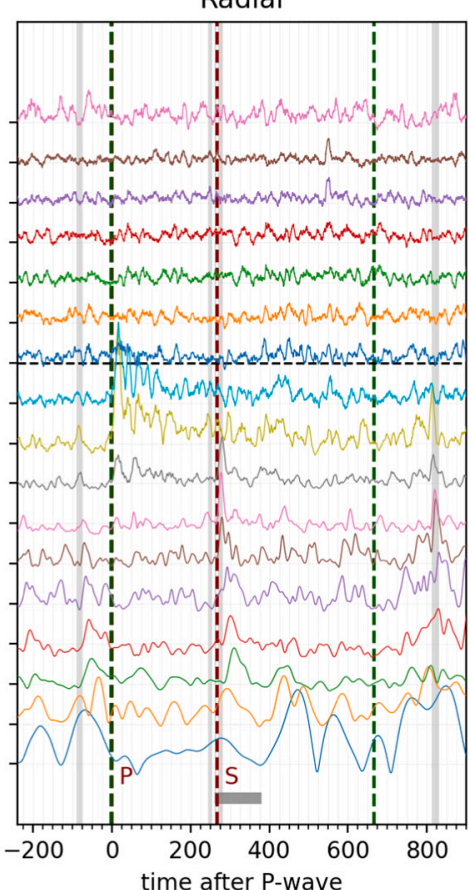

Transverse

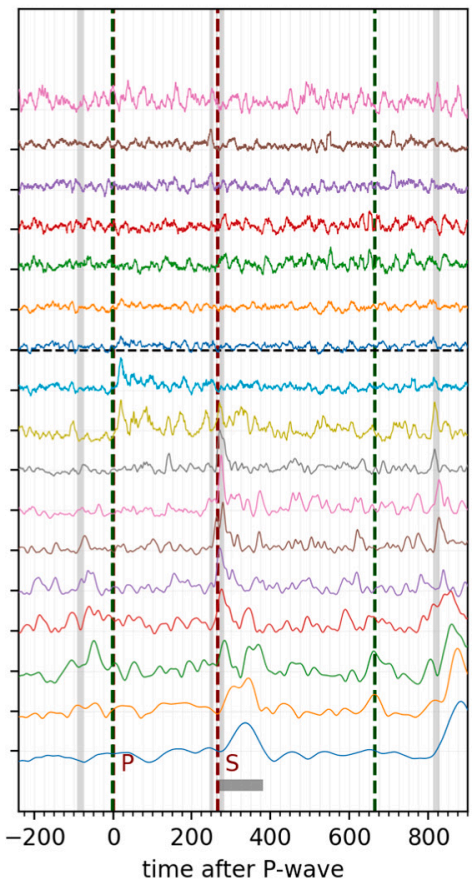

Fig. 17. Filter bank of S0183a (LF QB) energy envelopes. Layout follows Fig. 6.

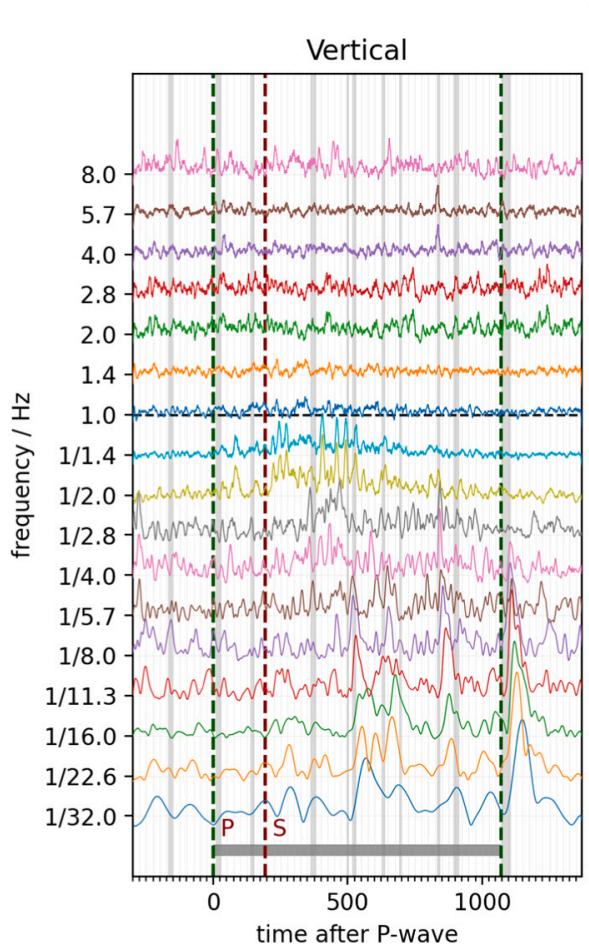

Event S0189a (0.031-8.000 Hz)

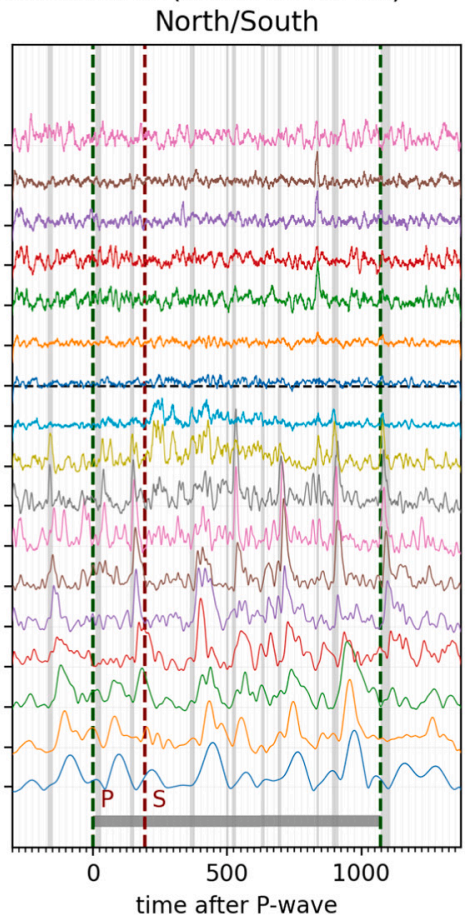

East/West

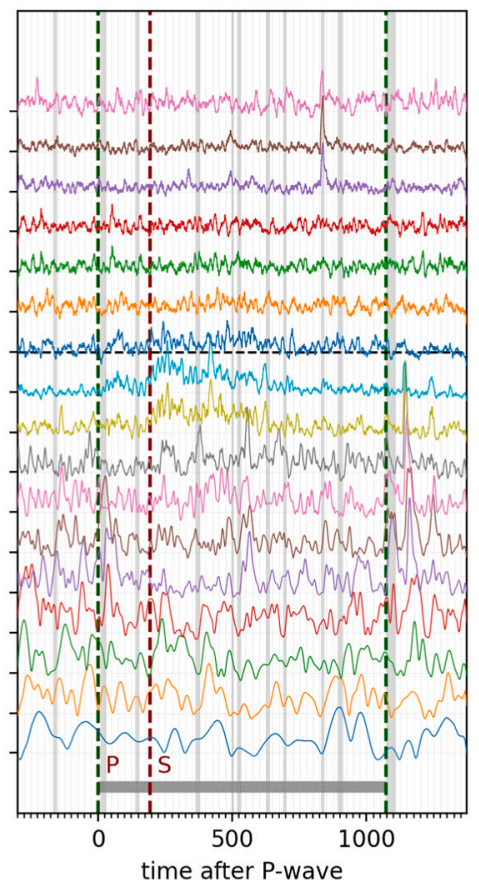

Fig. 18. Filter bank of S0189a (LF QB) energy envelopes. Layout follows Fig. 6.

\subsubsection{S0183a - LF quality $B$}

S0183a (origin time 2019-06-03 02:22:25 UTC, 19:54 LMST) has a strong P-wave with polarised energy that provides a back-azimuth value of $73^{\circ}\left(-11^{\circ},+10^{\circ}\right)$ (Fig. 8). Across the duration of the event, the vertical component is relatively clean with energy visible between $\sim 1.5-8$ s. Unlike the quality A events described earlier, the S-wave energy for this event is weak. This event does not have an obvious S-wave arrival with typical coda, and the horizontal components are contaminated by energy from glitches, so picking the S-phase arrival is rather ambiguous (Fig. 17). Using the identified $P$ wave $( \pm 1 \mathrm{~s})$ and $S$ wave $( \pm 60 \mathrm{~s})$ picks, the distance for this event is computed as $46.2^{\circ}\left(-18.0^{\circ},+18.1^{\circ}\right)$. A time-window of multiple potential glitches masks what might be an Swave $252 \mathrm{~s}$ after the P-wave. Therefore, Giardini et al. (2020) interprets this signal as an indication of partial S-wave shadow zone between the 


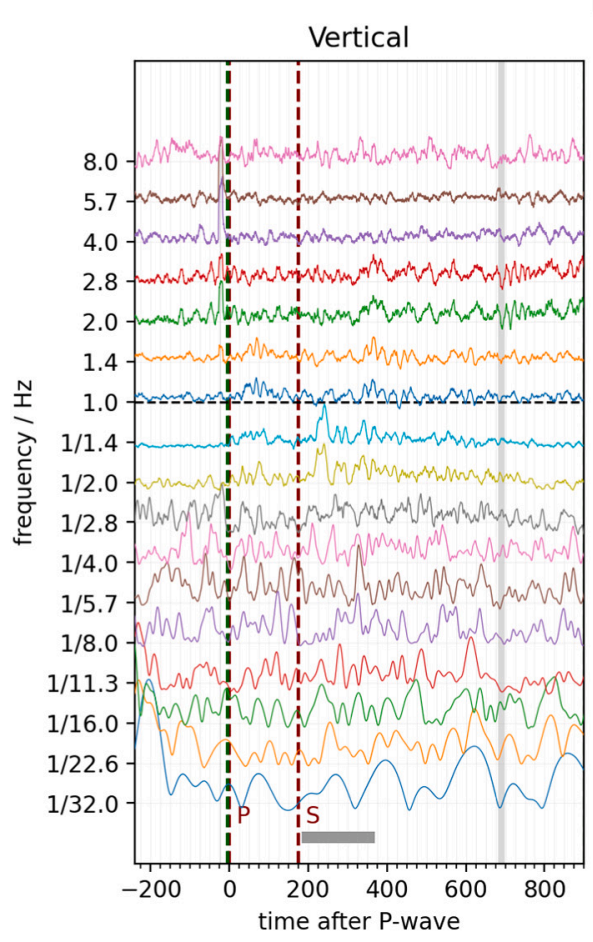

Event S0290b (0.031-8.000 Hz)

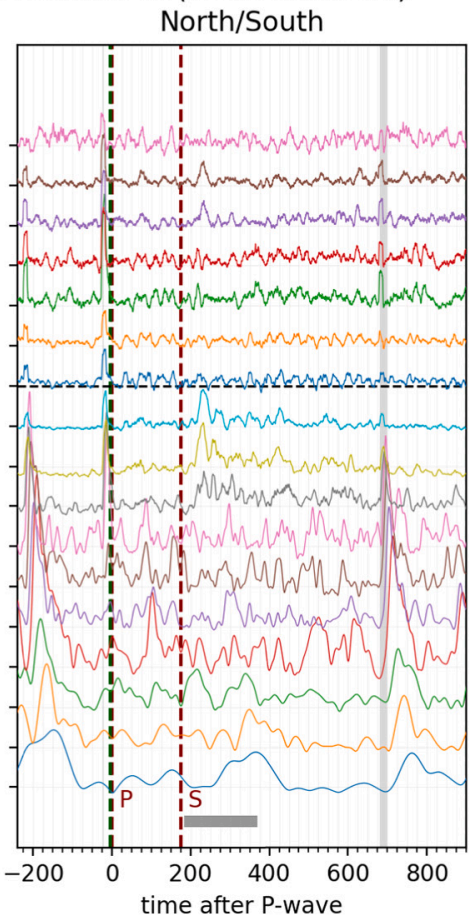

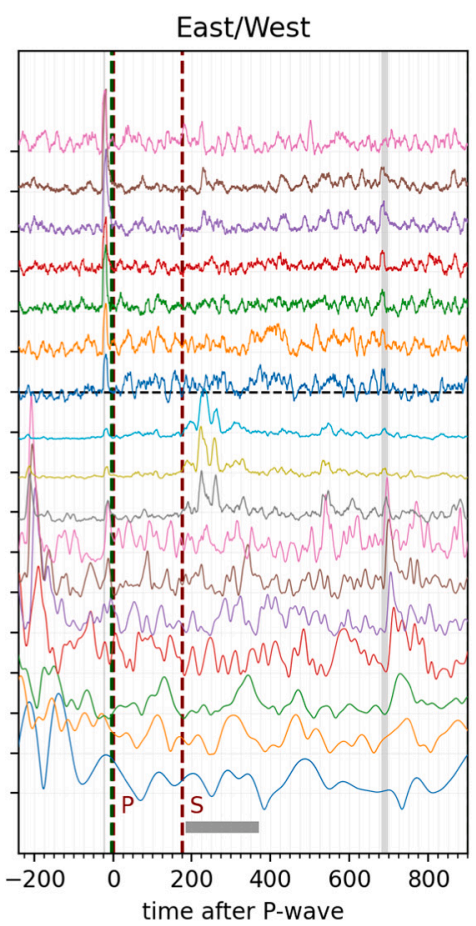

Fig. 19. Filter bank of S0290b (LF QC) energy envelopes. Layout follows Fig. 6 .

distances of $\sim 35-55^{\circ}$. A potential alternative S-wave pick - restricted to much lower frequencies is visible after $420 \mathrm{~s}$, below $4 \mathrm{~s}$ period. If this pick was identified as $\mathrm{S}$, the event would move to an epicentral distance of $\sim 60^{\circ}$,however no other event shows such a low-frequency S-wave.

\subsubsection{S0189a - LF quality $B$}

S0189a (origin time 2019-06-09 05:36:11 UTC, 19:11 LMST) is rather narrow band event with energy concentrated between $1-5 s$. This event occurred during the evening hours, with a duration of approximately $18 \mathrm{~min}$. The background noise during the event is very quiet, but the signal is challenging to interpret. The filter bank in Fig. 18 shows there are multiple glitches occurring throughout, predominately on the North component. One of these, at $800 \mathrm{~s}$, includes a donk as seen in the high frequency energy. Phase onsets are not impulsive and phase picks are made in the spectral domain, with uncertainty of $\pm 20 \mathrm{~s}$ for both P and S. SNR values are $S N R_{S} 3.9, S N R_{W} 2.8$ and $S N R_{P} 2.3$.

The distance of this event is computed as $32^{\circ}\left(-6.0^{\circ},+6.6^{\circ}\right)$, and the event magnitude is $M_{\mathrm{FB}}^{\mathrm{Ma}} 2.8$. S0189a has been one of the key events to understand the effects of environmental factors on the seismic recordings. Readers are advised to see Supplementary Information SI1, Giardini et al. (2020) for a comprehensive discussion. Martire et al. (2020) tested an acoustic origin for S0105a, S0133a, S0152a, S0185a, S0189a, S0234c, S0234d and S0290b. They suggest that S0189a, as well as S0133a, are associated with a nocturnal waveguide infrasound source as they are relatively monochromatic and have energy ratios consistent with such a source model. An acoustic origin is also proposed as a contributing source for the recorded background seismic noise in (Stutzmann et al., 2020). However, it is not difficult to sustain that these events have a similar source to other LF and BB family events - there is general similarity in the event alignment in Fig. 10.

\subsection{5. $S 0290 b-L F$ quality $B$}

S0290b (origin time 2019-09-21 03:15:42, 22:08 LMST), is remarkable for a unique, late arriving packet of energy during the S-wave coda (Fig. 19), arriving about $30 \mathrm{~s}$ after the $\mathrm{S}$ pick. This energy appears to be have a sustained polarisation for about 60 of seconds (Fig. 20). There is no indication that this motion is elliptical. The P-phase pick is preceded by a strong donk.

\subsection{6. $S 0105 a-L F$ quality $C$}

S0105a (origin time 2019-03-14 20:59:45, 18:02 LMST) was the first marsquake to be observed in the project, a full 35 Sols after the science quality data began to be collected. This is not the earliest event in the catalogue as, retrospectively, a few SF events have been found from even before WTS was placed above SEIS. The surprising delay in observing our first marsquake can now be understood in terms of noise - the small amplitude events were simply extremely unlikely to be detected until the background noise stabilised at low levels for significant periods of the Sol - see Fig. 3. This weak event takes place during very light evening winds, but is corrupted by a number of glitches that are strongest on the North component, including shortly after the P-wave arrival. P and S phases may be identified in the filterbank or spectrogram with uncertainty of $\pm 20 \mathrm{~s}$ (see Fig. 21). The $\mathrm{S}-\mathrm{P}$ distance is $31.2^{\circ}\left(-6.0^{\circ},+6.7^{\circ}\right)$, with an aligned distance of $29.6^{\circ}$. This event is described in detail in Daubar et al. (2020) as a candidate impact signal - the event occurred within a narrow time window during which repeat satellite images indicate the presence of a small $1.5 \mathrm{~m}$ wide impact crater within $40 \mathrm{~km}$ of SEIS. On review of observed signal, considering its similarity to other subsequently observed LF family events and the lack of seismic energy in the $1-3 \mathrm{~Hz}$ bandwidth, the paper concludes that this signal is unlikely to be a close-by impact.

\subsubsection{S0154a-BB quality $C$}

S0154a occurred at 2019-05-04 07:01 UTC (19:41 LMST), and has an aligned distance of $33.7^{\circ}$ and magnitude $M_{\mathrm{FB}}^{\mathrm{Ma}} 2.9$. This event uniquely excites energy at $1.2 \mathrm{~Hz}$ that is visible approximately $8 \mathrm{~min}$ after the first observed arrival. As seen in Fig. 22, the phase is labelled $x 3$. Such a narrow-banded excitation at this frequency has not been observed during any other event and is not yet understood. 

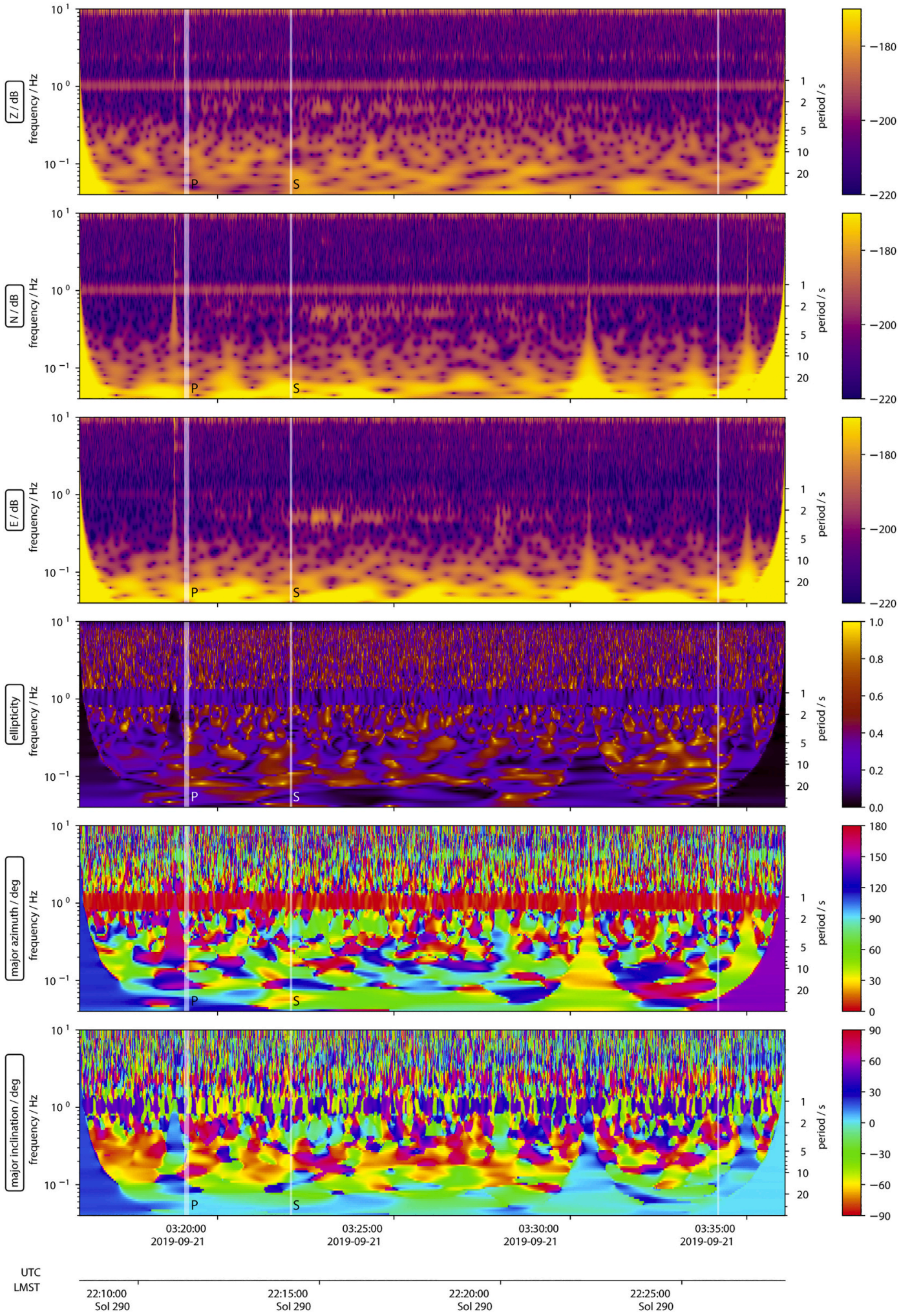

Fig. 20. Polarisation analysis for S0290b event. Figure layout and features follows Figs. 13 and 16.

\subsection{HF family}

We focus on two high amplitude HF family events here to outline the general characteristics.

\subsubsection{So128a - VF quality $B$}

S0128a occurred at 2019-04-07 09:31:41 UTC (15:28 LMST). This event was the first event in the HF family to be observed, and among the earliest marsquakes to be identified. Curiously, it still remains the largest HF family event yet recognised in terms of signal amplitude (Fig. 3), reaching a broadband amplitude of $38 \mathrm{~nm} / \mathrm{s}$ during the $\mathrm{Sg}$ coda on the East component. Like all HF and VF events, it can be observed on both SP and VBB sensors. It has a strong $2.4 \mathrm{~Hz}$ excitation and energy appears to exceed $10 \mathrm{~Hz}$. However, due to the spacecraft configuration 


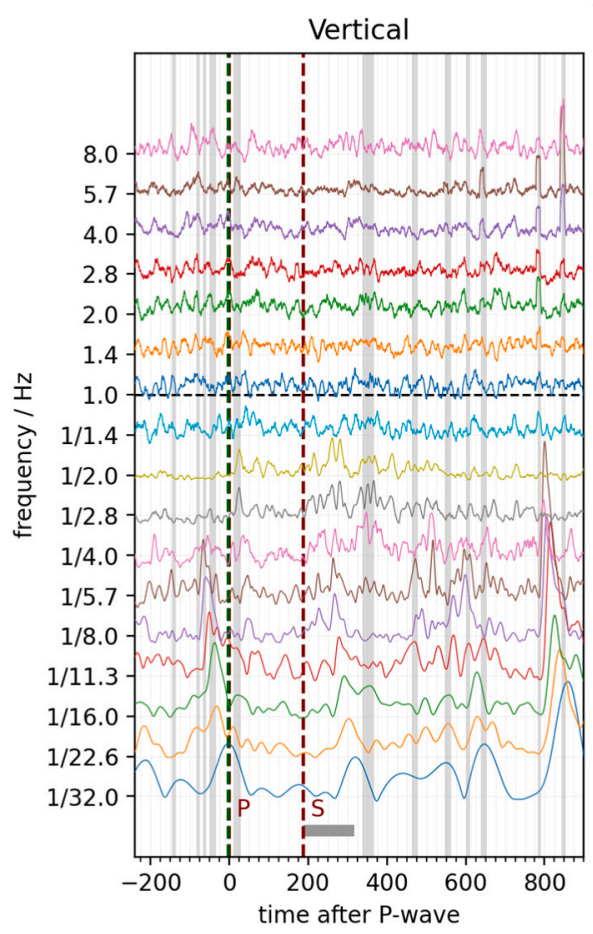

Event S0105a $(0.031-8.000 \mathrm{~Hz})$

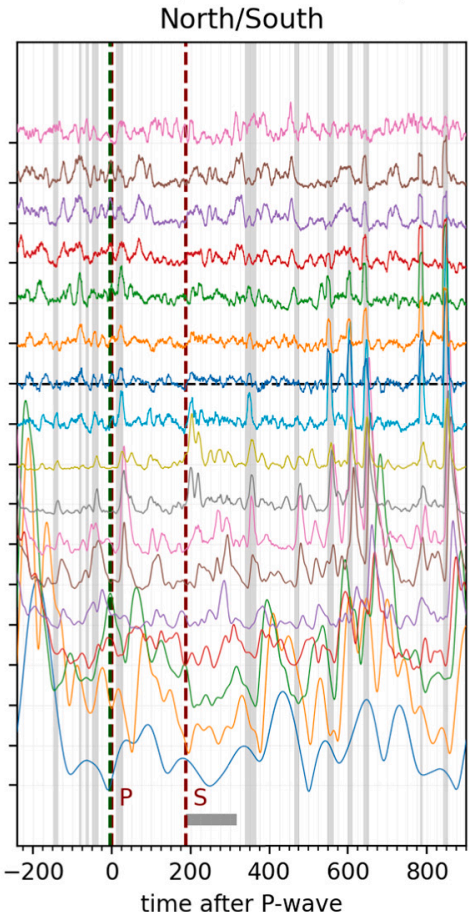

East/West

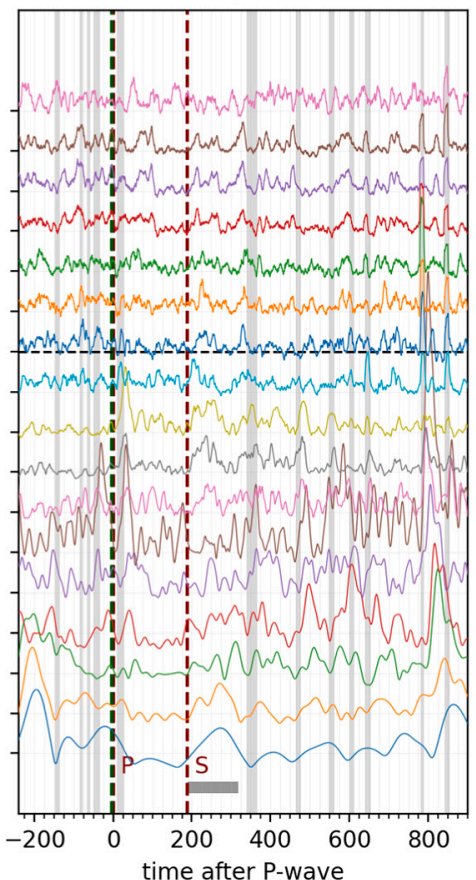

Fig. 21. Filter bank of S0105a (LF QC) energy envelopes. Layout follows Fig. 6.

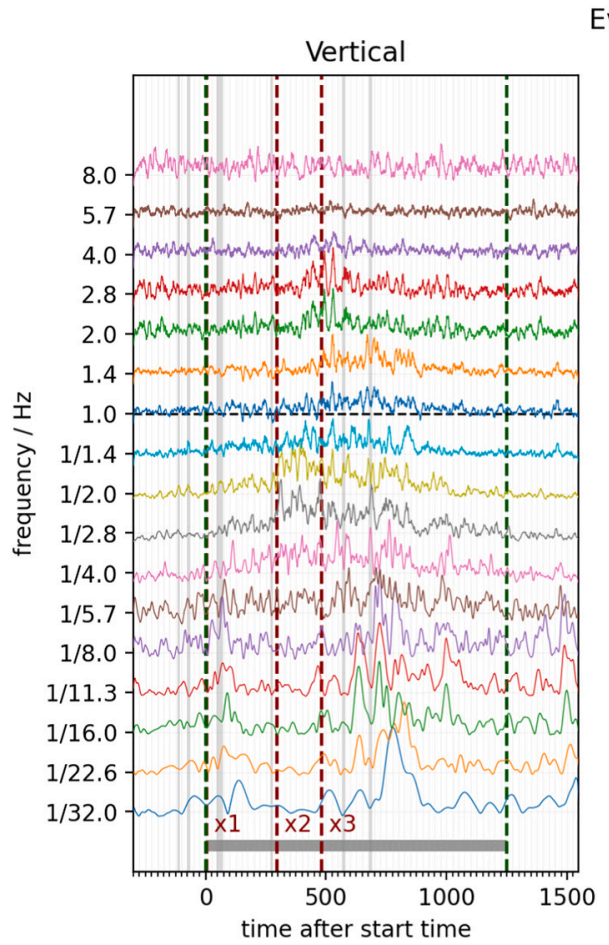

Event S0154a $(0.031-8.000 \mathrm{~Hz})$

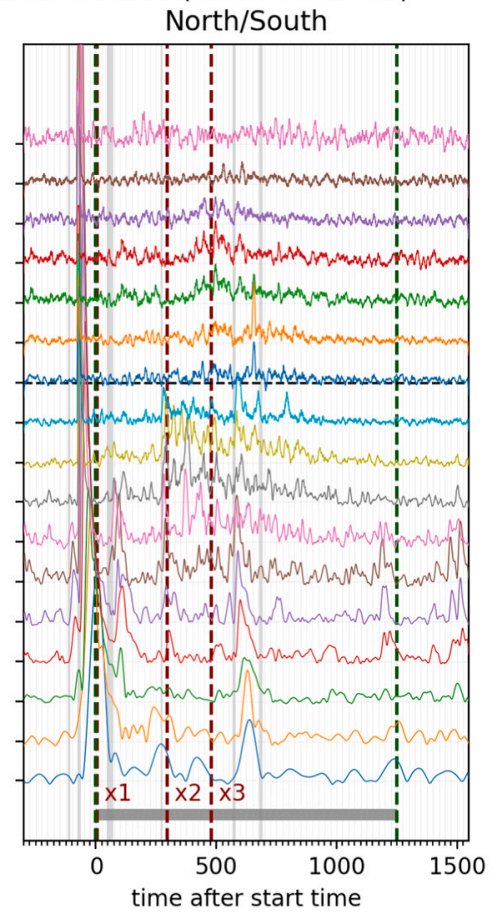

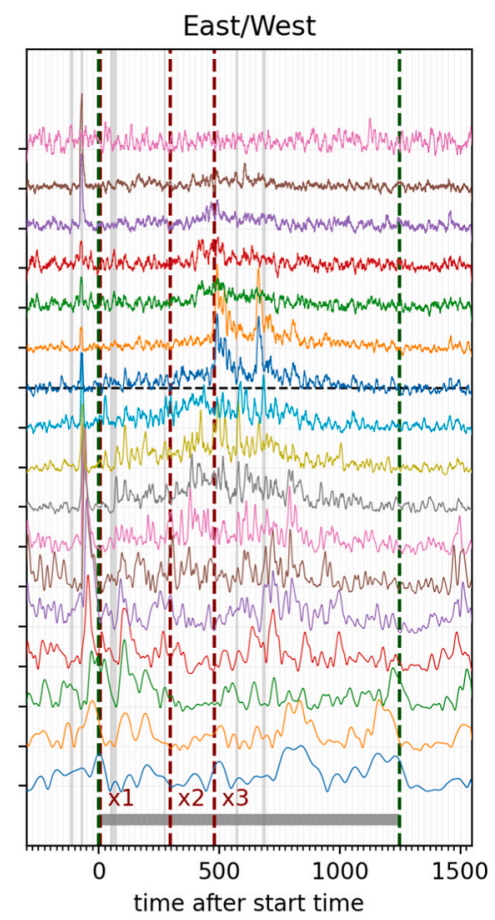

Fig. 22. Filter bank of S0154a (BB QC) energy envelopes. Layout follows Fig. 6. A unique narrow-band late- arriving phase is labelled as $x 3$.

at that time arising from limited bandwidth, data at sampling rates higher than 20 sps was not being collected at the time.

The event occurred in the late afternoon towards the end of the very windy period. The event emerges from a strong wind gust at about $7 \mathrm{~m} / \mathrm{s}$, and for the next $400 \mathrm{~s}$, accounting for the majority of the main energy, gusts continue to occur. After this point, the wind drops and becomes stable at about $3.5 \mathrm{~m} / \mathrm{s}$. About $875 \mathrm{~s}$ after the onset of the event, shortly after the event energy is no longer visible, a series of robot arm motions occur. These activities can be seen in Figs. 23 and 24. Nevertheless, the $\mathrm{VF}$ event, and in particular the strong $\mathrm{S}$ wave and coda, are clearly seen even in the broadband time domain waveforms.

As it is standard for HF family events, the Pg and Sg body wave phase picks are made using an STA/LTA detector tuned to the $2.4 \mathrm{~Hz}$ mode. The Pg arrival is not clear, it is likely the onset is obscured by the heavy 

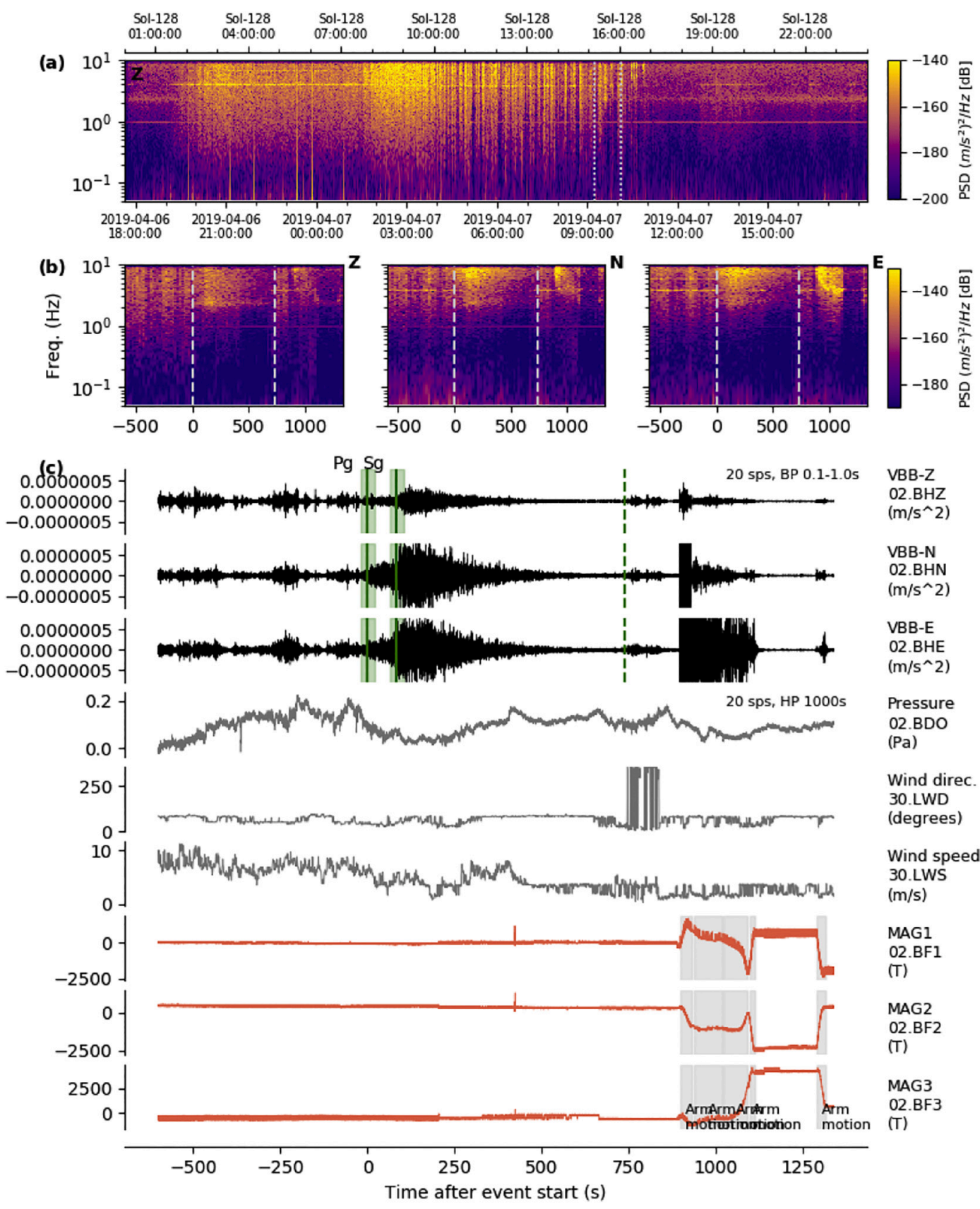

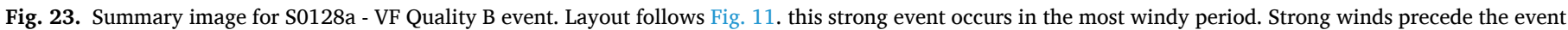
and obscure the identification of the Pg phase. Within minutes of the event ending, robot arm activity is observed.

wind gust at the time. Both Pg and Sg phases are assigned an uncertainty of \pm 20 s. The $\mathrm{S}-\mathrm{P}$ time is $84 \mathrm{~s}$, leading to an epicentral distance of $7.8^{\circ}$. This makes S0128a one of the closest events to the lander in the HF family observed so far. The magnitude is $M_{\mathrm{FB}}^{\mathrm{Ma}} 2.0$ and the SNR values are $S N R_{S} 7.1$ and $S N R_{P} 98.8$. Since there are some gaps in the wind data $S N R_{W}$ cannot be estimated. The fluctuating SNRs reflect the fact the the seismic data is noisy, although the pressure is relatively quiet during the main part of the event. The coda and attenuation of S0128a have been analyzed in detail by Lognonné et al. (2020).

\subsubsection{S0475a - VF quality $B$}

S0475a occurred on 2020-03-29 00:37:54 UTC ( 17:34 LMST), shortly after sunset, and is among the last events in the V3 catalogue. Fig. 25 indicates this event includes energy above $10 \mathrm{~Hz}$, up to $16 \mathrm{~Hz}$. Since the background noise is light, picks are easier to identify - both Pg and Sg have uncertainties for $\pm 10 \mathrm{~s}$. The event has a distance of $13.9^{\circ}$ and a magnitude of $M_{\mathrm{FB}}^{\mathrm{Ma}} 1.9$. SNR values are $S N R_{S} 5.8, S N R_{W} 2.8$ and $S N R_{P} 5$.9. At this time of the Sol, donks are occurring in an extremely repetitive manner - above $13.5 \mathrm{~Hz}$, they are constantly a feature in the data.

\subsection{3. $S 0343 b$ - HF quality $B$}

S0343b occurred on 2019-11-14 11:53:35 UTC ( $19: 51$ LMST). This HF event includes energy from about $6 \mathrm{~Hz}$ to below $1 \mathrm{~Hz}$ (Fig. 26). It is rather unusual for HF family events to include energy below $1 \mathrm{~Hz}$. the event is visible on all three components of the VBB as well as the SP. The event occurs in an extremely quiet period of the Sol, and has SNR values of $S N R_{S} 4.5$ and $S N R_{P} 3.6$. Pg and $S g$ are assigned uncertainties of $\pm 20 s$, the distance and magnitude are estimated to be $27^{\circ}$ and $M_{\mathrm{FB}}^{\mathrm{Ma}} 1.9$ respectively. 


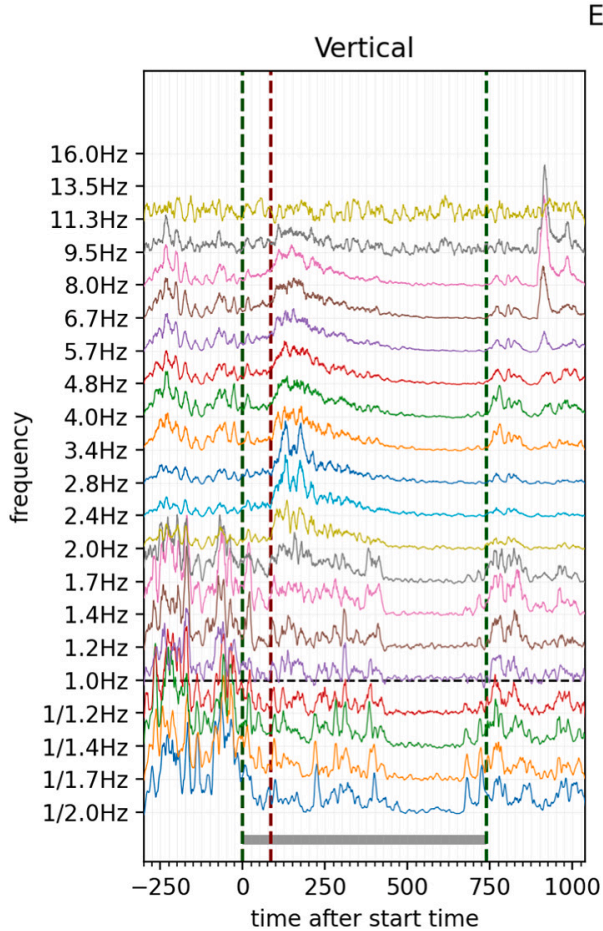

Event S0128a (0.500-16.000 Hz)

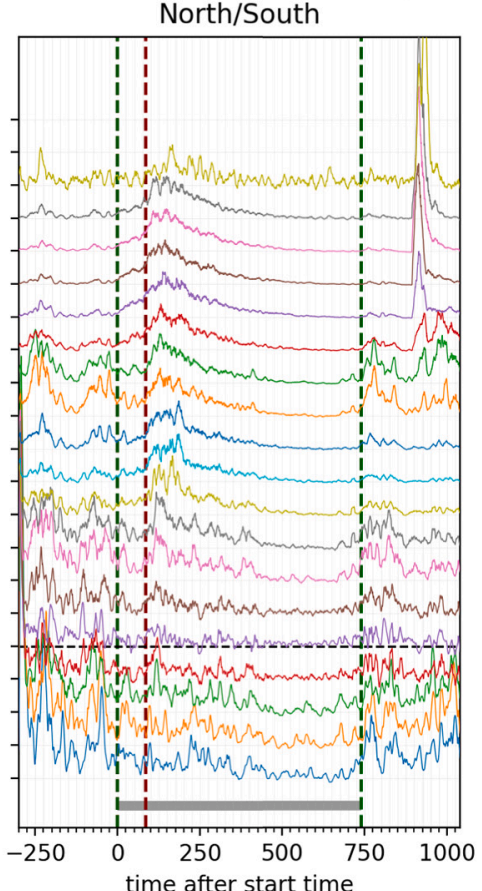

East/West

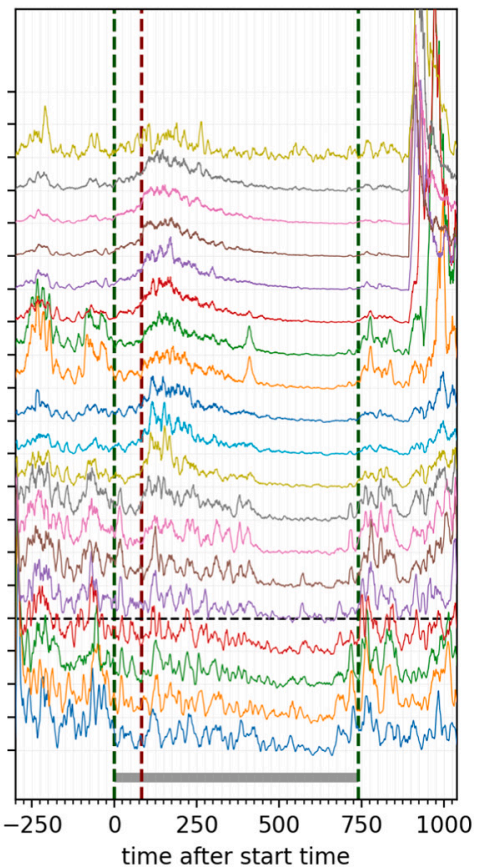

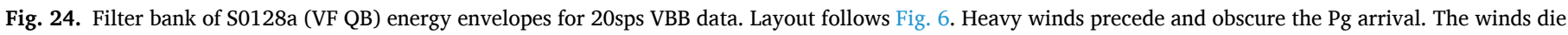
down around $400 \mathrm{~s}$ after the beginning of the event, as visible at frequencies below $1.7 \mathrm{~Hz}$.

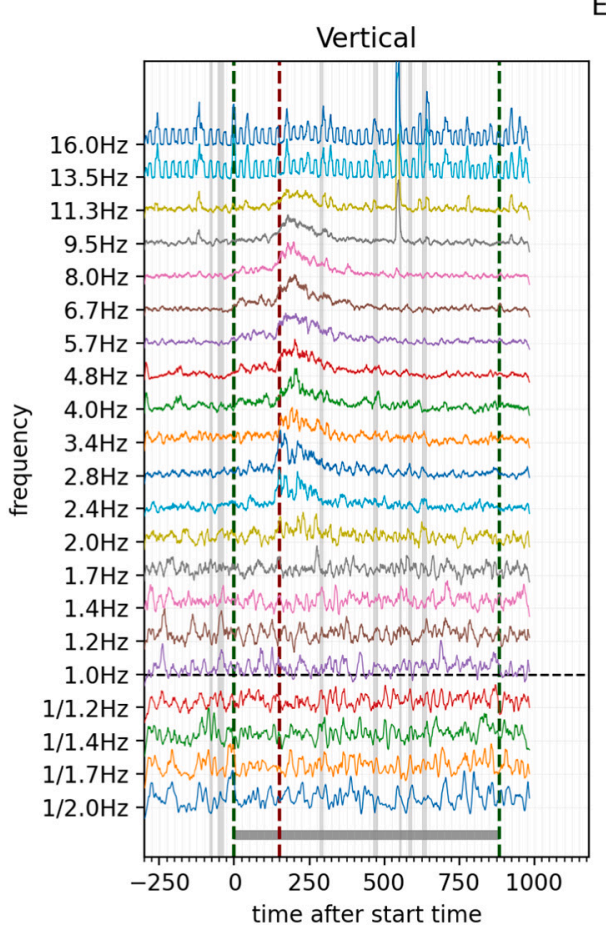

Event S0475a $(0.500-16.000 \mathrm{~Hz})$
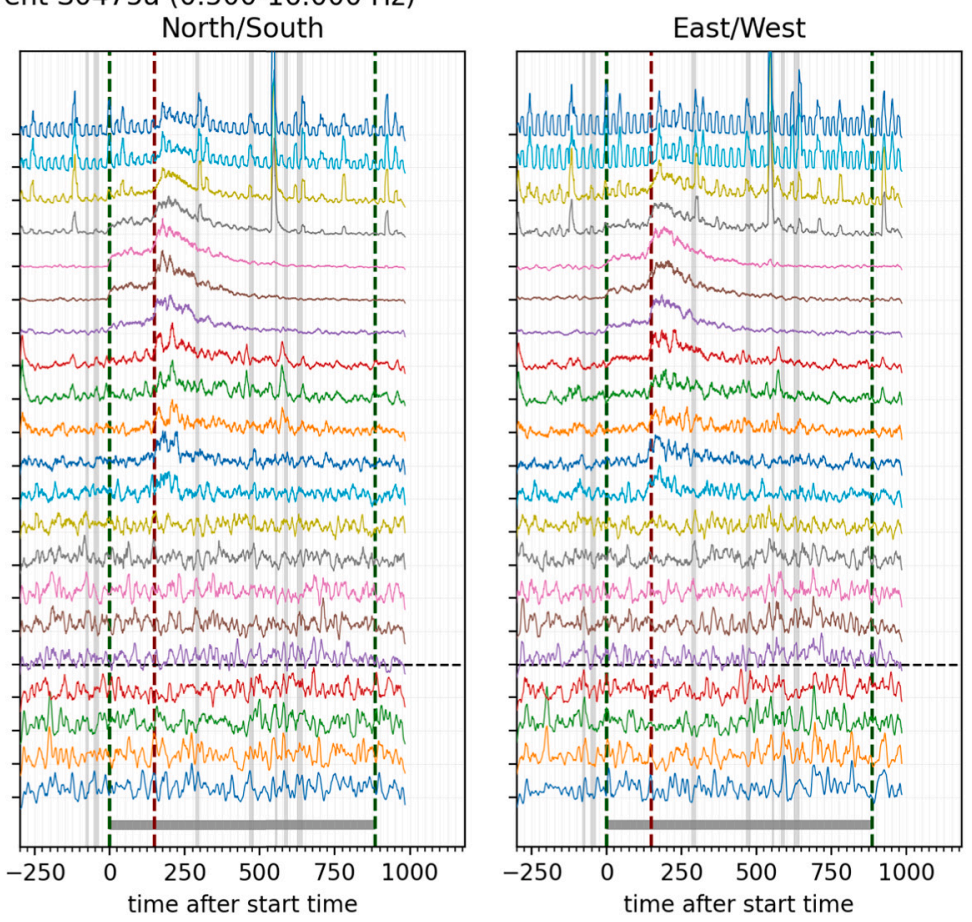

Fig. 25. Filter bank of S0475a (VF QB) energy envelopes for 100sps SP data. Layout follows Fig. 6. Note donks at 13.5 Hz and above.

This is a rare case in which 100 sps SP data is not available for an HF family event.

\subsection{SF events}

SF events are short duration (at the order of $\sim 25 s$ ) high frequency events that, like VF events, exhibit more energy on the horizontal components than the vertical. The high frequency content and very short duration suggest that these events occur nearby the seismometer package. An example is in Fig. 5. A comprehensive description of these events is in Dahmen et al. (2020). 


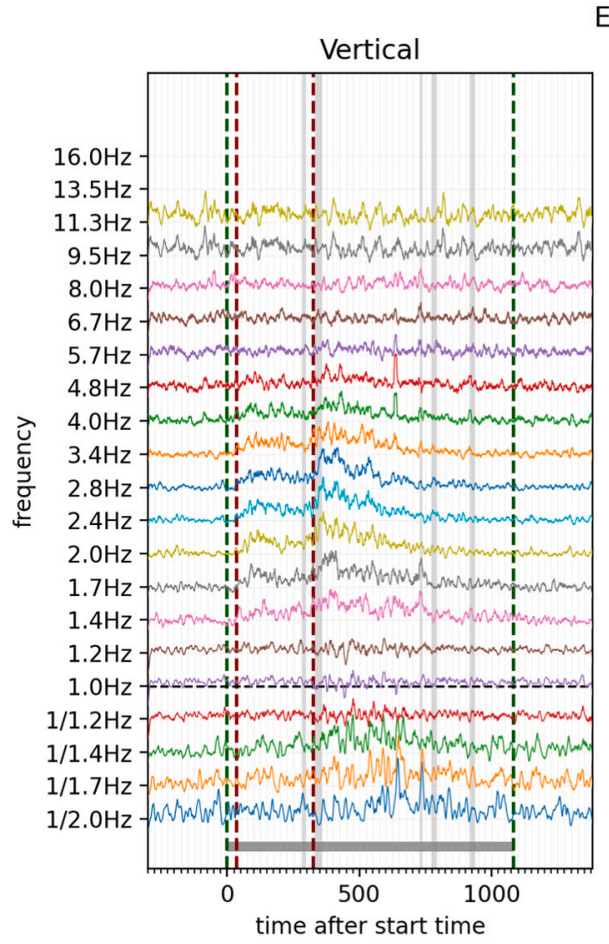

Event S0343b (0.500-16.000 Hz)
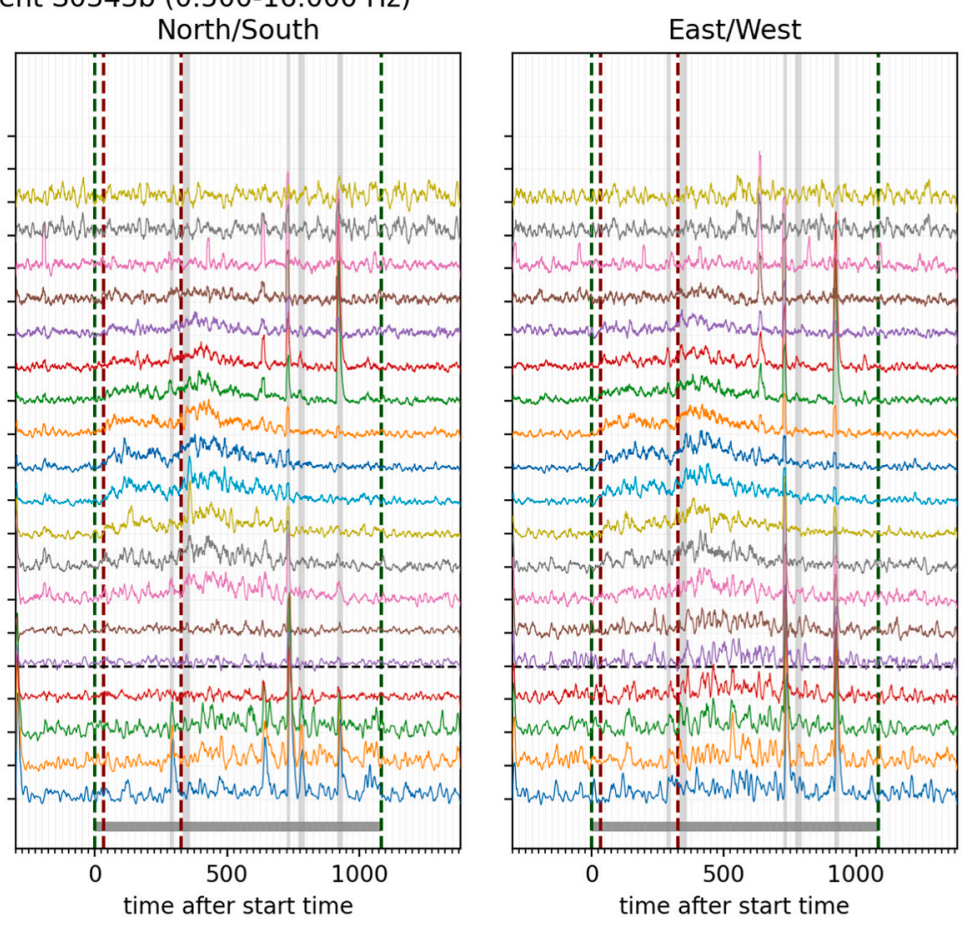

Fig. 26. Filter bank of S0343b (HF QB) energy envelopes for 20sps VBB data. Layout follows Fig. 6.

\section{Initial catalogue statistics}

The marsquake catalogue is being mined in various dedicated publications, summarised below and a full description is outside the scope of this current paper. It is expected that future descriptions of the Martian Catalogue would routinely update and extend catalogue analysis updates adopted from these papers.

van Driel et al. (2020) investigates in detail the high frequency family as available in the V3 catalogue. Event spectra are presented highlighting similarities and differences between the $\mathrm{HF}, \mathrm{VF}$ and $2.4 \mathrm{~Hz}$ events types. Variations of the events in terms of distances and amplitudes are shown, as is size-frequency distribution and catalogue completeness. VF events have a distinctly different size distribution to $\mathrm{HF}$ and $2.4 \mathrm{~Hz}$, with a shallower slope, indicating there are a greater proportion of larger events when compared to smaller events with respect to the $\mathrm{HF}$ and $2.4 \mathrm{~Hz}$ events. The temporal evolution of seismicity rates is also highlighted. Although LF family events so far appear to have a steady occurrence rate, the HF family have an apparent seasonality that is significant even when the heavily changing ability to detect events across the martian day and season is taken into account.

Böse et al. (2020) determine magnitudes for all LF and HF family events, and indicate how magnitudes vary with event type and distance.

Giardini et al. (2020) explores the overall Martian seismicity rates and compares these to various tectonic regimes on Earth as well as the Moon. They find that the overall seismicity is similar to that of deformed continental regions on Earth, but that the lack of events above magnitude 4 is likely significant at this stage. As the catalogue grows over time, and we begin to observe the seismicity of a second Martian year of seismicity, the preliminary understanding of seismic rates and apparent seasonality will improve.

Dahmen et al. (2020) detail the SF events, with their strongly clustered event occurrences. SF events can be sub-classified of similar waveforms suggesting that there area limited number of distinct sources that repeat over 10's of days at similar times of the day. In the initial part of the catalogue, these event occur dominantly near sunset. Later, they begin to be observed at any time of the Sol when noise is low.

\section{Conclusions}

After 478 Sol on Mars, and roughly 400 Sols/14 Earth months after SEIS began collecting high quality science data, the InSight mission has recorded nearly 500 distant marsquake events, and over 700 events resembling local thermal cracking. SEIS continues to record excellent data, both VBB and SP sensors perform well. Despite the very significant reductions in environmental noise observed by moving SEIS onto the ground, decoupling stresses along the tether, and covering with the Wind and Thermal Shield (WTS), SEIS remains susceptible to Martian weather, and quiet conditions are only observed for a few hours most Sols. This is key since all seismic signals observed so far are only marginally above the noise, and the majority can only be detected during these quiet windows.

Marsquakes can be divided into 2 main types, separated by frequency content. A first type, with 42 cases, is dominated by low frequency energy. We interpret these events to be of a relatively deep source, and generate mantle-going P- and S-waves which can often be identified from impulsive energy arrivals. Distances are inferred from 2 separate techniques - using travel times from a suite of a priori Martian velocity models when $\mathrm{P}$ and $\mathrm{S}$ arrivals are readily identified, and an alignment approach matching energy envelopes. This second approach is particularly useful to estimate distance from weaker events or events that do not have obvious impulsive arrivals. These events span in distance from about 25 to above 100. Magnitudes range from 2.5 to 3.7. Two of these events can be located, as there is clear P wave polarisation.

The remaining marsquakes excite higher frequencies, from the 2.4 $\mathrm{Hz}$ resonance and higher. This energy is interpreted as coming from regional crustal sources and consists of reflected body waves. A minority of events (23) are characterised by high amplitudes on horizontal components above $5 \mathrm{~Hz}$. A few of these events include energy that rise beyond the normal $10 \mathrm{~Hz}$ limit to about $35 \mathrm{~Hz}$. The majority of the high frequency events are a very weak excitation of the $2.4 \mathrm{~Hz}$ resonance mode. These events are inferred to be shallow events occurring within the Martian crust, and the high frequency energy is attributed to crustal reverberations of body waves. These events are characterised by 2 strong pulses of non-polarised energy that are identified as $\mathrm{Pg}$ and $\mathrm{Sg}$ 
phases, though there is a strong variation in the observed travel time difference between the $\mathrm{Sg}$ and $\mathrm{Pg}$ arrivals. Using a simple velocity model, distances are estimated to range from 3 to 50, and magnitudes vary from 1.3 to 2.6 .

All marsquakes have long duration, ranging from $5 \mathrm{~min}$ to up to an hour. There does not appear to be any seasonality for the lower frequency events. In contrast, the high frequency events seem to be modulated over time - despite generally favourable conditions, these events were rarely observed until about Sol 200 . The rate significantly increased, at times 4-5 events were seen each day. Around Sol 400, the rate began to drop. Observing a second Martian year, will help unravel what is driving the occurrence of these events.

A very short duration event is also commonly identified in the seismic data, over 700 times so far. This $20-30$ s pulse of energy is distinct from other signals induced by the lander or the environment, with broad energy mainly on the horizontals ranging from 5 to $9 \mathrm{~Hz}$, sometimes ranging up to $35 \mathrm{~Hz}$. Considering these events cluster in distinct patterns with similar signals that occur at very similar times of the Martian day (during the late afternoon and early evening) for short periods of time, up to a few weeks, it is plausible these events are local thermal cracking that may be associated with local rocks or the Martian regolith.

It is expected this description of the MQS catalogue will be periodically updated, especially if there are significant changes or breakthroughs in terms of our observations or understanding of seismicity. Further, the catalogue paper will be the avenue for applying original methods and interpretations to the emerging catalogue. This may include, for instance, updating the seismicity event rates presented in Giardini et al. (2020) the event seasonality presented in van Driel et al., 2020, or the magnitude relations in Böse et al. (2020).

\section{Data availability}

The InSight seismic event catalogue version 3 InSight Marsquake Service (2020c) and waveform data InSight Mars SEIS Data Service (2019) are available from the IPGP Datacenter and IRIS-DMC, as are previous catalogue versions. Seismic waveforms are also available from NASA PDS (National Aeronautics and Space Administration Planetary Data System) (https://pds.nasa.gov/).

Supplementary data to this article can be found online at https://doi. org/10.1016/j.pepi.2020.106595.

\section{Declaration of Competing Interest}

The authors declare that they have no known competing financial interests or personal relationships that could have appeared to influence the work reported in this paper.

\section{Acknowledgements}

The authors would like to thank PEPI Editor Prof. Vernon Cormier, Adam Ringler and another reviewer who provided careful and critical reviews that have improved the manuscript.

We acknowledge NASA, CNES, their partner agencies and Institutions (UKSA, SSO, DLR, JPL, IPGP-CNRS, ETHZ, IC, MPS-MPG) and the flight operations team at JPL, SISMOC, MSDS, IRIS-DMC and PDS for providing SEED SEIS data.

We also acknowledge the funding by (1) Swiss National Science Foundation and French Agence Nationale de la Recherche (SNF-ANR project "Seismology on Mars", ANR-14-36CE-0012-02 and MAGIS, ANR19-31CE-0008-08), (2) Swiss State Secretariat for Education, Research and Innovation (SEFRI project "MarsQuake Service-Preparatory Phase"), (3) ETH Research grant ETH-06 17-02 and, for French coauthors, (4) the French Space agency CNES. Additional support came from the Swiss National Supercomputing Centre (CSCS) under project ID s922. AH is funded by UKSA through grant \#ST/R002096/1.
This paper is InSight Contribution Number 159.

\section{References}

InSight Marsquake Service, 2020a. Mars Seismic Catalogue, InSight Mission; V1 2/1/ 2020. ETHZ, IPGP, JPL, ICL, ISAE-Supaero, MPS, Univ. Bristol. https://doi.org/ $10.12686 / \mathrm{A} 6$.

InSight Marsquake Service, 2020b. Mars Seismic Catalogue, InSight Mission; V2 2020 04-01. ETHZ, IPGP, JPL, ICL, ISAE-Supaero, MPS, Univ. Bristol. https://doi.org/ $10.12686 /$ A7.

InSight Marsquake Service, 2020c. Mars Seismic Catalogue, InSight Mission; V3 2020-0701. ETHZ, IPGP, JPL, ICL, ISAE-Supaero, MPS, Univ. Bristol. https://doi.org/ 10.12686/A8.

Ahern, T., Dost, B., 2012. SEED Reference Manual Standard for the Exchange of Earthquake Data SEED Format Version 2.4. Technical Report. FDSN.

Anderson, D.L., Miller, W.F., Latham, G.V., Nakamura, Y., Toksöz, M.N., Dainty, A.M., Duennebier, F.K., Lazarewicz, A.R., Kovach, R.L., Knight, T.C.D., 1977. Seismology on Mars. J. Geophys. Res. 82, 4524-4546. https://doi.org/10.1029/ js082i028p04524.

Banerdt, W.B., Smrekar, S.E., Banfield, D., Giardini, D., Golombek, M., Johnson, C.L., Lognonné, P., Spiga, A., Spohn, T., Perrin, C., Stähler, S.C., Antonangeli, D., Asmar, S., Beghein, C., Bowles, N., Bozdag, E., Chi, P., Christensen, U., Clinton, J., Collins, G.S., Daubar, I., Dehant, V., Drilleau, M., Fillingim, M., Folkner, W., Garcia, R.F., Garvin, J., Grant, J., Grott, M., Grygorczuk, J., Hudson, T., Irving, J.C., Kargl, G., Kawamura, T., Kedar, S., King, S., Knapmeyer-Endrun, B., Knapmeyer, M., Lemmon, M., Lorenz, R., Maki, J.N., Margerin, L., McLennan, S.M., Michaut, C., Mimoun, D., Mittelholz, A., Mocquet, A., Morgan, P., Mueller, N.T., Murdoch, N., Nagihara, S., Newman, C., Nimmo, F., Panning, M., Pike, W.T., Plesa, A.C., Rodriguez, S., Rodriguez-Manfredi, J.A., Russell, C.T., Schmerr, N., Siegler, M., Stanley, S., Stutzmann, E., Teanby, N., Tromp, J., van Driel, M., Warner, N., Weber, R., Wieczorek, M., 2020. Initial results from the InSight mission on Mars. Nat. Geosci. 13, 183-189. https://doi.org/10.1038/s41561-020-0544-y.

Banfield, D., Rodriguez-Manfredi, J.A., Russell, C.T., Rowe, K.M., Leneman, D., Lai, H.R., Cruce, P.R., Means, J.D., Johnson, C.L., Mittelholz, A., Joy, S.P., Chi, P.J., Mikellides, I.G., Carpenter, S., Navarro, S., Sebastian, E., Gomez-Elvira, J., Torres, J., Mora, L., Peinado, V., Lepinette, A., Hurst, K., Lognonné, P., Smrekar, S.E. Banerdt, W.B., 2019. InSight auxiliary payload sensor suite (APSS). Space Sci. Rev. 215, 4. https://doi.org/10.1007/s11214-018-0570-x.

Banfield, D., Spiga, A., Newman, C., Forget, F., Lemmon, M., Lorenz, R., Murdoch, N. Viudez-Moreiras, D., Pla-Garcia, J., Garcia, R.F., Lognonné, P., Karatekin, O., Perrin, C., Martire, L., Teanby, N., Hove, B.V., Maki, J.N., Kenda, B., Mueller, N.T., Rodriguez, S., Kawamura, T., McClean, J.B., Stott, A.E., Charalambous, C., Millour, E., Johnson, C.L., Mittelholz, A., Määttänen, A., Lewis, S.R., Clinton, J., Stähler, S.C., Ceylan, S., Giardini, D., Warren, T., Pike, W.T., Daubar, I., Golombek, M., Rolland, L., Widmer-Schnidrig, R., Mimoun, D., Beucler, E., Jacob, A., Lucas, A., Baker, M., Ansan, V., Hurst, K., Mora-Sotomayor, L., Navarro, S. Torres, J., Lepinette, A., Molina, A., Marin-Jimenez, M., Gomez-Elvira, J., Peinado, V., Rodriguez-Manfredi, J.A., Carcich, B.T., Sackett, S., Russell, C.T., Spohn, T., Smrekar, S.E., Banerdt, W.B., 2020. The atmosphere of Mars as observed by InSight. Nat. Geosci. 13, 190-198. https://doi.org/10.1038/s41561-020-0534-0.

Böse, M., Clinton, J., Ceylan, S., Euchner, F., van Driel, M., Khan, A., Giardini, D., Lognonné, P., Banerdt, W., 2017. A probabilistic framework for single-station location of seismicity on Earth and Mars. Phys. Earth Planet. Inter. 262 https://doi. org/10.1016/j.pepi.2016.11.003.

Böse, M., Giardini, D., Stähler, S., Ceylan, S., Clinton, J., Van Driel, M., Khan, A., Euchner, F., Lognonné, P., Banerdt, W., 2018. Magnitude scales for marsquakes. Bull. Seismol. Soc. Am. 108 https://doi.org/10.1785/0120180037.

Böse, M., Stähler, S., Giardini, D., Ceylan, S., Clinton, J., Knapmeyer, M., van Driel, M., Charalambous, C., Horleston, A., Kawamura, T., Khan, A., Orhand-Mainsant, G., Scholz, J.-R., Lognonné, P., Banerdt, B.W., 2020. Magnitude scales for Mars calibrated from InSight data. Bull. Seismol. Soc. Am. 108 (5A), 2764-2777.

Ceylan, S., van Driel, M., Euchner, F., Khan, A., Clinton, J., Krischer, L., Böse, M., Stähler, S., Giardini, D., 2017. From initial models of seismicity, structure and noise to synthetic seismograms for Mars. Space Sci. Rev. 211, 595-610. https://doi.org/ 10.1007/s11214-017-0380-6.

Ceylan, S., Clinton, J., Giardini, D., Bose, M., Horleston, A., Kawamura, T., Khan, A., Orhand-Mainsant, G., Scholz, J., Stähler, S., Euchner, F., Banerd, W., Lognonné, P., Banfield, D., Beucler, E., Garcia, R., Kedar, S., Panning, M., Pike, W.T., Smrekar, S., Spiga, A., Dahmen, N., Hurst, K., Stott, A., Lorenz, R., Schimmel, M., Stutzmann, E., ten Pierick, J., Conejero, V., Pardo, C., Perrin, C., 2020. Companion guide to the Marsquake catalogue from InSight, sols 0-478: data content and non-seismic events. Phys. Earth Planet. Inter. https://doi.org/10.1016/j.pepi.2020.106597.

Charalambous, C., Stott, A.E., Pike, T., McClean, J., Warren, T., Spiga, A., Banfield, D., Garcia, R.F., Clinton, J., Stähler, S.C., López, S.N., Lognonné, P.H., Kawamura, T., Driel, M.v., Böse, M., Ceylan, S., Khan, A., Horleston, A.C., Orhand-Mainsant, G., Sotomayor, L.M., Murdoch, N., Giardini, D., Banerdt, W.B., 2020. A Comodulation Analysis of Atmospheric Energy Injection Into the Ground Motion at InSight, Mars. http://www.essoar.org/doi/10.1002/essoar.10503206.1 (in review).

Clinton, J.F., Giardini, D., Lognonné, P., Banerdt, B., Van Driel, M., Drilleau, M., Murdoch, N., Panning, M., Garcia, R., Mimoun, D., Golombek, M., Tromp, J., Weber, R., Böse, M., Ceylan, S., Daubar, I., Kenda, B., Khan, A., Perrin, L., Spiga, A., 2017. Preparing for in sight: an invitation to participate in a blind test for martian seismicity. Seismol. Res. Lett. 88, 1290-1302. https://doi.org/10.1785/ 0220170094. 
Clinton, J., Giardini, D., Base, M., Ceylan, S., van Driel, M., Euchner, F., Garcia, R.F., Kedar, S., Khan, A., Stähler, S.C., Banerdt, B., Lognonne, P., Beucler, E., Daubar, I., Drilleau, M., Golombek, M., Kawamura, T., Knapmeyer, M., Knapmeyer-Endrun, B., Mimoun, D., Mocquet, A., Panning, M., Perrin, C., Teanby, N.A., 2018. The Marsquake service: securing daily analysis of SEIS data and building the Martian seismicity catalogue for InSight. Space Sci. Rev. 214, 133. https://doi.org/10.1007/ s11214-018-0567-5.

Dahmen, N.L., Clinton, J.F., Ceylan, S., van Driel, M., Giardini, D., Stähler, S., Böse, M. Charalambous, C., Horleston, A., Kawamura, T., Khan, A., Orhand-Mainsant, G., Scholz, J., Euchner, F., Pike, William T., Weber, R.C., Lognonné, P., Banerdt, W.B., 2020. Super high frequency events: a new class of events recorded by the InSight seismometers on Mars. J. Geophys. Res. Planets. https://doi.org/10.1029/ 2020JE006599.

Daubar, I.J., Lognonné, P., Teanby, N.A., Collins, G.S., Clinton, J., Stähler, S., Spiga, A., Karakostas, F., Ceylan, S., Malin, M., McEwen, A.S., Maguire, R., Charalambous, C., Onodera, K., Lucas, A., Rolland, L., Vaubaillon, J., Kawamura, T., Böse, M., Horleston, A., Driel, M., Stevanović, J., Miljković, K., Fernando, B., Huang, Q., Giardini, D., Larmat, C.S., Leng, K., Rajšić, A., Schmerr, N., Wójcicka, N., Pike, T., Wookey, J., Rodriguez, S., Garcia, R., Banks, M.E., Margerin, L., Posiolova, L., Banerdt, B., 2020. A new crater near InSight: implications for seismic impact detectability on Mars. J. Geophys. Res. Planets. https://doi.org/10.1029/ 2020JE006382.

van Driel, M., Ceylan, S., Clinton, J.F., Giardini, D., Alemany, H., Allam, A., Ambrois, D. Balestra, J., Banerdt, B., Becker, D., Böse, M., Boxberg, M.S., Brinkman, N., Casademont, T., Chèze, J., Daubar, I., Deschamps, A., Dethof, F., Ditz, M., Drilleau, M., Essing, D., Euchner, F., Fernando, B., Garcia, R., Garth, T., Godwin, H., Golombek, M.P., Grunert, K., Hadziioannou, C., Haindl, C., Hammer, C., Hochfeld, I, Hosseini, K., Hu, H., Kedar, S., Kenda, B., Khan, A., Kilchling, T., KnapmeyerEndrun, B., Lamert, A., Li, J., Lognonné, P., Mader, S., Marten, L., Mehrkens, F., Mercerat, D., Mimoun, D., Möller, T., Murdoch, N., Neumann, P., Neurath, R. Paffrath, M., Panning, M.P., Peix, F., Perrin, L., Rolland, L., Schimmel, M., Schröer, C., Spiga, A., Stähler, S.C., Steinmann, R., Stutzmann, E., Szenicer, A., Trumpik, N., Tsekhmistrenko, M., Twardzik, C., Weber, R., WerdenbachJarklowski, P., Zhang, S., Zheng, Y., 2019. Preparing for InSight: evaluation of the blind test for martian seismicity. Seismol. Res. Lett. 90, 1518-1534. https://doi.org/ 10.1785/0220180379.

van Driel, M., Ceylan, S., Clinton, J.F., Giardini, D., Horleston, A., Margerin, L., Stähler, S., Böse, M., Charalambous, C., Kawamura, T., Khan, A., Orhand Mainsant, G., Scholz, J., Euchner, F., Knapmeyer, M., Pike, W., Lognonné, P., Banerdt, W., 2020. High frequency seismic events on Mars observed by InSight. J. Geophys. Res. Planets (submitted).

Garcia, R.F., Kenda, B., Kawamura, T., Spiga, A., Murdoch, N., Lognonné, P., WidmerSchnidrig, R., Compaire, N., Orhand-Mainsant, G., Banfield, D., Banerdt, W.B., 2020 Pressure effects on the SEIS-InSight instrument, improvement of seismic records and characterization of long period atmospheric waves from ground displacements. J. Geophys. Res. Planets 125. https://doi.org/10.1029/2019je006278.

Giardini, D., Lognonné, P., Banerdt, W.B., Pike, W.T., Christensen, U., Ceylan, S., Clinton, J.F., van Driel, M., Stähler, S.C., Böse, M., Garcia, R.F., Khan, A., Panning, M., Perrin, C., Banfield, D., Beucler, E., Charalambous, C., Euchner, F., Horleston, A., Jacob, A., Kawamura, T., Kedar, S., Mainsant, G., Scholz, J.R., Smrekar, S.E., Spiga, A., Agard, C., Antonangeli, D., Barkaoui, S., Barrett, E., Combes, P., Conejero, V., Daubar, I., Drilleau, M., Ferrier, C., Gabsi, T., Gudkova, T., Hurst, K., Karakostas, F., King, S., Knapmeyer, M., Knapmeyer-Endrun, B., Llorca-Cejudo, R., Lucas, A., Luno, L., Margerin, L., McClean, J.B., Mimoun, D., Murdoch, N., Nimmo, F., Nonon, M. Pardo, C., Rivoldini, A., Manfredi, J.A., Samuel, H., Schimmel, M., Stott, A.E., Stutzmann, E., Teanby, N., Warren, T., Weber, R.C., Wieczorek, M., Yana, C., 2020 The seismicity of Mars. Nat. Geosci. 13, 205-212. URL: 10.1038/s41561-020-05398, doi:https://doi.org/10.1038/s41561-020-0539-8.

Hanka, W., Saul, J., Weber, B., Becker, J., Harjadi, P., Fauzi, GITEWS Seismology Group, 2010. Real-time earthquake monitoring for tsunami warning in the Indian Ocean and beyond. Nat. Hazards Earth Syst. Sci. 10, 2611-2622. http://www.nat-hazar ds-earth-syst-sci.net/10/2611/2010/. https://doi.org/10.5194/nhess-10-2611. 2010.

InSight Mars SEIS Data Service, 2019. SEIS raw data, Insight Mission. IPGP, JPL, CNES, ETHZ, ICL, MPS, ISAE-Supaero, LPG, MFSC. https://doi.org/10.18715/SEIS. INSIGHT.XB_2016.

Kenda, B., Drilleau, M., Garcia, R.F., Kawamura, T., Murdoch, N., Compaire, N., Lognonné, P., Spiga, A., Widmer-Schnidrig, R., Delage, P., Ansan, V., Vrettos, C., Rodriguez, S., Banerdt, W.B., Banfield, D., Antonangeli, D., Christensen, U., Mimoun, D., Mocquet, A., Spohn, T., 2020. Subsurface structure at the InSight landing site from compliance measurements by seismic and meteorological experiments. J. Geophys. Res. Planets 125. https://doi.org/10.1029/2020JE006387.

Khan, A., van Driel, M., Böse, M., Giardini, D., Ceylan, S., Yan, J., Clinton, J., Euchner, F., Lognonné, P., Murdoch, N., Mimoun, D., Panning, M., Knapmeyer, M., Banerdt, W., 2016. Single-station and single-event marsquake location and inversion for structure using synthetic Martian waveforms. Phys. Earth Planet. Inter. 258 https://doi.org/ 10.1016/j.pepi.2016.05.017

Lognonné, P., Banerdt, W., Giardini, D., Pike, W., Christensen, U., Laudet, P., de Raucourt, S., Zweifel, P., Calcutt, S., Bierwirth, M., Hurst, K., Ijpelaan, F., Umland, J., Llorca-Cejudo, R., Larson, S., Garcia, R., Kedar, S., KnapmeyerEndrun, B., Mimoun, D., Mocquet, A., Panning, M., Weber, R., Sylvestre-Baron, A., Pont, G., Verdier, N., Kerjean, L., Facto, L., Gharakanian, V., Feldman, J., Hoffman, T., Klein, D., Klein, K., Onufer, N., Paredes-Garcia, J., Petkov, M., Willis, J., Smrekar, S., Drilleau, M., Gabsi, T., Nebut, T., Robert, O., Tillier, S., Moreau, C., Parise, M., Aveni, G., Ben Charef, S., Bennour, Y., Camus, T., Dandonneau, P., Desfoux, C., Lecomte, B., Pot, O., Revuz, P., Mance, D., ten Pierick, J., Bowles, N.,
Charalambous, C., Delahunty, A., Hurley, J., Irshad, R., Liu, H., Mukherjee, A., Standley, I., Stott, A., Temple, J., Warren, T., Eberhardt, M., Kramer, A., Kühne, W., Miettinen, E.P., Monecke, M., Aicardi, C., André, M., Baroukh, J., Borrien, A., Bouisset, A., Boutte, P., Brethomé, K., Brysbaert, C., Carlier, T., Deleuze, M., Desmarres, J., Dilhan, D., Doucet, C., Faye, D., Faye-Refalo, N., Gonzalez, R., Imbert, C., Larigauderie, C., Locatelli, E., Luno, L., Meyer, J.R., Mialhe, F., Mouret, J., Nonon, M., Pahn, Y., Paillet, A., Pasquier, P., Perez, G., Perez, R., Perrin, L., Pouilloux, B., Rosak, A., Savin de Larclause, I., Sicre, J., Sodki, M., Toulemont, N., Vella, B., Yana, C., Alibay, F., Avalos, O., Balzer, M., Bhandari, P. Blanco, E., Bone, B., Bousman, J., Bruneau, P., Calef, F., Calvet, R., D’Agostino, S., de los Santos, G., Deen, R., Denise, R., Ervin, J., Ferraro, N., Gengl, H., Grinblat, F., Hernandez, D., Hetzel, M., Johnson, M., Khachikyan, L., Lin, J., Madzunkov, S., Marshall, S., Mikellides, I., Miller, E., Raff, W., Singer, J., Sunday, C., Villalvazo, J., Wallace, M., Banfield, D., Rodriguez-Manfredi, J., Russell, C., Trebi-Ollennu, A., Maki, J., Beucler, E., Böse, M., Bonjour, C., Berenguer, J., Ceylan, S., Clinton, J., Conejero, V., Daubar, I., Dehant, V., Delage, P., Euchner, F., Estève, I., Fayon, L., Ferraioli, L., Johnson, C., Gagnepain-Beyneix, J., Golombek, M., Khan, A., Kawamura, T., Kenda, B., Labrot, P., Murdoch, N., Pardo, C., Perrin, C., Pou, L., Sauron, A., Savoie, D., Stähler, S., Stutzmann, E., Teanby, N., Tromp, J., van Driel, M., Wieczorek, M., Widmer-Schnidrig, R., Wookey, J., 2019. SEIS: Insight's seismic experiment for internal structure of Mars. Space Sci. Rev. 215 https://doi org/10.1007/s11214-018-0574-6.

Lognonné, P., Banerdt, W.B., Pike, W.T., Giardini, D., Christensen, U., Garcia, R.F., Kawamura, T., Kedar, S., Knapmeyer-Endrun, B., Margerin, L., Nimmo, F., Panning, M., Tauzin, B., Scholz, J.R., Antonangeli, D., Barkaoui, S., Beucler, E., Bissig, F., Brinkman, N., Calvet, M., Ceylan, S., Charalambous, C., Davis, P., van Driel, M., Drilleau, M., Fayon, L., Joshi, R., Kenda, B., Khan, A., Knapmeyer, M., Lekic, V., McClean, J., Mimoun, D., Murdoch, N., Pan, L., Perrin, C., Pinot, B., Pou, L., Menina, S., Rodriguez, S., Schmelzbach, C., Schmerr, N., Sollberger, D., Spiga, A., Stähler, S., Stott, A., Stutzmann, E., Tharimena, S., Widmer-Schnidrig, R., Andersson, F., Ansan, V., Beghein, C., Böse, M., Bozdag, E., Clinton, J., Daubar, I., Delage, P., Fuji, N., Golombek, M., Grott, M., Horleston, A., Hurst, K., Irving, J., Jacob, A., Knollenberg, J., Krasner, S., Krause, C., Lorenz, R., Michaut, C., Myhill, R., Nissen-Meyer, T., ten Pierick, J., Plesa, A.C., Quantin-Nataf, C., Robertsson, J., Rochas, L., Schimmel, M., Smrekar, S., Spohn, T., Teanby, N., Tromp, J., Vallade, J., Verdier, N., Vrettos, C., Weber, R., Banfield, D., Barrett, E., Bierwirth, M., Calcutt, S., Compaire, N., Johnson, C.L., Mance, D., Euchner, F., Kerjean, L., Mainsant, G., Mocquet, A., Rodriguez Manfredi, J.A., Pont, G., Laudet, P., Nebut, T., de Raucourt, S., Robert, O., Russell, C. T., Sylvestre-Baron, A., Tillier, S., Warren, T., Wieczorek, M., Yana, C., Zweifel, P., 2020. Constraints on the shallow elastic and anelastic structure of Mars from InSight seismic data. Nat. Geosci. 13, 213-220. URL: https://doi.org/10.1038/s41561-020 -0536-y, doi:https://doi.org/10.1038/s41561-020-0536-y.

Lorenz, R.D., Nakamura, Y., Murphy, J.R., 2017. Viking-2 Seismometer Measurements on Mars: PDS Data Archive and Meteorological Applications. Earth and Space Science 4, 681-688. http://doi.wiley.com/10.1002/2017EA000306. https://doi.org/10.1002/ 2017EA000306.

Martire, L., Garcia, R.F., Rolland, L., Spiga, A., Lognonné, P.H., Banfield, D., Banerdt, W. B., Martin, R., 2020. Martian infrasound: numerical modeling and analysis of InSight's data. J. Geophys. Res. Planets 125. https://doi.org/10.1029/ 2020JE006376.

Mimoun, D., Murdoch, N., Lognonné, P., Hurst, K., Pike, W.T., Hurley, J., Nébut, T. Banerdt, W.B., 2017. The noise model of the SEIS seismometer of the InSight mission to Mars. Space Sci. Rev. 211, 383-428. https://doi.org/10.1007/s11214-017-0409-

Murdoch, N., Mimoun, D., Garcia, R.F., Rapin, W., Kawamura, T., Lognonné, P., Banfield, D., Banerdt, W.B., 2017. Evaluating the wind-induced mechanical noise on the InSight seismometers. Space Sci. Rev. 211, 429-455. https://doi.org/10.1007/ s11214-016-0311-y.

Panning, M.P., Beucler, E., Drilleau, M., Mocquet, A., Lognonné, P., Banerdt, W.B., 2015. Verifying single-station seismic approaches using earth-based data: preparation for data return from the InSight mission to Mars. Icarus 248, 230-242. https://doi.org/ 10.1016/j.icarus.2014.10.035.

Panning, M., Lognonné, P., Bruce Banerdt, W., Garcia, R., Golombek, M., Kedar, S., Knapmeyer-Endrun, B., Mocquet, A., Teanby, N., Tromp, J., Weber, R., Beucler, E., Blanchette-Guertin, J.F., Bozdağ, E., Drilleau, M., Gudkova, T., Hempel, S., Khan, A., Lekić, V., Murdoch, N., Plesa, A.C., Rivoldini, A., Schmerr, N., Ruan, Y., Verhoeven, O., Gao, C., Christensen, U., Clinton, J., Dehant, V., Giardini, D., Mimoun, D., Thomas Pike, W., Smrekar, S, Wieczorek, M., Knapmeyer, M., Wookey, J., 2017. Planned products of the Mars structure service for the InSight mission to Mars. Space Sci. Rev. 211. https://doi.org/10.1007/s11214-016-0317-5.

Panning, M.P., Pike, W.T., Lognonné, P., Banerdt, W.B., Murdoch, N., Banfield, D., Charalambous, C., Kedar, S., Lorenz, R.D., Marusiak, A.G., McClean, J.B., Nunn, C., Stähler, S.C., Stott, A.E., Warren, T., 2020. On-deck seismology: lessons from InSight for future planetary seismology. J. Geophys. Res. Planets 125. https://doi.org/ 10.1029/2019JE006353.

Peterson, J.R., 1993. Observations and Modeling of Seismic Background Noise. Technical Report. USGS. https://doi.org/10.3133/OFR93322.

Scholz, J.R., Widmer-Schnidrig, R., Davis, P., Lognonné, P., Pinot, B., Garcia, R.F., Hurst, K., Pou, L., Nimmo, F., Barkaoui, S., Raucourt, S.D., Knapmeyer-Endrun, B., Knapmeyer, M., Mainsant, G., Compaire, N., Cuvier, A., Beucler, E., Bonnin, M., Joshi, R., Sainton, G., Stutzmann, E., Schimmel, M., Horleston, A., Böse, M., Ceylan, S., Clinton, J., Driel, M.V., Kawamura, T., Khan, A., Stähler, S.C., Giardini, D., Charalambous, C., Stott, A.E., Pike, W.T., Christensen, U.R., Banerdt, W. B., 2020. Detection, Analysis and Removal of Glitches From InSight's Seismic Data From Mars. https://doi.org/10.1029/2020EA001317. 
Smrekar, S.E., Lognonné, P., Spohn, T., Banerdt, W.B., Breuer, D., Christensen, U., Dehant, V., Drilleau, M., Folkner, W., Fuji, N., Garcia, R.F., Giardini, D., Golombek, M., Grott, M., Gudkova, T., Johnson, C., Khan, A., Langlais, B., Mittelholz, A., Mocquet, A., Myhill, R., Panning, M., Perrin, C., Pike, T., Plesa, A.C., Rivoldini, A., Samuel, H., Stähler, S.C., van Driel, M., Van Hoolst, T., Verhoeven, O. Weber, R., Wieczorek, M., 2019. Pre-mission InSights on the interior of Mars. Space Sci. Rev. 215, 3. https://doi.org/10.1007/s11214-018-0563-9.

Spiga, A., Banfield, D., Teanby, N., Forget, F., Lucas, A., Kenda, B., Rodriguez

Manfredi, J., Widmer-Schnidrig, R., Murdoch, N., Lemmon, M., Garcia, R., Martire, L., Karatekin, O., Le Maistre, S., Van Hove, B., Dehant, V., Lognonné, P., Mueller, N., Lorenz, R., Mimoun, D., Rodriguez, S., Beucler, E., Daubar, I.,

Golombek, M., Bertrand, T., Nishikawa, Y., Millour, E., Rolland, L., Brissaud, Q.,
Kawamura, T., Mocquet, A., Martin, R., Clinton, J., Stutzmann, E., Spohn, T., Smrekar, S., Banerdt, W., 2018. Atmospheric science with InSight. Space Sci. Rev. 214 https://doi.org/10.1007/s11214-018-0543-0.

Storchak, D.A., Schweitzer, J., Bormann, P., 2011. Seismic phase names: Iaspei standard. In: Encyclopedia of Earth Sciences Series Part 5, pp. 1162-1173. https://doi.org/ 10.1007/978-90-481-8702-7_11.

Stutzmann, E., Schimmel, M., Lognonné, P.H., Horleston, A.C., Ceylan, S., Driel, M.v., Stähler, S.C., Banerdt, W.B., Calvet, M., Charalambous, C., Clinton, J., Drilleau, M., Fayon, L., Garcia, R.F., Giardini, D., Hurst, K., Jacob, A., Kawamura, T., Kenda, B., Margerin, L., Murdoch, N., Panning, M.P., Pike, T., Scholz, J.R., Spiga, A., 2020. The Polarization of Ambient Noise on Mars. J. Geophys. Res. Planets. https://doi.org/ 10.1029/2020JE006545. In press. 